\title{
Short Beam Shear Strength Evaluations of GFRP Composites: Correlations Through Accelerated and Natural Aging
}

\author{
William Todd Barker \\ West Virginia University, wtbarker@mix.wvu.edu
}

Follow this and additional works at: https://researchrepository.wvu.edu/etd

Part of the Structural Engineering Commons

\section{Recommended Citation}

Barker, William Todd, "Short Beam Shear Strength Evaluations of GFRP Composites: Correlations Through Accelerated and Natural Aging" (2019). Graduate Theses, Dissertations, and Problem Reports. 3776. https://researchrepository.wvu.edu/etd/3776

This Problem/Project Report is protected by copyright and/or related rights. It has been brought to you by the The Research Repository @WVU with permission from the rights-holder(s). You are free to use this Problem/Project Report in any way that is permitted by the copyright and related rights legislation that applies to your use. For other uses you must obtain permission from the rights-holder(s) directly, unless additional rights are indicated by a Creative Commons license in the record and/ or on the work itself. This Problem/Project Report has been accepted for inclusion in WVU Graduate Theses, Dissertations, and Problem Reports collection by an authorized administrator of The Research Repository @ WVU. For more information, please contact researchrepository@mail.wvu.edu. 


\title{
Short Beam Shear Strength Evaluations of GFRP Composites: Correlations Through Accelerated and Natural Aging
}

\author{
William Barker \\ Problem Report submitted to the \\ College of Engineering and Mineral Resources at \\ West Virginia University in \\ partial fulfillment of the requirements \\ for the degree of \\ Master of Science \\ In \\ Civil Engineering \\ Hota V.S. GangaRao, PhD, Chair \\ Ruifeng Liang, $\mathrm{PhD}$ \\ Rakesh K. Gupta, PhD \\ Sushant Agarwal, PhD
}

\section{Department of Civil and Environmental Engineering}

\author{
Morgantown, West Virginia \\ 2019
}

Keywords: Durability, Composites, FRP, Aging, pH, Temperature, Short beam Shear Copyright 2019 William Barker 


\section{$\underline{\text { Abstract }}$ \\ Short Beam Shear Strength Evaluations of GFRP Composites: \\ Correlations Through Accelerated and Natural Aging}

William Barker

Fiber Reinforced Polymers (FRP) composites have been materials of interest in replacing or reinforcing steel, wood, and concrete, but lack of understanding of degradation under physical and chemical aging is a main concern. Through many years of research, the understanding of aging or durability of GFRPs has improved. To be able to evaluate aging related degradation rates, an accelerated aging methodology under varying environments is introduced. Accelerated aging is a concept used to age composites in a lab controlled environment under varying $\mathrm{pH}$ conditions ( 2 to 13 ) and temperatures $\left(\sim-20^{\circ}\right.$ to $\left.+160^{\circ} \mathrm{F}\right)$. Once acceleratedly aged testing is completed, Arrhenius relationships and Time-Temperature Superposition principles can be used to correlate the accelerated data with the naturally aged data to create strength reduction (knock-down) factors for 100-year service life.

In this work, accelerated and natural aged data for glass fiber reinforced vinyl-ester composites was collected through in-lab testing and literature data. Knowing that interlaminar shear strength (ILSS) is the most detrimental mechanical property, this work was solely focused on the degradation of ILSS of glass fiber reinforced vinyl-ester under varying $\mathrm{pH}$ environments and temperatures. The degradation of ILSS in composites has been found to follow two aging trends. Most of the ILSS degradation occurs within the first 3-10 years of service followed by a more gradual trend. The focus of this report is to understand the reason behind a large amount of strength loss in the initial service life. Accelerated testing was also performed on vinyl ester composites with different thicknesses, as well as pure vinyl ester samples. Examining how degradation occurs with varying thicknesses and the resin system apart from the composite is very crucial in understanding the reasons behind aging.

To achieve 100-year service knock-down factors, a correlation between acceleratedly aged and naturally aged data was formulated. In this study, the correlation was possible in a neutral $\mathrm{pH}$ environment due to the lack of natural aged data in alkaline and acidic environments. Therefore, alkaline and acidic environment knock-down factors are based solely on the plots shifted with acceleratedly aged data. Through hundreds of samples tested, alkaline environment is found to be the most detrimental compared to other chemical aging conditions, especially under elevated temperatures $\left(\sim 150^{\circ} \mathrm{F}\right)$. Under high alkaline $(\mathrm{pH} \sim 13)$ conditions, significant strength loss of up to $70 \%$ within the first thirty days of aging was observed, especially under high temperature conditions. 100-year service knock-down factors were arrived at using the Arrhenius relationship. This relationship is formed through reaction rates based solely on temperature dependency. 


\section{Acknowledgements}

I would like to thank Dr. Hota GangaRao for giving me the opportunity to work under his guidance in attending graduate school at West Virginia University. With the guidance of Hota, I was able to develop a further understanding on behaviors of structures. I would also like to thank Dr. Sushant Agarwal for his support and much needed help for understanding the chemical responses of the presented research and for providing a testing fixture to complete my work. I would also like to thank Dr. Ruifeng Liang and Dr. Rakesh Gupta for serving on my committee, and presenting me with important information to add to my work. Also, great thanks to Jerry Nestor for taking the time to create hundreds of coupon samples to test for this research. 


\section{Table of Contents}

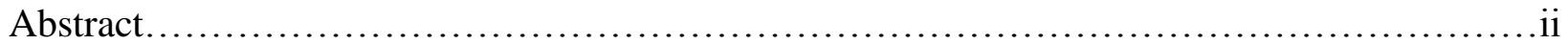

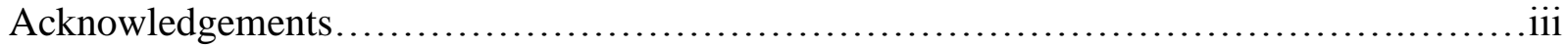

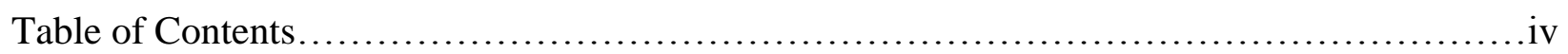

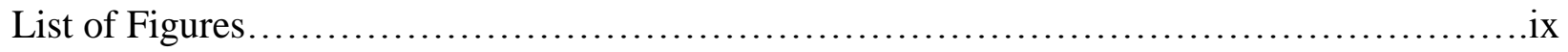

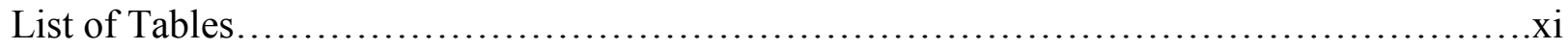

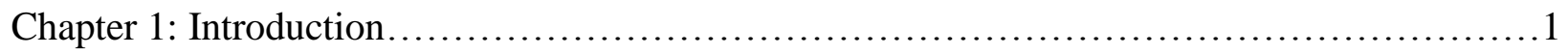

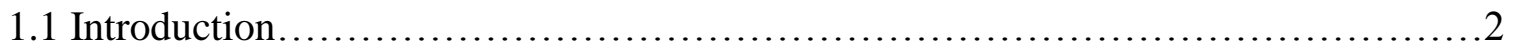

1.2 Need for Accelerated Aging Research..........................................

1.3 Structure of the Work Presented.............................................5

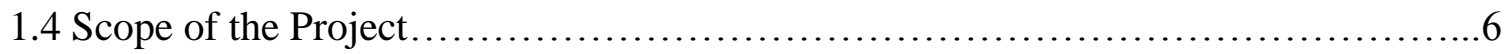

Chapter 2: Literature Review.................................................... 7

2.1 Components of GFRP Composites...................................... 7

2.1.1 Glass Fibers.......................................................

2.1.2 Vinyl-ester Resins $\ldots \ldots \ldots \ldots \ldots \ldots \ldots \ldots \ldots \ldots \ldots \ldots \ldots \ldots \ldots \ldots \ldots \ldots \ldots .8$

2.1.3 Fiber-Matrix Interface........................................ 9

2.2 Aging Environments................................................ 10

2.2.1 Alkaline Environment...........................................11

2.2.2 Acidic Environment........................................... 12

2.2.3 Natural Environment.............................................. 14

2.2.3.1 UV Radiation/ Characterization...............................14

2.2.3.2 Exposure to Humidity and Absorbed Moisture..................15

2.3 Temperature Environments of GFRP Composites............................16

2.3.1 High Temperature Environments.................................. 17

2.3.2 Low Temperature Environments................................ 18

2.3.3 Thermal Shock/Fatigue of the Composite............................ 19

2.4 Arrhenius Relationship................................................20

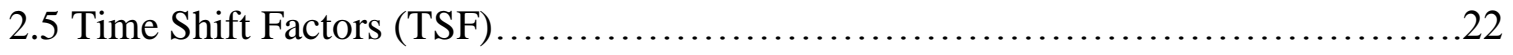




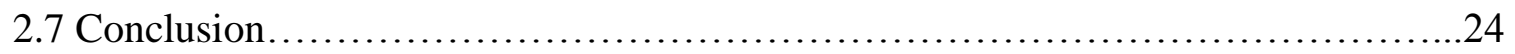

Chapter 3: Data Collection.......................................................... 25

3.1 Accelerated Aging Data.................................................... 26

3.1.1 Material Constraints and Sample Preparation (0-150 Days).............27

3.1.2 Previous Work/Literature Sample Preparation/Testing (150 + Days).......28

3.1.3 Testing of Different Thickness Samples.............................29

3.1.4 Accelerated Aging of Vinyl-ester Samples..............................31

3.2 Natural Aging Data........................................................

3.2.1 Indoor Environment Data...................................... 34

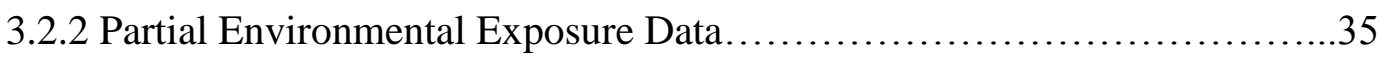

3.2.3 Full Environmental Exposure Data..................................36

3.3 Presentation of Data...................................................

Chapter 4: Methodology for Accelerated and Natural Aging................................38

4.1 Accelerated Aging Methodology .......................................... 38

4.1.1 Limitations to this Methodology .................................42

4.2 Arrhenius Plots...................................................... 42

4.3 Activation Energy...................................................... 43

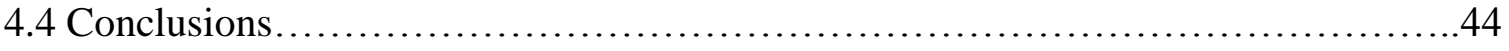

Chapter 5: Time-Temperature Superposition Principle..................................45

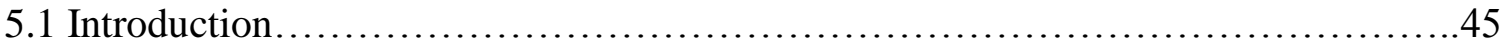

5.2 Time Shift Factors................................................. 46

5.2.1 Time-Shift Factors vs. Temperature..............................46

5.2.2 Approximating Time Shift Factors for Range of Temperatures.............48

5.3 Accelerated Data Shift for Long-Term Degradation Trends.....................50

Chapter 6: Correlation between Neutral Environment Field and Accelerated Aged Data........52

Chapter 7: Conclusions/Recommendations and Knock-Down Factors......................59

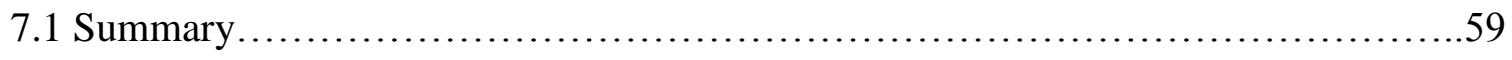




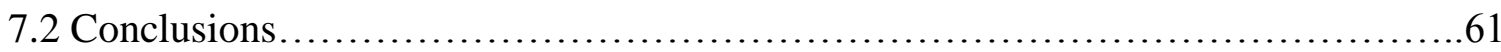

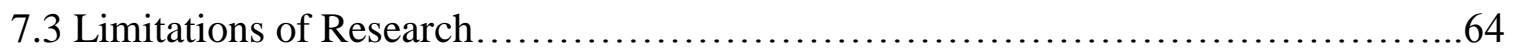

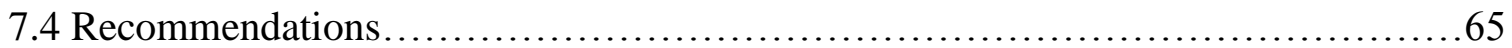

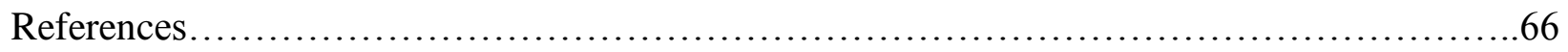

Appendix A: Accelerated Aging Retention Data.........................................69

A.1 Vinyl-ester Interlaminar Shear Strength Retention \% Tables (0-150 Days)..........70

A.1.1 Longitudinal Retention \% ........................................................................70

A.1.2 Transverse Retention \% \%.....................................................................

A.2 Vinyl-ester Interlaminar Shear Strength Retention \% Plots (0-150 Days)...........71

A.2.1 Longitudinal Neutral Environment..................................71

A.2.2 Longitudinal Acidic Environment......................................71

A.2.3 Longitudinal Alkaline Environment..................................72

A.2.4 Transverse Neutral Environment....................................72

A.2.5 Transverse Acidic Environment.......................................73

A.2.6 Transverse Alkaline Environment....................................73

A.3 Vinyl-ester Interlaminar Shear Strength Retention \% Tables (150 + Days) ............74

A.3.1 Neutral Environment............................................ 74

A.3.2 Acidic Environment................................................. 74

A.3.3 Alkaline Environment............................................. 74

A.4 Vinyl-ester Interlaminar Shear Strength Retention \% Plots (150 + Days) ............75

A.4.1 Neutral Environment................................................ 75

A.4.2 Acidic Environment.............................................. 75

A.4.3 Alkaline Environment............................................76

A.5 Vinyl-ester Interlaminar Shear Strength Data (1/8” Thick Samples)................76

A.5.1 Retention (\%) Table.............................................. 76

A.5.2 Retention (\%) Plot............................................... 77

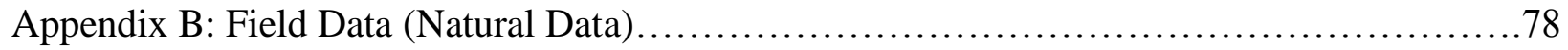

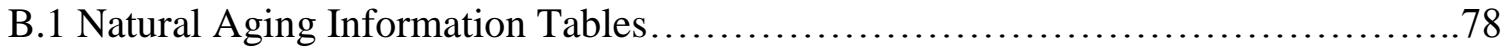


B.1.1 Natural Aging Material Information.................................78

B.1.2 Natural Age Strength \& Sample Size.....................................79

B.1.3 Natural Age Strength Retention \% (Samples used for Degradation Plots)..80

B.2 Natural Aging Plots............................................................... 80

B.2.1 Indoor Environment............................................. 80

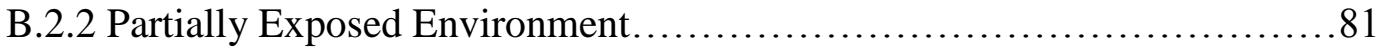

B.2.3 Fully Exposed Environment.......................................81

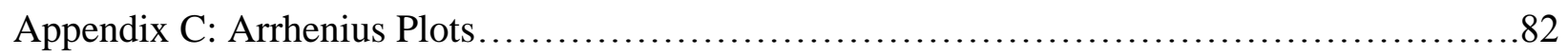

C.1 Arrhenius Plots Longitudinal (0-90 Days) ...................................... 82

C.1.1 Neutral Environment................................................ 82

C.1.2 Acidic Environment................................................ 82

C.1.3 Alkaline Environment...............................................83

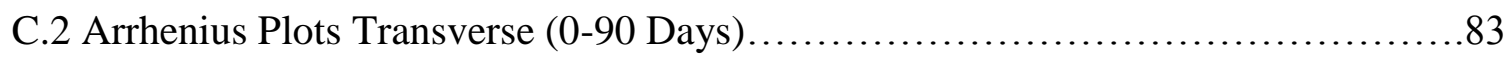

C.2.1 Neutral Environment............................................. 83

C.2.2 Acidic Environment.............................................. 84

C.2.3 Alkaline Environment............................................ 84

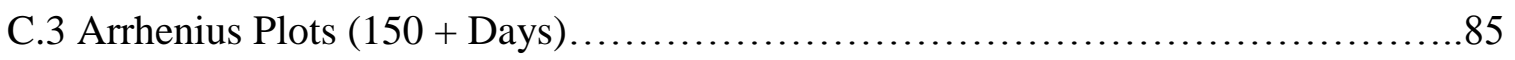

C.3.1 Neutral Environment .............................................. 85

C.3.2 Acidic Environment.................................................. 85

C.3.3 Alkaline Environment.............................................. 86

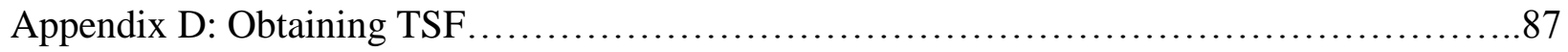

D.1 Obtaining TSF Longitudinal (0-90 Days) ....................................... 87

D.1.1 Neutral Environment............................................ 87

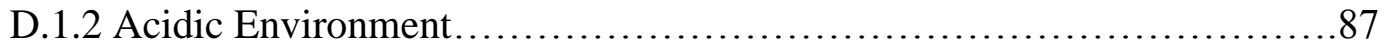

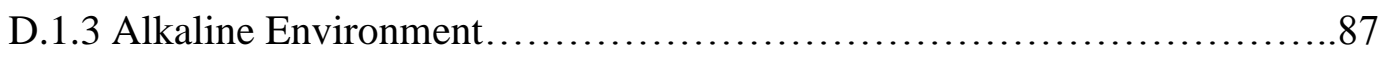

D.2 Obtaining TSF Transverse (0-90 Days) ..................................... 88

D.2.1 Neutral Environment............................................. 88

D.2.2 Acidic Environment.............................................. 88 
D.2.3 Alkaline Environment............................................. 88

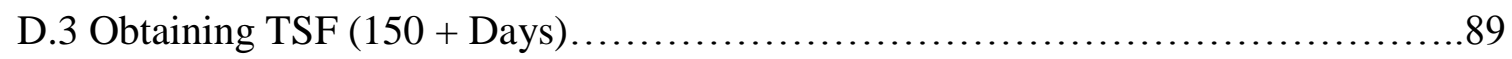

D.3.1 Neutral Environment.............................................. 89

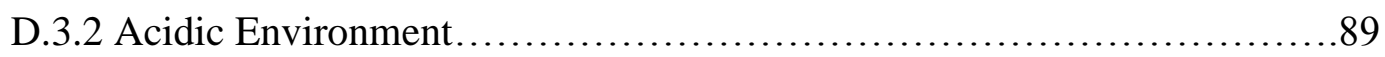

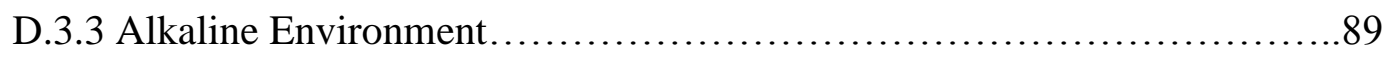

Appendix E: Time Shift Factors vs. Temperature Relationships.............................90

E.1 Longitudinal TSF vs. Temperature (0-90 Days).............................. 90

E.2 Transverse TSF vs. Temperature (0-90 Days) ................................ 91

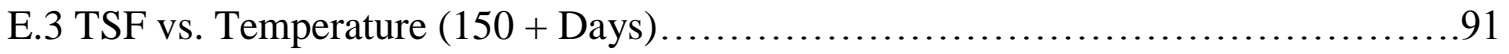

Appendix F: Accelerated Shifted Data for Long-Term Degradation Trends...................99

F.1 Longitudinal Degradation Plots (0-90 Days) ................................... 92

F.1.1 Neutral Environment........................................... 92

F.1.2 Acidic Environment.............................................. 93

F.1.3 Alkaline Environment..............................................93

F.2 Transverse Degradation Plots (0-90 Days)_.................................94

F.2.1 Neutral Environment............................................ 94

F.2.2 Acidic Environment.............................................. 94

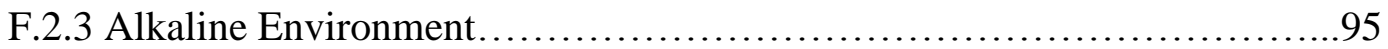

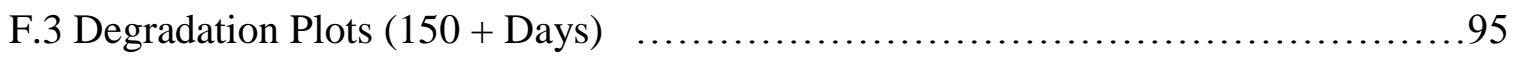

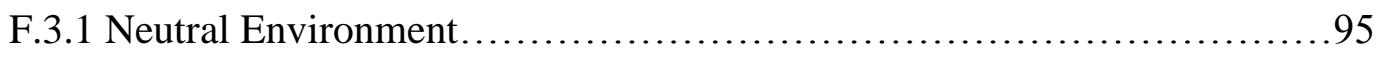

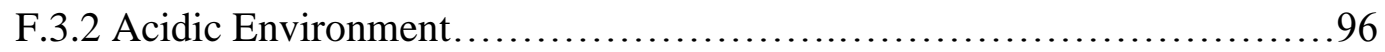

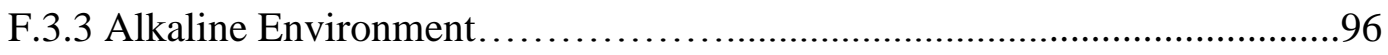




\section{List of Figures}

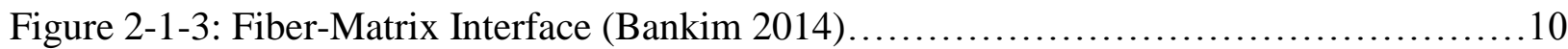

Figure 2-2-1: Interlaminar Shear Strength and Tensile Strength for GFRP Bars after Being

Embedded in Concrete at $60^{\circ} \mathrm{C}$ for Approximately 1 Year (Dejke, 1996)....................12

Figure 2-2-2: Growth Rate of Stress Corrosion Cracking (Three Stages) (Pearce, 2001)........13

Figure 2-3-1: Interlaminar Shear Strength of Vinyl-ester Specimens Following Exposure to (a)

Water, (b) Salt Solution, and (c) Concrete Pore Solution at Varying Temperatures (Chin).......17

Figure 2-3-2: Different Types of Damages in GFRP Composites (Bankim 2014)...............18

Figure 2-4-1: Arrhenius Plot for Service Life as Function of Temperature and Percent Retention

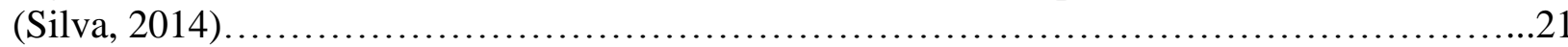

Figure 3-1: Degradation of Acceleratedly Aged Data between 0-420 Days Aged in an Alkaline

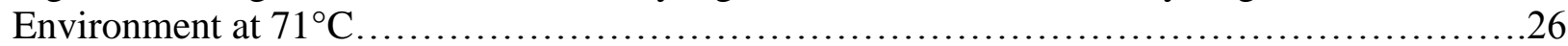

Figure 3-1-1: Aging Environments for Samples..................................... 28

Figure 3-1-3: 1/4" and 1/8" Thick Comparisons at High Temperatures in an Alkaline

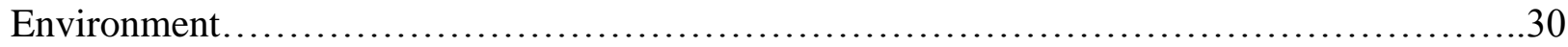

Figure 3-1-4: Representation of Vinyl-ester Resin Curing in the Mold........................ 31

Figure 3-1-5: Vinyl-ester Accelerated Aged Retention Plot in an Alkaline Environment (0-14 days) for different temperatures................................................... 33

Figure 3-3-1: Degradation of Longitudinally Cut Samples under Alkaline Environment........37

Figure 3-3-2: Degradation of Transversely Cut Samples under Alkaline Environment..........37

Figure 5-2-1: Obtaining TSF Neutral Environment 150 + Days Accelerated Aging............47 
Figure 5-2-2: TSF vs. Temperature for 150 + Days of Accelerated Aging..................49

Figure 6-1: Neutral Environment Correlation Degradation Plot 0-3 Years Prediction..........55

Figure 6-2 Neutral Environment Correlation Degradation Plot 3-100 Years Prediction .........56 


\section{$\underline{\text { List of Tables }}$}

Table 3-1-2: Organization of Literature Data.......................................29

Table 3-2: Sample Split of Natural Aged Samples Tested.................................34

Table 3-2-2: Field Aging Degradation Curves (Neutral Environment)......................34

Table 4-3: Vinyl-ester Interlaminar Shear Strength Activation Energy Values................43

Table 5-2-1: Average Time Shift Factors for Given Environment and Aging Protocols..........48

Table 5-2-2: TSF vs. $T^{\circ}$ Relationships for Different Environments and Aging Protocols........49

Table 5-3: Shifted Degradation Curve Relationships for Different Environments and Aged

Protocol......................................................................51

Table 6-1: Field and Accelerated Aged Degradation Curves used for Correlation...............53

Table 6-2: TSF for the Accelerated Aged and natural Aged Correlation......................55

Table 6-3: Estimated Strength Retention in the Field for Vinyl-ester and Neutral pH after

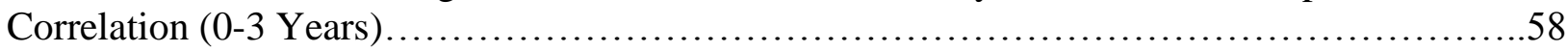

Table 6-4: Estimated Strength Retention in the Field for Vinyl-ester and Neutral pH after

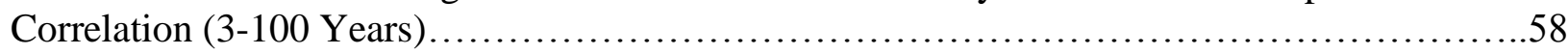

Table 7-1: 100 Year Service Life Knock-Down Factors for ILSS GFRP Vinyl-ester Under

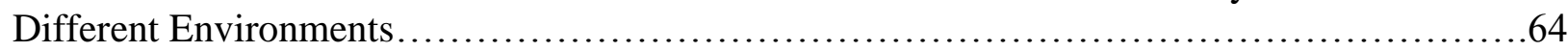

Table A-1: Notation for Terms Presented in Degradation Plots and Tables...................69

Table A-2: Original Shear Strengths for Acceleratedly Aged Data.......................69 


\section{Chapter 1: Introduction}

According to the American Infrastructure Report Card from ASCE in 2017, America's infrastructure grade is a D+ (Kemp, 2017). Infrastructure is deteriorating throughout the country, and rehabilitation and replacing infrastructure is needed. With limited money to spend, FRP composites provide a unique approach to improving the infrastructure in America. FRP composites are cost-effective, and have a high strength to weight ratio. Research and development of composites into infrastructure is a must, but full understanding of how long these composites can last in a 100 year service life is a question of interest. It is very important that we continue to gather information needed to be able to put composites in design codes and implement them into infrastructure applications in both the new construction and in rehabilitation of in-service systems.

Fiber reinforced polymers (FRP) composites are susceptible to degradation under both physical and chemical aging (Lorenzo et al., 2018). FRP composites can be used as alternative materials in infrastructure components (reinforcing bars, wraps, etc.). Understanding thermo-mechanical durability (75 to 100 year service life) of these composites for infrastructure applications under harsh environments (i.e. alkaline, acidic environments) is important to implement safe, yet efficient designs. Reduced bond integrity between the fibers and matrix, oxidation and chain scissions of matrix, hydrolysis, etc. are a few of the many parameters that govern durability responses of polymer composites.

When a composite is first acquired, the initial material properties are given by the manufacturer. These properties do not take into account any type of reductions due to environmental conditioning. Depending on the type of environmental exposure of composites, strength and stiffness reduction factors are applied in design computations. Some environments 
are more hazardous than others which is why the factors differ for different environments under 100 year service life.

It is evident from literature (Lorenzo et. al, 2018; Mahato et. al, 2015; Mishra et. al, 2010; Ratna et. al, 2004), that durability affects shear strength (consequently leads to faster shear failure) more than any other type of failure in bending or tension. Data presented here in is solely based on how FRP composites behave under harsh environments through shear testing. Data was collected based on hundreds of aged samples tested, and analyzed (Lorenzo et. al, 2016; Dittenber et al., 2016) through multiple strength vs. age plots. Once the aging process (includes short-term lab aging and natural field aging) and the subsequent testing for mechanical properties are done, the data (natural and accelerated) can be correlated to naturally aged data of composites exposed to natural weathering conditions. The data (accelerated vs. natural) correlation is made by using the Arrhenius relationship and Time-Temperature superposition principle. Through this we can arrive at design factors (knock-down or strength reduction factors) and suggest an implementation action plan for design procedures of structural systems.

\subsection{Objectives}

It is imperative to understand the need for good structural designs is to meet serviceability and strength limit states and arrive at accurate strength reduction factors to be incorporated in design procedures for safe designs. Ultimate strengths and deformations must be less than load induced strengths and serviceability requirements. When analyzing/designing an FRP structural system for infrastructure application, it is important to take into consideration environmental and chemical effects in the surrounding infrastructure environment. Some of these effects are $\mathrm{pH}$, temperature, creep, fire, fatigue, impact, U.V. radiation, freeze/thaw cycles, thermal fatigue, etc. 
To be able to implement these effects, one must implement design factors affecting the strength and stiffness including deformations into the design.

Implementation of design factors is done by multiplying the initial FRP material resistance values with knock-down factors in order to take into consideration the environmental and chemical effects surrounding the FRP over a 100 year service life. One needs to follow the Load and Resistance Factor Design (LRFD) when applying these design factors. This can be explained through Equation 1-1.

$$
R_{n}=\emptyset * R
$$

Note: $R_{n}=$ nominal strength $\varnothing=$ knock down factor for given $p H$ and other environments, $R=$ ultimate strength

Researchers are still studying these chemical and environmental effects and using different aging prediction models to arrive at knock-down design factors. It is important that research is continued into aging because these factors are what is holding back further implementation of FRP composites into civil infrastructure. Herein, the research objective is to obtain these factors based on the effects (ILSS) of $\mathrm{pH}$ and temperature values for Glass Fiber Reinforce Polymer (Vinyl ester based resin) composites. This research is based solely on the failure modes of Short Beam Shear.

\subsection{Need for Accelerated Aging Research}

Civil engineering structures need to be designed to be durable and sustainable. These structures need to be designed for a service life of 75-100 years. The performance of these structures are designed around the type of material being used and the environment of their surroundings. Like common structural materials (e.g. concrete and steel), FRP composites also 
need to maintain the strength and bond to service an adequate structural life of 75-100 years. The difference between traditional materials like steel and concrete compared to FRP composites is that there is a lack of information and data on the service life of FRP composites over a structure's service life of 75-100 years. With composites being relatively new in infrastructure applications, accelerated aging needs to be performed to understand the degradation of strength and stiffness of the material; thus the safe structural response after 75-100 year service life.

To be able to understand this degradation on a larger note, FRP composites need to be implemented into civil infrastructure to accrue natural data for future correlations to accelerated test data under laboratory conditions. Without this natural data, correlations are difficult and research is solely based on degradation curves of accelerated test data under controlled laboratory environments. These simulated lab environments are much harsher than field environments using much higher temperatures and harsher $\mathrm{pH}$ environments. Therefore, accelerated aging will give a larger loss in a shorter period of time compared to natural aging. The acceleratedly aged data gathered in a short period of time results in decent correlations with the extrapolated data relating to degradation under natural environment. If natural aging data is found for the given environment, correlation between natural trends and accelerated trends can be determined for better understanding of long term behaviors of these FRP materials. With lack of naturally aged data under acidic and alkaline environments, only naturally aged data trends would be developed from those data available from neutral $\mathrm{pH}$ environment. Once accelerated testing is completed, the idea is that good estimation of the performance of FRP composites under different environments can be obtained and knock-down factors can be arrived at with reasonable accuracy. 


\subsection{Structure of the Work Presented}

To be able to achieve 100 year service life resistance (knock-down) factors, the followed procedure was used:

1. Data collection of acceleratedly and naturally aged data under different environments.

2. Creating retention plots for acceleratedly aged data under different environments

3. Developing an Arrhenius relationship \& obtaining Time Shift Factors (TSF)

4. Shifting the acceleratedly aged data to create long-term degradation plots using the TimeTemperature Superposition (TTS) Principle.

5. Correlation of accelerated and natural aged data.

6. Development of formulas for degradation factors \& strength retention (knock-down) factors.

Following this introductory chapter, a literature review is presented in Chapter 2. In Chapter 3, data collection of acceleratedly and naturally aged data is shown. Also in Chapter 3, a brief summary of acceleratedly aged data of composites with different thicknesses and aging of vinyl ester resin is presented. In Chapter 4, the methodology of using the Arrhenius relationship and the meaning of Activation Energy is presented. The Time-Temperature Superposition (TTS) principle and how to obtain Time Shift Factors (TSF) to shift acceleratedly aged data is presented in Chapter 5. Chapter 6 shows how to correlate the acceleratedly and naturally aged data together to determine knock-down factors. Chapter 7 explains the conclusions, limitations, and recommendations to the study and presents the final knock-down factors. 


\subsection{Scope of the Project}

The scope of this project is to understand the degradation rates of interlaminar shear strength (ILSS) of glass fiber reinforced vinyl ester in varying $\mathrm{pH}$ and temperature environments. Through previous researches (Lorenzo et al., 2018; Dittenber et al. 2012), we know that the degradation rates of ILSS are higher than tensile or flexural strength; therefore designs should be driven by the ILSS of the composite. ILSS has two different distinct trends. Initial trend is the high rate of degradation that occurs within the first 90 days of aging, followed by slower degradation rates after $150+$ days. Noting that most degradation of the composite under ILSS occurs within the first 90 days of accelerated aging, testing protocol was arrived at to obtain as much data within the first 90 days to understand this trend.

Arrhenius relationships were determined for two distinct sets of durations (0-90 days aging and 150 + days aging). Each set of data was analyzed independently, and final knock-down factors were given for the two sets of data. Arrhenius relationship appears to be the best model to use since the degradation of these composites is based solely on different $\mathrm{pH}$ environments and temperatures. Using the different rates of degradation seen in different temperatures, one can obtain time shift factors and predict long-term degradation rates. 


\section{Chapter 2: Literature Review}

\subsection{Components of GFRP Composites}

FRP composites can be made (manufactured) of different types of fibers (glass, aramid, carbon, etc.) and different types of resin (vinyl ester, polyester, etc.). The main focus of this report is the degradation of glass fiber reinforced vinyl ester. The different component properties and responses to the environment is explained below. ILSS failures occur mostly in the fiber/matrix interface, therefore the properties of the interface are explained below.

\subsubsection{Glass Fibers}

Glass fiber materials possess quite a few useful properties such as fiber and corrosion resistance, high strength, comparatively low density, excellent optical and electrical properties, good thermal and sound insulation characteristics (Bankim et al., 2015). Glass fibers have been used widely in reinforced plastics for the production of corrosion resistant pipelines, storage containers, and apparatus in the chemical, oil, and gas industries. They are also used in building, rail, road transport, and many other engineering applications. There are two main forms of glass fibers which are continuous fibers and stapleglass fibers.

Continuous fibers consist of indefinite large lengths, straight-linearity, and a parallel arrangement of filaments in fiber tows. Continuous glass fibers are used for the manufacturing of textile materials and products in various branches of technology (Bankim et al., 2015). Staple fibers are produced by breakdown of glass melt steam by using air, steam, or gas flow. These are then characterized by small lengths, twists, and random dispositions. These staple glass fibers are made-up into bulk fibers, mats, and fabrics with the use of organic binders. Staple glass fibers are used for many applications in the industry. Some of these include thermal, sound, and electrical 
insulation, anticorrosive protection, and filtration of chemically aggressive high temperature mediums.

Glass fibers need to withstand the environmental conditions to retain enough strength to prevent failure. The strength of the fiber is influenced by the way the fiber is formed, and by the physical-chemical interaction between the environment and the fiber surface. The composition of glass fibers is very resistant to chemical, thermal, electrical, and optical environments. However, the mechanical properties of glass fibers are an exception. When fibers are in the presence of moisture or aqueous solutions, they absorb liquids and initiate micro-cracking, especially under freeze-thaw effects. These cracks and environments can reduce the strength of the fibers up to $30 \%$ of their original strength.

\subsubsection{Vinyl Ester Resins}

Matrix (cured resin) helps to protect the fibers from attacks, such as mechanical and environmental. This matrix also ensures that the fibers in the composite remain in the same orientation angle which allows loads to be transferred to the individual fibers and layers. The properties of the matrix are strong in chemical stability, diffusivity, and toughness. Vinyl ester is known for its ease of processing, low viscosity, and high level of environmental resistance.

Vinyl ester resin contains fewer polar groups than other resin systems like polyester. Vinyl ester is very low in diffusivity and absorbability because the cross-link density can be better controlled. With vinyl ester having good cross-links, it is more stable and can resist water penetration into the composite.

Stress-corrosion characteristics are very important in deciding on the resin you would like to use in a composite. The composite is influenced in a strong degree by the type of resin used. 
With GFRP composites being the most susceptible to alkali environments, it's important to understand that vinyl ester resin seems to exhibit the highest resistance to stress corrosion in an alkali environment.

Vinyl ester resins contain large number of hydroxyl groups, which promote the absorption of moisture from the environment (Hammami et. al, 2014). Once moisture is absorbed, the matrix will begin to expand which causes debonding at the fiber-matrix interface. The moisture could also accelerate the thermal decomposition of the matrix at elevated temperatures, and it could result in a premature failure of the composite.

Taking into account all of the positive and negative aspects of using vinyl ester resin to mold your composite, it is important to notice that vinyl ester seems to be the most durable and tough compared to other resins used in GFRP composites.

\subsubsection{Fiber-Matrix Interface}

The three-dimensional region between the bulk fiber and bulk matrix is referred to as the "interface" (Bankim et. al, 2014). The interface is a heterogeneous area between the matrix and the fibers, which is only a few micrometers thick. Figure 2-1-3 provides a visual representation of the fiber-matrix interface. The bonding between the fiber and the matrix (cured resin) can differ based on the chemistry and molecular make up. Atomic arrangement, molecular conformation, and chemical constitution of the fiber and matrix are some of the differences which make each fiber/matrix system unique. The specific properties of the fiber and matrix are not the only way to explain the strength of the composite. One must also consider the interface between the fiber and matrix for the strength as well. If a composite is not well bonded at the interface, failure could result through debonding or delamination. 


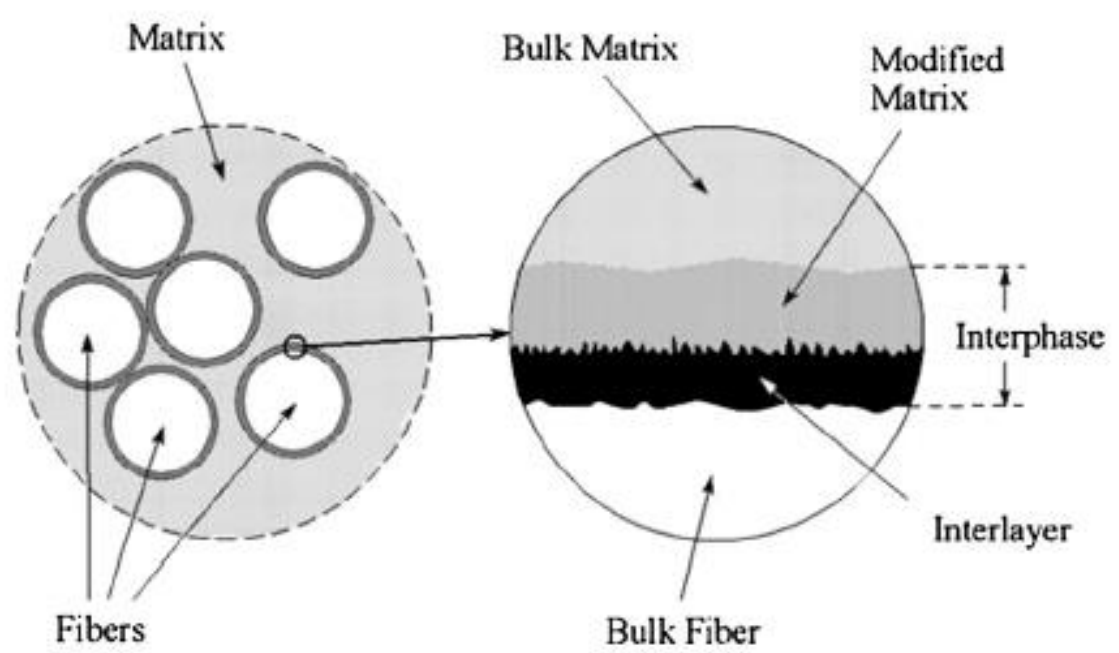

Figure 2-1-3: Fiber-Matrix Interface (adapted from Bankim et al., 2014)

The mechanical behaviors of FRP composites are controlled by the interfacial adhesion at the fiber-matrix interface. At elevated temperatures, thermal expansion will begin to degrade the fiber-matrix interface which results in lower interlaminar shear strength. Any deterioration of this interface reduces the transfer of the loads between fibers, and thus weakens the composite material (Nkurunziza et al., 2005). In addition, water molecules seep through the interfacial materials, resulting in further reduction in interfacial bond strength between the fibers and resin. There are three major modes of damage that occur at the interface, and these are: 1. Osmotic cracking of the matrix; 2. Differential swelling of the interface, and 3. Separation between the fiber and matrix (resultant of modes 1 and 2).

\subsection{Aging Environments of GFRP Composites}

It has been proven that moisture, alkalinity, and temperature are the main parameters affecting the durability of composites. The moisture absorbed by the composites, combined with the temperature of exposure, induces stresses in the material that damage the fibers, the matrix, and their interface, thus gradually decreasing the strength of the composite material with time 
(Nkurunziza et al., 2005). GFRP composites used as reinforcement (concrete reinforcement) do not corrode in chloride environment due to their non-metallic nature, but the alkaline environment from concrete plays a major role in degradation of the interface. The effects of moisture, especially in cases of alkaline and acid solution, are recognized as the most detrimental in terms of property degradation.

\subsubsection{Alkaline Environment}

Even though the mechanisms of how alkali solutions affect strength loss are not clearly indicated, one can assume that the attack of glass fibers is by a process of dissolution of silica $\left(\mathrm{SiO}_{2}\right)$ by chemically reacting with alkaline ions $\left(\mathrm{OH}^{-}\right)$. The $\mathrm{SiOH}$ by-product forms as a gel on the surface of glass fibers while the $\mathrm{SiO}$ byproduct forms as a solution (Nkurunziza et al., 2005). When the $\mathrm{SiO}$ begins to form as a solution, it causes a loss in weight and diameter of the fiber. Therefore, it also creates a loss of strength and modulus of the fibers. Studies show that the degradation of GFRP in sodium hydroxide $(\mathrm{NaOH})$ solution is more severe than in actual concrete environment (referring to GFRP reinforcement in concrete). This is due to the higher alkalinity of $\mathrm{NaOH}$ and the high movement of $\mathrm{OH}^{-}$ions.

The resistance of glass fibers to an alkaline environment also depends on the makeup of the fibers and the sizing chemistry of glass in addition to resin type. Resins of lower diffusivity and higher elongation (e.g. PU) perform better than stiff resins. For example, the addition of alumina increases the fiber resistance to water, but decreases their resistance to alkaline environments. One way to increase glass fibers resistance to alkaline environments is adding zirconium dioxide $\left(\mathrm{ZrO}_{2}\right)$, and it will produce alkali resistant (AR) fibers. Another way is to create a composite material with an impervious matrix (acts as a barrier) which will prevent the alkali to reach glass fibers. Vinyl ester is a high-performance resin and after cure (i.e., matrix) is better 
suited to help prevent the alkali to reach the fibers. However, water or alkalis will end up penetrating through micro cracks and attack the resin. The type of resin as a binder can slow down and prevent ASR type of degradation for a prolonged period of time. Studies showed (Benmokrane et al., 2002; Dejke, 1996; Ceroni et al., 2006, Vijay, 1999, Wang et al., 2015) that alkaline environments are the most critical environments under short-term exposure, but other environments become similarly critical with more time. When composites are exposed to alkali environment, one can see retention levels in a GFRP rebar as low as 3\% of the original strength (Figure 2-2-1) in one year.

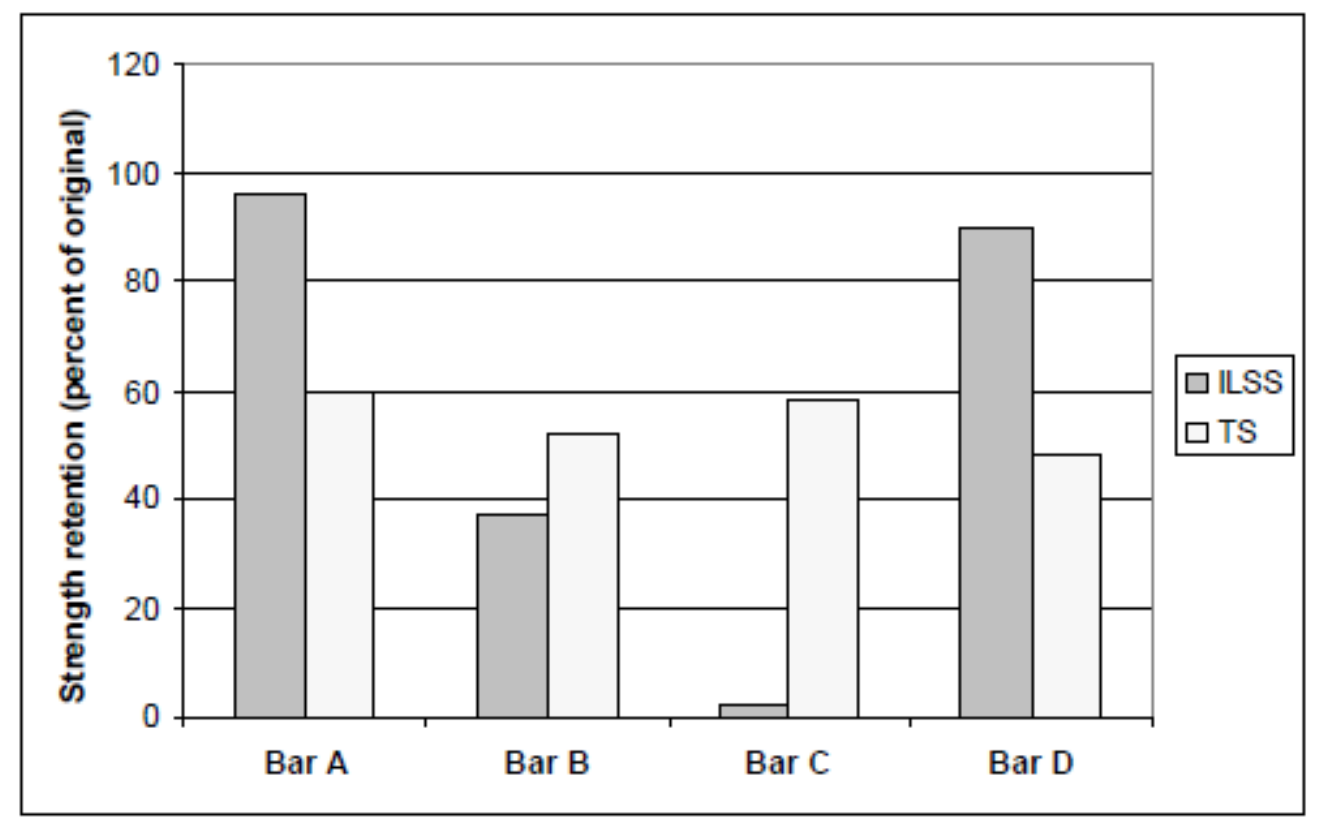

Figure 2-2-1: Interlaminar Shear Strength and Tensile Strength for GFRP Bars after Being Embedded in Concrete at $60^{\circ} \mathrm{C}$ for Approximately 1 year (adapted from Dejke, 1996)

\subsubsection{Acidic Environment}

It is known that GFRP composites will come into contact with acidic environments like acid rain and acidic chemicals throughout their service life. Throughout acidic exposure, 
transformations begin to happen in the composite. The fiber/matrix interface begins to degrade which causes the composite to absorb moisture. This absorbed moisture continues to gradually degrade the fiber interfaces which will cause internal damages (micro-cracks and blisters). Some of these damages can either be reversible or irreversible based on the exposure time and conditions of the environment. If the environment is known before the implementation of the composite, coupling agents can be used to help delay corrosion processes and minimize loss in mechanical properties (Surendra et al., 2007).

Glass composites are very susceptible to rapid stress corrosion in acidic environments due to the loss of reliability of the fiber/matrix interface. Stress corrosion cracking depends on the amount of glass fibers exposed. Stress corrosion cracking involves planar fracture with a three stage process when the stress applied externally, in which the first stage refers to single fiber transverse crack initiation, the second stage refers to crack growth spreading to neighboring fibers through the matrix, and the third stage is the stable propagation of the crack across the specimen resulting in failure (Surendra et al., 2007). Figure 2-2-2 represents the growth rate of stress corrosion cracking and how it stabilizes out before it fails in stage 3 (Pearce et al., 2001)

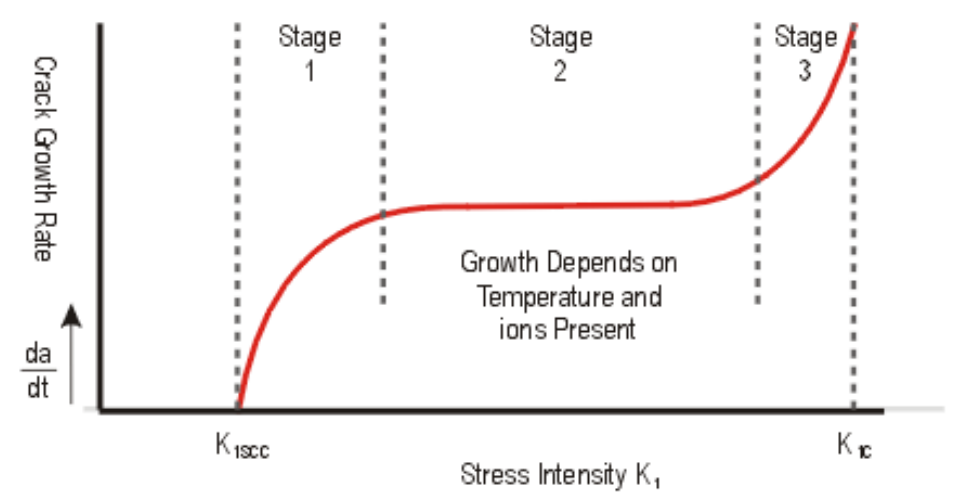

Figure 2-2-2: Growth Rate of Stress Corrosion Cracking (Three Stages) (adapted from Pearce et al., 2001) 
The acid can then reach the fibers by flowing through the micro cracks and voids in the matrix, which are developed typically through stress corrosion cracking. Acid can reach also through diffusion of $\mathrm{Cl}^{-}$ions which weaken the interfacial bond. Once the acid is directly in contact with the surface of the fibers, cracks will begin to grow more quickly and strength begins to decrease. As the concentration of acid increases in an environment, the degradation increases in the composite.

\subsubsection{Natural Environment}

With natural environment being assumed to have $\mathrm{pH}$ ranging typically from 6 to 8 (near neutral), minimal degradation is assumed from the $\mathrm{pH}$ itself. Instead, there are multiple other factors found in a neutral environment which can cause degradation. Some of these factors consist of UV radiations, exposure to humidity, and environmental conditioning such as freeze-thaw, drywet cycles, thermal variations and others.

\subsubsection{UV Radiation/Characterization}

Exposure to UV light causes degradation of polymeric constituents through a mechanism of photo degradation (Carra et al., 2013). The degradation begins at the outer surface which the light is exposed to on the composite. This type of degradation will cause surface discoloration and oxidation of the composite. Vinyl ester produces the most visible variation for the eye compared to other polyester matrixes. It is important to understand that if the light penetration is limited to the surface then it may only result in surface discoloration, but if the UV light penetrates through the exterior surface, then it will result in degradation of the composite (especially the matrix).

Exposure to UV radiation causes hydrogen abstraction from the polymer molecules, which generates free radicals and these free radicals can initiate other reactions causing brittleness and 
subsequently lower the molecular weights and loss of thermal diffusivity and load bearing capacity (Bankim et al., 2014). The severity of the degradation depends on the type of polymer used and the duration of the UV exposure. UV radiation can cause random chain scission (degradation of the main polymer chain) or increase in brittleness.

Studies have shown that UV degradation depends on the thickness of the composite. Samples exposed for 1000 hours of UV exposure has shown up to $40 \%$ degradation of the mechanical properties (.13 mm thick samples). Samples as thick as $0.25-0.50 \mathrm{~mm}$ have shown no strength or stiffness degradation effects from the UV exposure.

\subsubsection{Exposure to Humidity and Absorbed Moisture}

Exposure to humidity occurs in a neutral environment depending on the location of which the composite is being introduced into infrastructure. States with higher humidity will cause a greater impact on the composites compared to low humid areas. It is known that the attention of the composite needs to be focused at the interface between the fibers and matrix. This area is of high concern since it is the area where stress transfer and distribution of loading occurs. The integrity of a composite structure is mostly established by the adhesion responses or aging of the

fiber and the matrix (Mahato et al., 2015). The creation of high bond is important in high humid areas due to the absorption of the moisture. As the composite goes through this swelling phase from the moisture of humid environment, residual stresses and strains incorporate themselves inside the composite. The more severe of the swelling, the larger are the induced residual stresses and strains.

The most common damage modes are matrix cracking, delamination growth, and fiber fracture when exposed to absorbed moisture in general (precipitation, humidity, etc.) (Sethi et al., 
2015; Gautier et al., 1999; Mula et al., 2006; Bankim et al., 2014; Mohato et al., 2015). Absorbed moisture is one of the most recognized causes of long-term failure of composites. When composites are exposed to moisture, there are multiple modes of failure such as plasticization of matrix; differential swelling; embrittlement of macromolecular skeleton by hydrolysis; osmotic cracking; hygrothermic shock; localized damage at the fiber/matrix interface, etc. (Sethi et al., 2015). Moisture is introduced to the composite by diffusion flow along the fiber/matrix interface or through voids/cracks. Moisture causes the matrix to swell and create residual stresses inside the matrix. Avoiding high areas of humidity and precipitation will help with longer service lives of FRP composites in infrastructure.

\subsection{Temperature Environments of GFRP Composites}

Another harsh environment for composites to be subjected to, would be high and low temperatures, thermal shock, and thermal fatigue. Any composite is sensitive to temperature variations due to the thermal stresses between fibers and matrixes due to differential thermal expansion coefficients of resin versus fiber in a composite. Degradation of composite strength varies with respect to temperature. Shown in Figure 2-3-1, as temperature increases, degradation occurs at quicker rates. In areas where freeze-thaw cycling is common, response of composites under freeze-thaw is of great design interest due to the constant swelling and condensing of the composite.

In this section of the review, subsections on reviews of high temperature, low temperature, and thermal fatigue are presented. Composites in this study are exposed to these different temperature conditions, and understanding a general knowledge of the effects of the temperatures are of great value. 

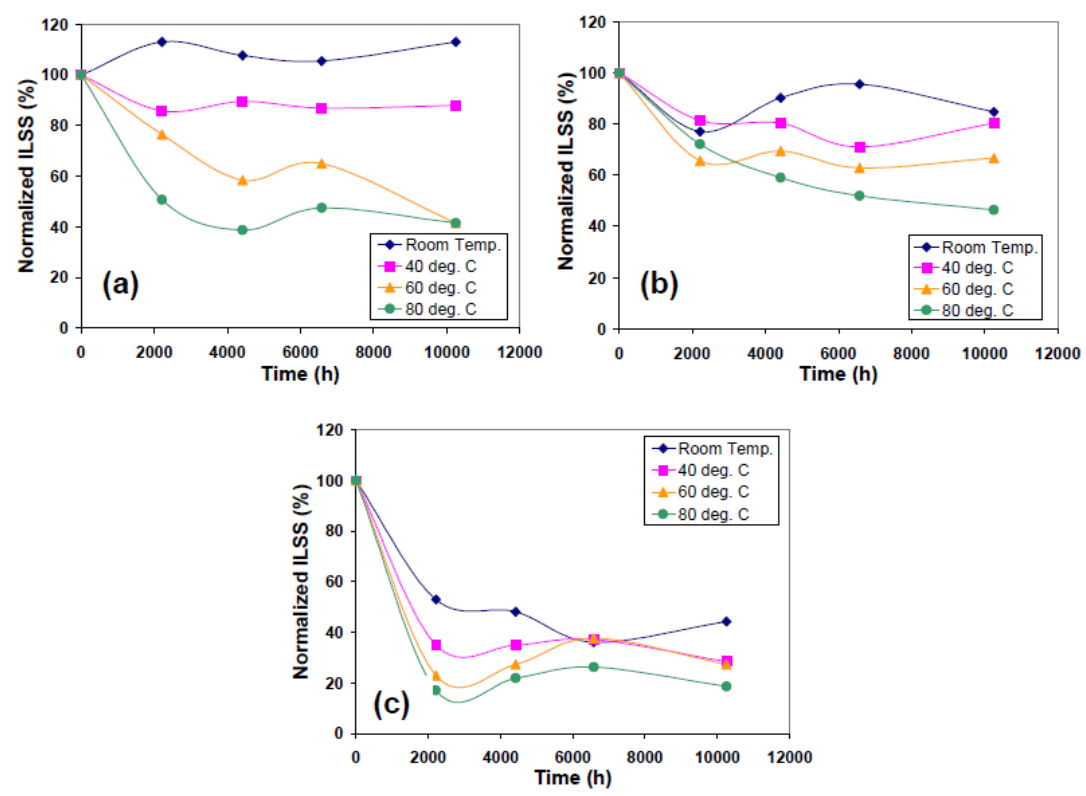

Figure 2-3-1: Interlaminar Shear Strength of Vinyl-ester Specimens Following Exposure to (a) Water, (b) Salt Solution, and (c) Concrete Pore Solution at Varying Temperatures (adapted from Chin)

\subsubsection{High Temperature Environments}

At elevated temperature differential, thermal expansion of the fiber and matrix may lead to the formation of micro cracks at the fiber/matrix interface due to large variations in thermal coefficients of expansion and contraction of fibers versus matrix (Bankim et al., 2014). The fiber/matrix interface is very vulnerable to these temperatures due to the aggressive reactions occurring from this exposure. These type of reactions can lead to the degradation of fibers and matrix, mass loss and shrinkage of the composite, and degrade surfaces with poor mechanical properties. The degraded interface affects the integrity and usefulness of a composite since thermal and mechanical loads are transferred through the interface from the matrix to the fibers. 
With the interface being weakened, thermally induced intraplymicro-cracks are formed in the matrix material of composite laminates (Mahato et al., 2015; Bankim et al., 2014). These cracks expose the interior of the composite to the external environment leading to accelerated damage to the bulk of the material. Interlaminar shear strength is severely weakened in the composite since shear relies on the transfer of these loads through the interfaces of the laminate/composite. Thermal aging alone causes significant changes to the physical matrix. Different types of damages can be seen in Figure 2-3-2.

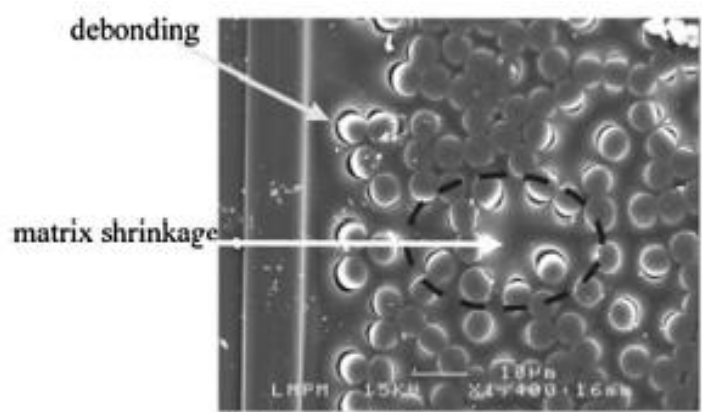

a)

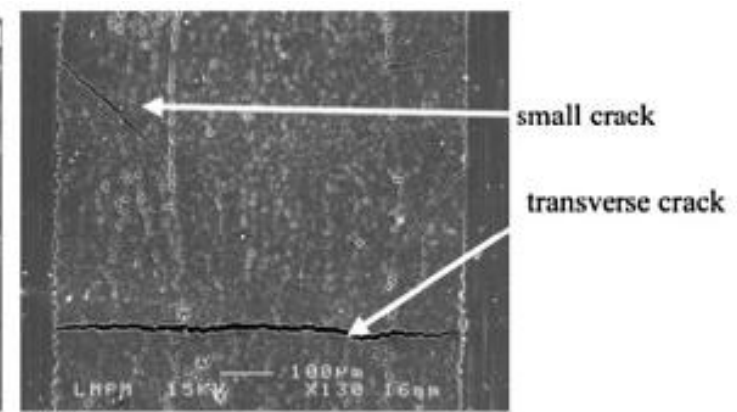

b)

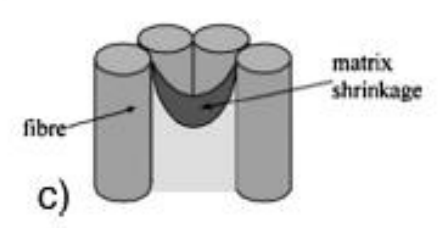

Figure 2-3-2: Different Types of Damages in GFRP Composites (adapted from Bankim et al., 2014)

\subsubsection{Low Temperature Environments}

When loads are applied, microcracks may generate and propagate in the matrix and/or at the fiber/matrix interface. Compared to higher temperature, less cracks generate at lower temperatures. As temperature becomes lower, the stiffness of the composite increases. Studies have shown (Bankim et al., 2014; Mohato et al., 2015) that low thermo-mechanical cycles can result in improvements in interfacial shear strength of laminated composites. Brittleness is the main failure characteristic found in low temperature environments. 
ILSS values increase with more conditioning time (low temperature environment) as per some studies and scenarios. Greater values of shear strength at longer conditioning times are made possible due to some suggested principles such as the key and lock principle at the fiber/matrix interface of the composite. The low temperature composite response leads to matrix hardening due to the large contraction. There is freezing of polymer chains which leads to a reduction in deformation process hence resulting in less polymer relaxation so it gets hardened (Mahato et al., 2015). The hardening causes the matrix to behave more like a stone like structure in which separation of fibers is almost negligible, if not impossible.

\subsubsection{Thermal Shock/Fatigue of the Composite}

When continuous fiber reinforced composites are subjected to temperature variations, local stresses are generated in the composites due to the different coefficients of thermal expansion and/or due to the ply orientation in the lay-up (Bankim et al., 2014). Thermal shock is defined as a sudden change in temperature associated with the operative environment of any engineering and structural material. Under varying temperature environments, thermal variations become cyclic and composites can fail under thermal fatigue. The thermal fatigue can cause various types of damages like transverse matrix cracking, fiber/matrix debonding, and delamination.

The differences in thermal coefficients of glass and resin may lead to an increase in residual stress in the fiber/matrix interface. Bond strength in the fiber/matrix interface also plays a role in the deterioration process. Lower bond strength may initiate a large fiber/matrix interfacial debonding in a shorter amount of time. An intralaminar crack initiates when the composite is made

up of weak fiber/matrix interface bonds. Laminates with low bond strength exhibit large areas of interfacial debonding that intensifies other damage mechanisms to promote laminate failure 
(Mahato et al., 2015). One of these damage mechanisms is known as matrix cracking which becomes a form of damage that can lead to complete delamination failure.

Temperature variations become more hazardous in certain environments like in the presence of an oxidative environment. Within this environment, composites experience mass loss and reduction in volume of the matrix causing the matrix to shrink, when compared to the fibers. This is caused by matrix oxidation under hazardous environment. Fiber/matrix debonding changes with the oxygen reaction to resin/sizing. With an increase in oxygen pressure due to oxidations, a thermo-oxidation phenomena accelerates and decreases the fiber/matrix debond time. When thermal fatigue occurs in an oxidative environment, coupling effects between thermal and transverse accelerate property degradation rates. When designing for thermal fatigue, it is also important to look into the oxidative environment around a composite structure (Bankim et al., 2014; Mohato et al., 2015).

\subsection{Arrhenius Relationship}

The Arrhenius equation describes the temperature dependence of reaction rates and helps in determining the rate of chemical reaction and the activation energies. The relationship is seen as an empirical relationship, and it can be used to model thermally-induced processes (Compos et al., 2006; Silva et al., 2014; Shilpa et al., 2010; Wang et al., 2015). Analyses of accelerated aged data at different temperatures reveals that an Arrhenius relationship seemed to be the best method to analyze the ILSS data.

An Arrhenius relationship was used to analyze the data to help understand the degradation rates and to arrive at design factors. The primary assumption of this model is that the dominant degradation mechanism of shear strength will be accelerated with the increase in temperature 
(Compos et al., 2006). Therefore these models are based on temperature being the dominant factor of acceleration in the aging process. These models can be written in different ways (Eqn. 2-1).

$$
k=A \exp \left(\frac{-E_{a}}{R T}\right) \text { or } \ln k=\ln A+\frac{-E_{a}}{R T}
$$

Note: $k=$ degradation rate (1/time); $A=$ constant of the material and degradation process; $E_{a}=$ activation energy; $R=$ universal gas constant; and $T=$ temperature in Kelvin

Interpreting the degradation rate $k$ as the inverse of the time required for a material property to reach a given value, the logarithm of $1 / k$ shows that the time for a property to degrade to a chosen value is a linear function of $1 / T$ with the slope $E_{a} / R$ (Silva et al., 2014).

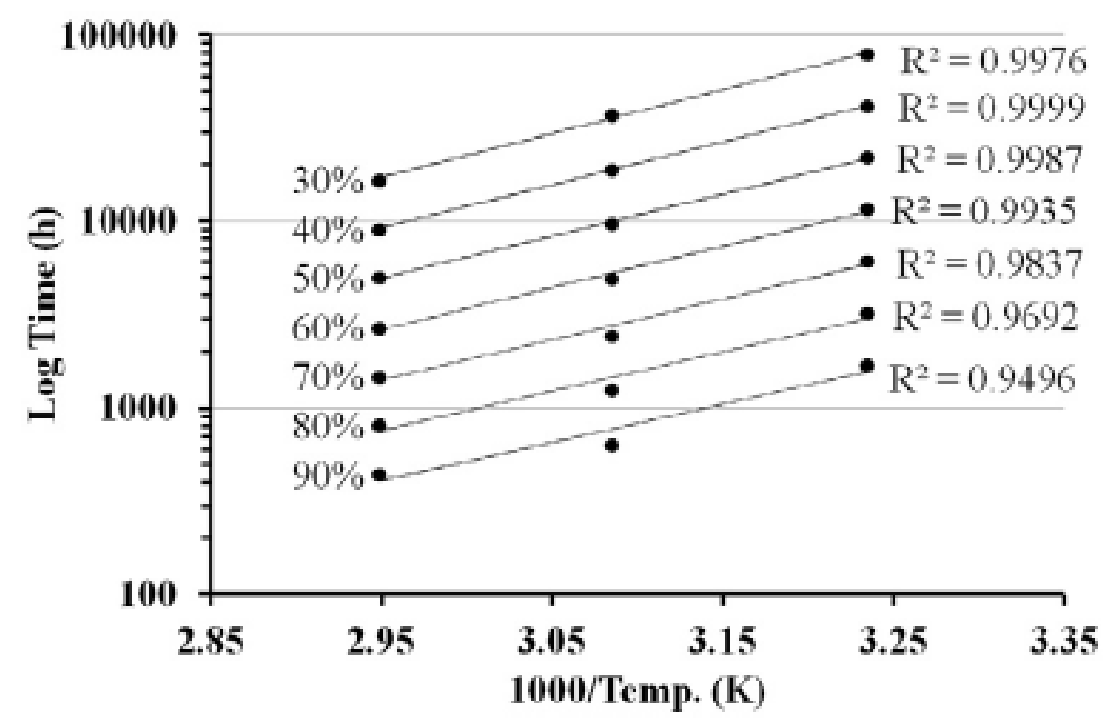

Figure 2-4-1: Arrhenius Plot for Service Life as Function of Temperature and Percent Retention (adapted from Silva et al., 2014) 


\subsection{Time Shift Factors (TSF)}

Once an Arrhenius relationship is developed and proven, an extrapolation of long-term behavior can be used assuming that the Arrhenius relationship is valid. The concept of time shift factors, TSF, is defined as the ratio between the times required for a certain decrease in a mechanical property at two different temperatures (Silva et al., 2014), (Eqn. 2-2). The time for a reaction to occur is proportional to the inverse of the reaction rate $\mathrm{k}$ and the ratio of $\mathrm{t}_{1}$ and $\mathrm{t}_{2}$ can be written as:

$$
\mathrm{TSF}=\frac{t_{1}}{t_{2}}=\frac{A e^{\frac{E_{a}}{T_{2} R}}}{A e^{\frac{E_{a}}{T_{1} R}}}=e^{\frac{E_{a}}{R}\left(\frac{1}{T_{2}}-\frac{1}{T_{1}}\right)}
$$

Note: $t_{1}=$ time needed for a specific decrease of a property at temperature $T_{1}, t_{2}=$ time needed for the same decrease at temperature $T_{2}$

TSF permits the degradation computation under a select service condition from the data acquired through accelerated aging. This is done by shifting the final data obtained in the accelerated laboratory conditions along the time axis to find the time $t_{1}$ at which, under a lower temperature, the same degradation is estimated to take place. Once the time shift factors (TSF) are calculated, it is possible to apply the regression curves to predict strength retention for natural aging conditions.

Time shift factors, in this scope of work, are very important, especially for alkaline and acidic environments and under higher aging temperatures. Long-term degradation predictions of composites aged in an alkaline and acidic environment is based solely on using these time shift factors to shift the retention plots. With no natural data in alkaline and acidic environments to correlate with, final knock-down factors in those environments are very dependent on these time 
shift factors. See Appendix D \& E to understand more on how to obtain TSF with varying temperatures.

\subsection{Strength Reduction Factors for Environmental Conditions}

When designing for civil structures, one has to take into account multiple environmental effects, degrading the materials. Understanding the amount of degradation of the material with the given service life is important for the safety of the infrastructure and the public using it. Civil structures are normally designed for a service life of 75-100 years. For FRP composites, determining these factors through better understanding of degradation mechanics and their rates is becoming critical from design view point, and years of research continues to shed better light on the physics of degradation and thus arriving at more accurate knock-down factors.

There are many issues in determining these factors. The main issue is being able to correlate other researcher's strength reduction or knock-down factors with factors obtained in this research. Such correlation is difficult due to the fact that researchers use different testing standards and testing methodologies. The absence of durability test standard makes data comparison difficult. If there is a consistent methodology used to correlate degradation rates of materials, then experimental variability can be minimized from data analyses. However, there are going to be variations in resin types, fiber types, fiber orientations, manufacturing processes, and many other types of variations which will continue to hinder high degree of accuracy, repeatability, and validity of the data. 


\subsection{Conclusion}

Understanding the background of the constituents of FRP composites (matrix, fibers, matrix/fiber interface, etc.), makes it possible to create accurate design (knock-down) factors. Using the Arrhenius relationship seems to be the most popular and reasonable decision when creating these long-term degradation curves. In this experimental study, glass reinforced thermosets using a vinyl-ester resin were studied for ILSS under different environments of $\mathrm{pH}$ and temperature.

The process and methodology of the data collected herein is presented throughout the rest of the reports and in the Appendix. The main focus of this study was to focus solely on interlaminar shear strength (ILSS) failure degradation curves. Data was split between the first 90 days and 150 + days using accelerated aging methodology because steep variations in data trends before 90 days and after 150 days. Alkaline environments were the most detrimental of the $\mathrm{pH}$ environments. This becomes a huge concern in using GFRP reinforcement in concrete due to major loss in material strength to failure within the first 30 days of exposure. 


\section{Chapter 3: Data Collection}

In this chapter, data collection will be explained. Some data used was from literature and previous work, but most data gathered was tested by the author in the lab. The ways data was collected and analyzed was very important in this study since the data was very unique in the type of resin and fiber used in a composite.

All acceleratedly aged data for 0-150 days of aging was tested in a laboratory at West Virginia University (WVU). Most natural data was tested as well by the author. Other acceleratedly aged data $(150+$ days $)$ and previous natural data was taken from the works of Maria Martinez de Lahidalga de Lorenzo et al. (2018) and David Dittenber et al. (2012). It was very important to note that all data were only affected from $\mathrm{pH}$ and temperature, and no other external agents are elaborated in this report.

Interlaminar shear strength degrades in two distinct different trends when analyzing the acceleratedly aged data (0-90 days and $150+$ days). Knock-down factors can be more accurate when analyzing the degradation rates as two different trends. As seen if Figure 3-1, two different trends can be seen. For data between 0-90 days acceleratedly aged, strength loss of up to $70 \%$ can be seen. For $150+$ days acceleratedly aged data, there is no significant strength loss. 


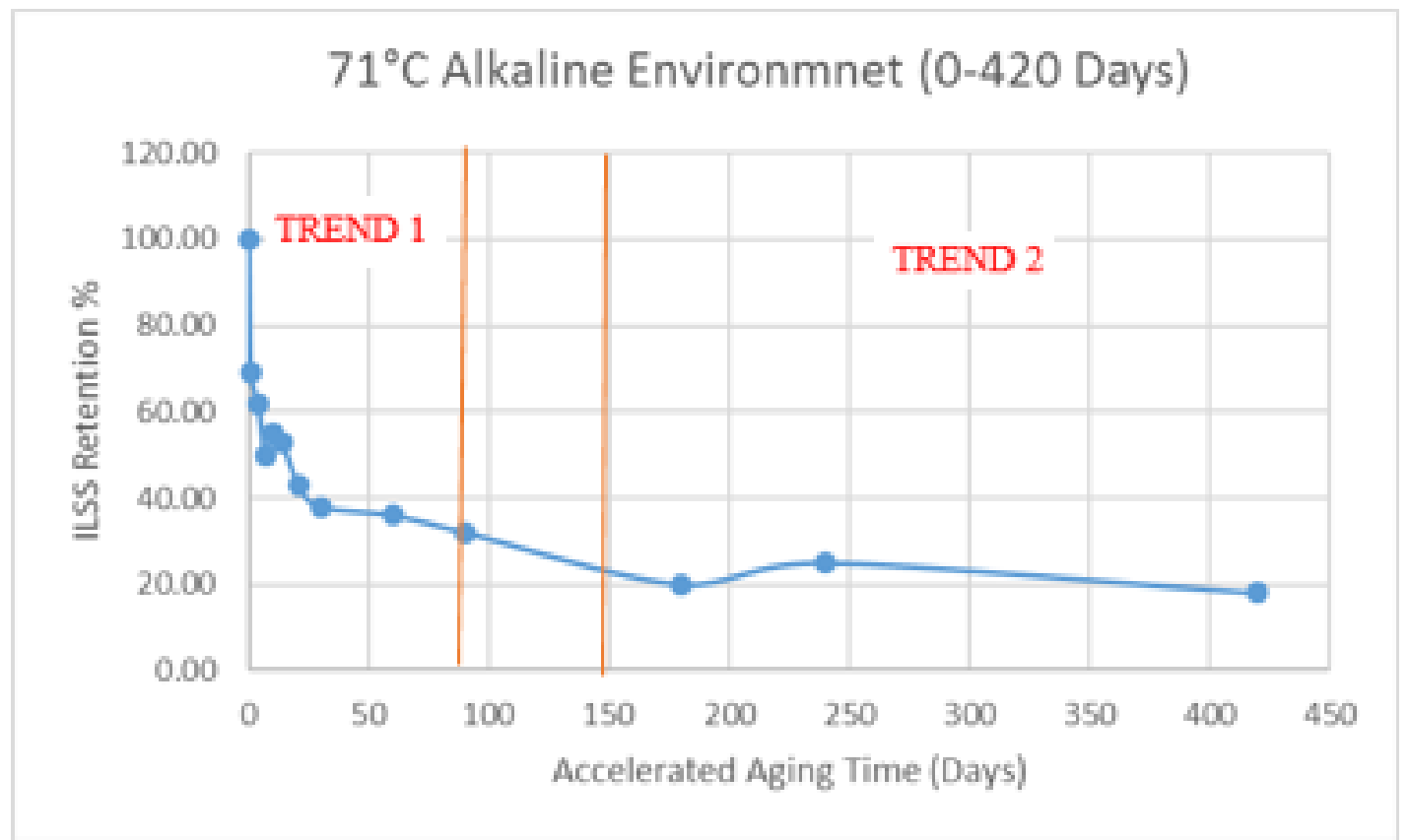

Figure 3-1: Degradation of Acceleratedly Aged Data between 0-420 Days Aged in an Alkaline Environment at $71^{\circ} \mathrm{C}$.

\subsection{Accelerated Aging Data}

There are specific parameters that were taken into account when collecting acceleratedly aged data. These are shown below:

- Composites consist of glass fibers and vinyl-ester resin

- Temperatures tested: $-22^{\circ} \mathrm{C}$, room temperature, and $71^{\circ} \mathrm{C}$

- pH environments tested: acidic (3), neutral (6-8), alkaline (13)

- Thicknesses: 1/4" and 1/8"

- Two trends tested: 0-90 days and $150+$ days

- Strength tested: Interlaminar Shear Strength 
- Composites were air dried for approximately 4 hours prior to testing in a room temperature environment.

These parameters were selected for specific reasons. Glass fibers are the most common type of fibers used in composites due to their strength to cost benefits. Vinyl ester is the most resistant to alkaline environments. Temperatures tested was to create a large range of data to create Time Shift Factors for temperatures that fall into that range. Environments composites will be exposed to will fall into the $\mathrm{pH}$ range tested. Different thicknesses were tested to see the differences in degradation rates of the composites in similar environments. The two trends tested have two different degradation rates and should be analyzed separately from one another. Interlaminar shear strength is the most detrimental mechanical property in terms of durability. The given parameters will be explained more in depth throughout the rest of Chapter 3.

\subsubsection{Material Constraints and Sample Preparation (0-150 Days)}

Samples were cut from two 24" x 24" plates using a circular saw blade with diamond tip. These composite plates consisted of four layers of $1 \mathrm{Oz} . / \mathrm{ft} .^{2}$ material with two layers at the top and two layers at the bottom. The rest of the makeup consisted of rovings. Assuming the density of glass and vinylester resin is $2.56 \mathrm{~g} / \mathrm{cm}^{3}$ and $1.2 \mathrm{~g} / \mathrm{cm}^{3}$, one can calculate the fiber volume fraction. With $54 \%$ of the weight being glass, the fiber volume fraction comes to be 0.34 . The dimensions for our test samples were 3 " long x $1 / 2$ " wide x $1 / 4$ " thick. All dimensions and testing protocol met the short-beam shear testing standards in the ASTM D-2344 code. All of the samples consisted of E-glass fibers reinforcing vinyl ester matrices. 465 samples of GFRP composites were aged and tested (215 longitudinal and 250 transverse). 
To establish aging trends, composites, both in the longitudinal and transverse directions, are aged at different temperatures and $\mathrm{pH}$ levels under controlled (lab) conditions. $\mathrm{pH}$ solutions of 3, 7, and 13 were used to simulate an acidic, neutral, and alkaline environment. Hydrochloric acid was mixed with tap water until a $\mathrm{pH}$ level of 3 was met. Tap water was used for neutral environment. Sodium hydroxide was mixed with tap water until a pH level of 13 was met. All three of these solutions were exposed to temperature environments of $-23.33^{\circ} \mathrm{C}, 22^{\circ} \mathrm{C}$, and $71^{\circ} \mathrm{C}$ (freezer, room temperature, and oven) and tested at specific days of interest within the schedule of 150 days. Figure 3-1-1 shows the aging containers and the environmental chamber that the test samples were exposed to.

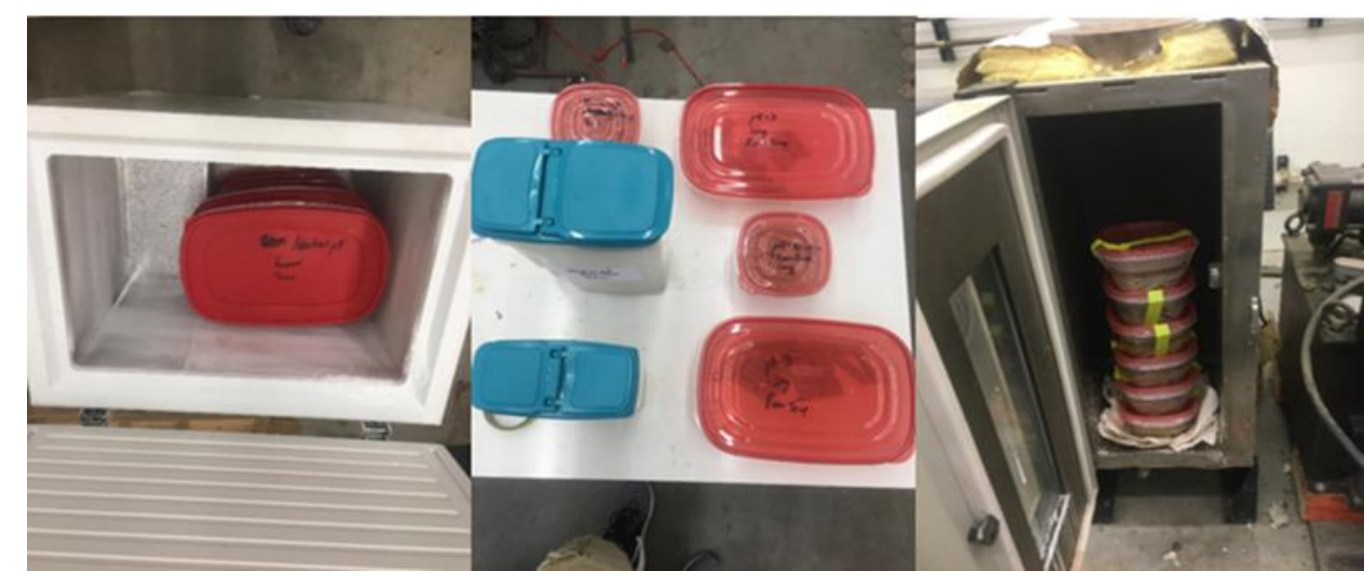

Figure 3-1-1: Aging Environments for Samples.

\subsubsection{Previous Work/Literature Sample Preparation/Testing (150 + Days)}

Accelerated aged data for more than 150 days was collected from previous work and literature (Lorenzo et al., 2018). This data was gathered and organized for all the different temperature and $\mathrm{pH}$ environments. The data was limited to interlaminar shear strength of vinylester GFRP composites. Some acceleratedly aged data was aged for as long as 540 days in the lab. Different groups for temperature and $\mathrm{pH}$ were established in order to organize and represent 
different data groups. Up to four different temperature groups were used in this organization, as exhibited in Table 3-1-2.

Table 3-1-2: Organization of Literature Data

\begin{tabular}{|c|c|}
\hline T1 & $-10^{\circ}$ to $15^{\circ} \mathrm{C}$ \\
\hline T2 & $15^{\circ} \mathrm{C}$ to $40^{\circ} \mathrm{C}$ \\
\hline T3 & $40^{\circ} \mathrm{C}-60^{\circ} \mathrm{C}$ \\
\hline T4 & Above $60^{\circ} \mathrm{C}$ \\
\hline
\end{tabular}

The $\mathrm{pH}$ environments were compared to the environments used in the in-lab testing of up to 150 days completed by the author (neutral, acidic, and alkaline). With reference to the temperature ranges, the temperature group up to $60^{\circ} \mathrm{C}(\mathrm{T} 2, \mathrm{~T} 3$, and $\mathrm{T} 4)$ were the most detrimental compared to $\mathrm{T} 1$. The data used from $\mathrm{T} 1$ contained little information in regards of degradation. Little degradation occurs at freezing temperature range, i.e, the rate of degradation at freezing environments causes no immediate danger to infrastructure. Data reported by previous researchers are presented in Appendix A.

\subsubsection{Testing of Different Thickness Samples}

It is important to look into how composites react with the given environments with respect to the thickness of the samples. A 14 day accelerated testing methodology was used to analyze the short-term shear strength degradation of the samples with respect to thickness. To be able to compare results with the $1 / 4$ " thick samples, samples were cut from a $1 / 8$ " thick plate. A total of 27 samples were cut out of the $1 / 8$ " thick vinyl ester GFRP composite plate. These composite plates consisted of two layers of $1 \mathrm{Oz} . / \mathrm{ft}^{2}{ }^{2}$ material with one layer at the top and one layer at the bottom. The rest of the makeup consisted of rovings. Assuming the density of glass and vinylester resin is $2.56 \mathrm{~g} / \mathrm{cm}^{3}$ and $1.2 \mathrm{~g} / \mathrm{cm}^{3}$, one can calculate the fiber volume fraction. With $54 \%$ of the 
weight being glass, the fiber volume fraction comes to be 0.34 . The coupon size used was $11 / 2$ " long x 1/4" wide x 1/8" thick. Samples were aged and tested up to 14 days. The samples were only exposed to an alkaline environment at two different temperatures (Room temperature and $71^{\circ} \mathrm{C}$ ).

Similar comparisons were seen with the $1 / 4$ " thick composite testing with respect to freezing temperatures and room temperature. In terms of differences, the $1 / 8$ " thick composite samples degraded at higher temperatures at a quicker rate. Also, more detrimental losses were seen out of the $1 / 8$ " thick samples at higher temperature exposures. A total loss of approximately $90 \%$ was seen in the $1 / 8^{\prime \prime}$ thick plate within the first 14 days. Within the first 14 days of aging of the $1 / 4$ " thick plate, approximately $60 \%$ loss was seen in the transverse samples (approximately $50 \%$ in the longitudinal cut samples). Comparisons between the 1/4" thick (transverse samples) and the $1 / 8$ " thick samples in alkaline solution at $71^{\circ} \mathrm{C}$ can be seen in Figure $3-1-3$. Data for $1 / 8^{\prime \prime}$ thick samples can be seen in Appendix A. This implies that moisture is diffusing through the thickness (albeit, slower for $1 / 4$ " thickness compared to $1 / 8$ " thickness) in an overall sense.

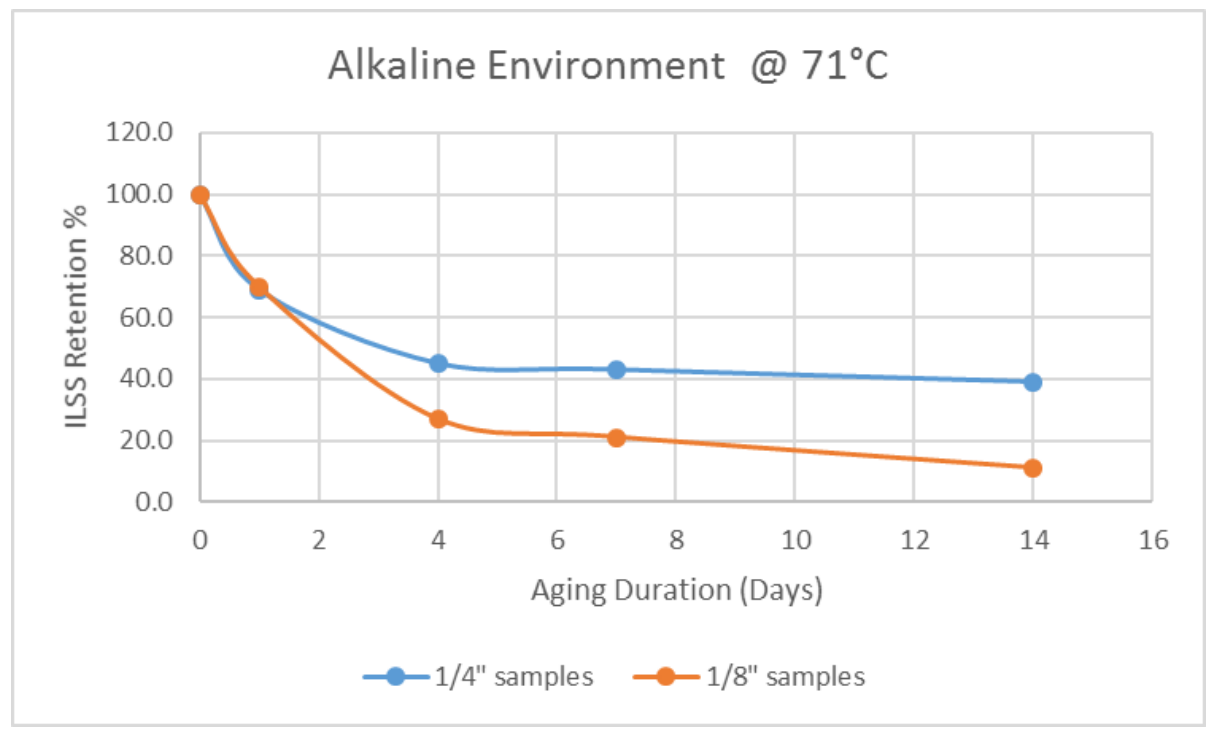

Figure 3-1-3: 1/4" and 1/8" Thick Composite Sample Aging Comparison at High Temperatures in an Alkaline Environment. 


\subsubsection{Accelerated Aging of Vinyl-ester Samples}

Through many sample tests $(\sim 100)$, we understand that alkaline environment causes the highest degradation rates in GFRP composites compared to any other $\mathrm{pH}$ environment. The main concern is whether this degradation is primarily associated with glass fibers, resin, fiber sizing or a combination of all the 3 parameters. Therefore, a protocol of accelerated aging of vinyl-ester resin is established, tests were conducted and data collected, in a systematic manner before the data analyses.

The matrix (cured vinyl ester resin) was manufactured in the West Virginia University Structure's laboratory. The resin made up of $99 \%$ vinyl-ester, $0.75 \%$ of methyl ethyl ketone peroxide (MEKP), and $0.25 \%$ cobalt naphthenate. Once the resin was created and mixed well, then the resin was poured into a 1/4" thick mold which can be seen in Figure 3-1-4. Due to the curing process, all samples were ranging between $0.15-0.25$ in. thickness.

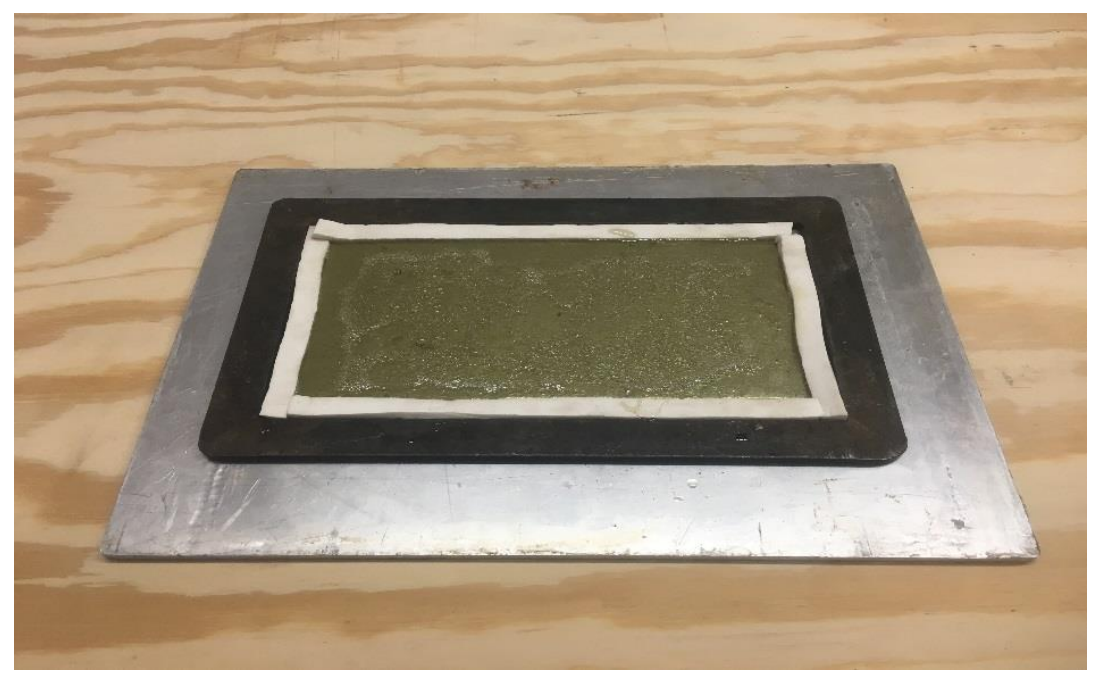

Figure 3-1-4: Representation of Vinyl ester Resin Curing in the Mold

Another aspect that is being tested in our study is to evaluate degradation rates when the samples are already pre-cut prior to aging, or aged as a plate then samples cut on testing days. 
Therefore, a protocol of 18 samples were cut with dimensions of $11 / 2$ " long x $1 / 2$ " wide x 0.15 "0.25 " thick. 9 samples were aged at room temperature and 9 samples were aged at $71^{\circ} \mathrm{C}$. Also, a plate cut $5 "$ × $5 "$ × $0.15-0.25 "$ thick was cut. The plate was aged at $71^{\circ} \mathrm{C}$. A 14 day accelerated aging procedure was used, and on testing days samples were cut out of the plate to be tested along with the samples already pre-cut.

Data results for acceleratedly aged testing (0-14 days) of vinyl-ester samples at different temperatures can be seen in Figure 3-1-5. One can see the initial strength loss occurring for the first day, but a post-curing effect happens between 1-7 days. Degradation between 7-14 days represents accurate trends for different temperature and sizing effects. As shown, there was no significant change between samples cut prior to aging and samples cut on corresponding testing days. No loss in strength was shown within the first 14 days of testing for samples exposed to room temperature. A loss of approximately $80 \%$ in the samples exposed to $71^{\circ} \mathrm{C}$ temperature environments is recorded. For early on degradation of vinyl-ester, temperature seems to be the main reason behind such high strength losses in samples. No sizing effects are displayed in the test data, therefore we can assume there is not a large effect on sizing degradation in composites, with respect to degradation as a function of $\mathrm{pH}$ and temperature. With such high degradation occurring at $71^{\circ} \mathrm{C}$, comparisons to GFRP composites aged at the same temperature can be made. Being able to prevent resin degradation at high temperatures, composites would see a large improvement in degradation in relation to temperature. Glass fibers degrade drastically in a presence of an alkaline environment, but the resin degrades in the presence of high temperatures. When these effects are combined, one can see the degradation shown in Figures 3-3-1 and 3-3-2. 


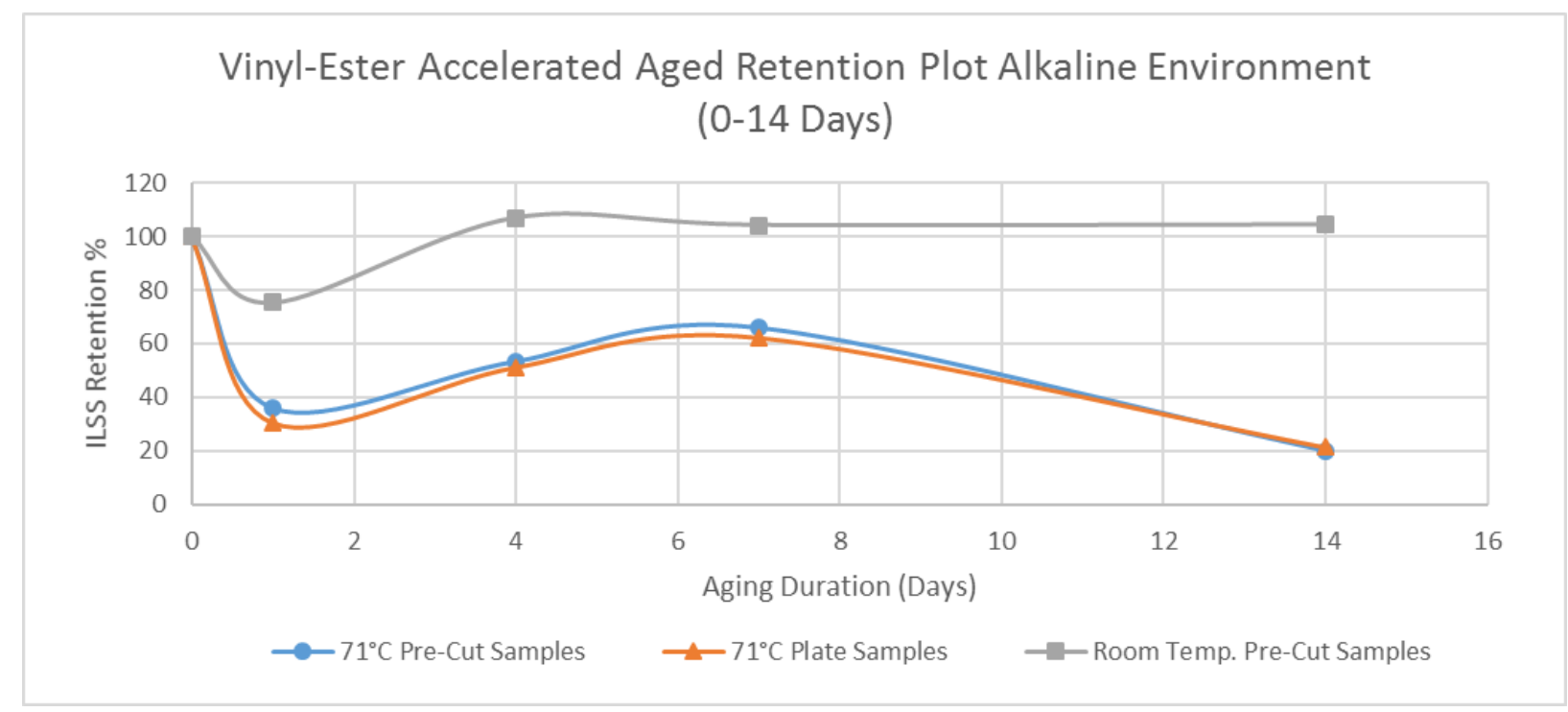

Figure 3-1-5: Pure Vinyl-ester Accelerated Aged Retention Plot in an Alkaline Environment (0-14 days) for different temperatures

\subsection{Natural Aging Data}

It is important to understand that natural age data is just as important as accelerated data to correlate with one another to create accurate resistance factors. Throughout this research, the collection of naturally aged data was very limited and rare to come across. This creates a large concern in achieving the objective of this project. Access to naturally aged data in acidic and alkaline environments was rare; hence correlation with the acceleratedly data under those given environments could not be made. A sample size of data of over 80 samples for neutral environment with natural aging was available and tested, but the age lifespan for usable data for correlation was only 11 years. Three different types of trends were created with different types of aging scenarios. The three trends consisted of: indoor environment (no environmental exposure), partial environmental exposure, and full environmental exposure. Three different trends were analyzed to present the differences in environmental exposure compared to an indoor laboratory exposure. The plots for these three different trends can be seen in Appendix B. 
Table 3-2: Sample Split of Natural Aged Samples Tested

\begin{tabular}{|c|c|}
\hline Aging Environment & Number of Samples \\
\hline Indoor Environment & 50 \\
\hline Partial Environmental Exposure & 5 \\
\hline Full Environmental Exposure & 28 \\
\hline Total & $\mathbf{8 3}$ \\
\hline
\end{tabular}

The leading source of data collected for this section stemmed from previous researches conducted at the Constructed Facilities Center (CFC) at WVU; (Lorenzo et al., 2018) and (Dittenber et al., 2012). A big problem in obtaining accurate natural data was that several sources did not provide the initial strength of the material. Samples without the original strength available was not tested since obtaining retention percentages would be impossible. Knowing these original strength of material would yield in a larger sample size to be used for correlation with accelerated data.

Once all plots are created, trend lines can be created to represent an average degradation curve for the given environmental exposures. Degradation curves for given natural data exposures are shown in Table 3-2-2.

Table 3-2-2: Field Aging Degradation Curves (Neutral Environment)

\begin{tabular}{|c|c|}
\hline Aging Environment & Field Degradation Curves \\
\hline Indoor Environment & $\mathrm{y}=-1.20 \ln (\mathrm{x})+99.81$ \\
\hline Parial Environmental Exposure & $\mathrm{y}=-3.40 \ln (\mathrm{x})+98.88$ \\
\hline Full Environmental Exposure & $\mathrm{y}=-3.60 \ln (\mathrm{x})+100$ \\
\hline
\end{tabular}

Note: $y=$ retention percentage, $x=$ natural aging time in days

\subsubsection{Indoor Environment Data}

The first trend analyzed is the data that was only exposed to laboratory environment. These samples had no exposure to the environment. Approximately 50 samples were tested and used to 
create the indoor environment degradation plot shown in Appendix B. It is very important to understand that indoor environmental data was not used in correlation, but for more of an understanding of how composites age without any exposure to environmental conditions. Some samples were aged up to 26 years inside the laboratory at West Virginia University. Multiple data points were analyzed at different years within that 26 years, and there was no significant change in strength. Some samples increased in strength and some decreased by approximately $20 \%$ in strength. This increase can be caused due to a number of reasons (small sample size teste, post curing reactions, etc.). An overall analysis of all our test data showed that there was no significant change in strength of the composite. Therefore, we understand that composites are very reliable and resistant to degradation in an indoor environment under neutral $\mathrm{pH}$ levels.

\subsubsection{Partial Environmental Exposure Data}

The second trend analyzed is the data that was exposed outdoors to a neutral environment, before moving the samples indoors. This data set was generated from samples exposed to the outdoors from the original manufacturing date to 2013. The samples were then moved into an indoor lab environment from 2013-2018. A very small sample size was tested (5 samples) and used to create the partial exposure degradation plot shown in Appendix B. This data was not used in correlation, but for an understanding of how composites age with partial environmental exposure. Some samples were aged in total up to 10 years outside the laboratory at West Virginia University. Multiple data points were analyzed at different years within the 10 years. With approximately 10 years of exposure (some samples less than 10 years exposure), there was up to $25 \%$ loss. With 10 years exposed to the environment, we see a loss that is expected with regards to shear strength since most loss occurs within the first three years of aging. 


\subsubsection{Full Environmental Exposure Data}

The third trend analyzed is data that was exposed fully to the natural environment. This data set was exposed outdoors of the West Virginia University Structural Laboratory. All samples were exposed to UV radiation, precipitation, humidity, and any other environmental exposure that would be seen in typical weathering conditions of West Virginia. Samples were exposed outdoors from 2007-2018 before testing at WVU in the second half of 2018 and first half of 2019. All samples came from vinyl ester GFRP composite plates. A large sample size of approximate 30 samples from the plates were tested (longitudinal and transverse cut samples). The degradation curve created using the results of these samples tested was used to create a correlation with neutral environment accelerated aged data to create early resistance factors. With 11 years of full exposure to the environment, up to $40 \%$ loss was recorded, but only an average of $25 \%$ loss.

\subsection{Presentation of Data}

Presenting the data in an accurate and easily presentable way is important to the understanding of the material. Retention plots were created for the different $\mathrm{pH}$ environments and temperatures and presented in Appendix A. The most detrimental retention plots can be seen in Figures 3-3-1 and 3-3-2. In these plots, both the longitudinal and transversely cut samples were the most affected, in terms of material properties, under alkaline environments. Neutral environments and acidic environments showed nowhere near the same level of concern as alkaline environments. Alkaline environments at high temperature present an early aggressive decrease of interlaminar shear strength in the composites $(70 \%$ loss within the first 30 days of accelerated aging at $71^{\circ} \mathrm{C}$ and $60 \%$ loss within the first 30 days at room temperature). 
It is important to understand that each plot displays different degradation patterns, and that with higher temperatures the samples were exposed to, the higher the degradation. Concrete environments present a high level of $\mathrm{pH}$ (alkaline environments) and can cause a serious concern to GFRP composite rebar if it is used (Ceroni et al., 2006; Chen, 2007; Chen et al., 2006; Dejke, 1996; Hyeong et al., 2007; Mathieu et al., 2010; Micelli et al., 2004). If GFRP is used as rebar, it is important to use additives and alkaline resistant fibers as needed.

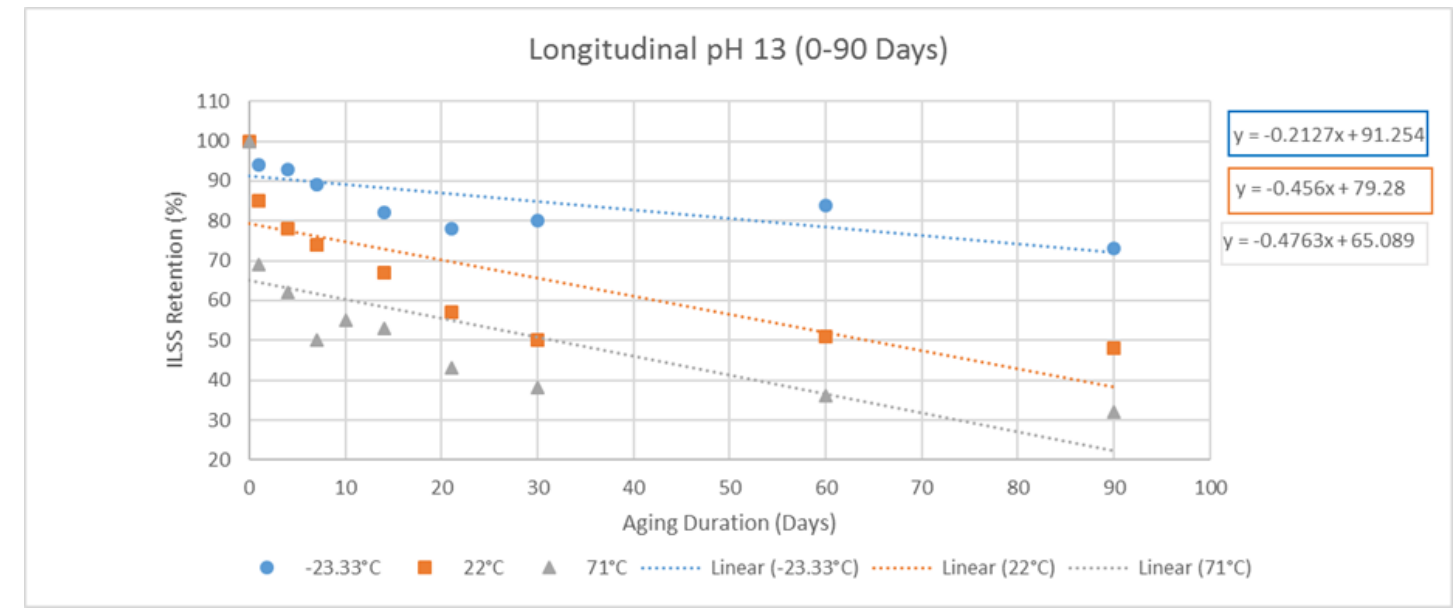

Figure 3-3-1: Degradation of Longitudinally Cut FRP Samples under Alkaline Environment

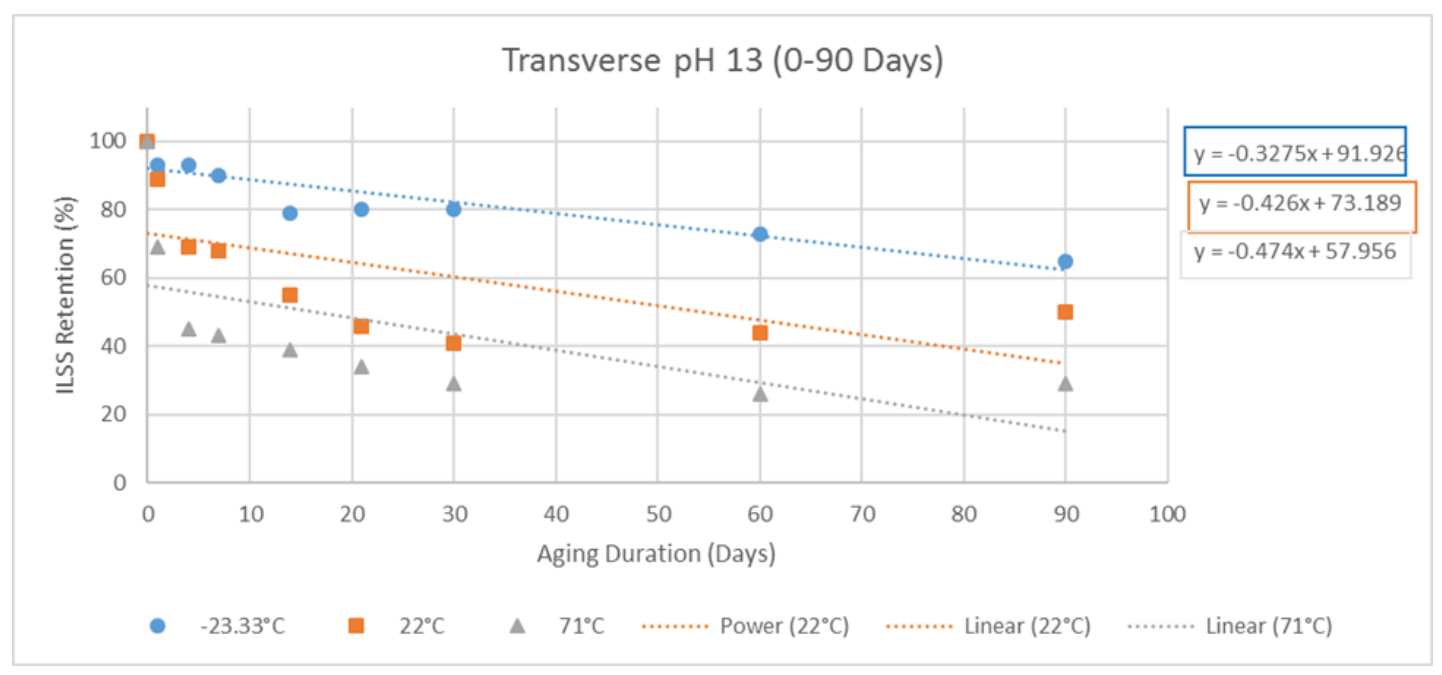

Figure 3-3-2: Degradation of Transversely Cut FRP Samples under Alkaline Environment 


\section{Chapter 4: Methodology for Accelerated and Natural Aging}

Through previous literature revelations including WVU research (Lorenzo et al., 2018; Dittenbur et al., 2012), we understand that interlaminar shear strength is the most sensitive mechanical property in terms of degradation rates and overall losses to composites under harsh environmental exposures of composites. To be able to implement these composites into infrastructure on a large scale, it is important to know the aging behavior in an accelerated and natural environmental settings. To understand the composite aging phenomenon under shear response, many accelerated tests were performed and analyzed by many researches (Lorenzo et al., 2018; Vijay, 1999; Wang et al., 2015). In this chapter, the methodology is presented correlating accelerated data with the naturally aged data to develop degradation plots and consequently strength reduction or resistance factors under different $\mathrm{pH}$ environments and thermal changes. It is important to understand the focus of this report wherein correlations could only be made with neutral environment data because naturally aged data could not be found or readily available with reference to acidic and alkaline environments. The correlations are made by applying the Arrhenius type relationships and time-temperature superposition principles to create degradation plots for the accelerated data. Once these plots are created, correlation with the naturally aged data under neutral environment are made to present strength reduction factors.

\subsection{Accelerated Aging Methodology}

In regards to durability, there are countless environmental effects that can cause degradation to composite materials. It is important to understand that the accelerated aging methodology only takes into account different temperatures and $\mathrm{pH}$ environments. Even though 
temperature fluctuations and $\mathrm{pH}$ environments are used under the accelerated methodology, it can provide a brief look into the most detrimental environments and temperatures.

To be able to have a better understanding of long term performance, lab based accelerated aging protocol was developed by other researchers (Compos et al., 2016; Silva et al. 2014; Chen, 2007) and refined by the author. Such a protocol is described in-depth as:

1. Test specimens were prepared for different aging environments under lab conditions. These environments are more aggressive compared to environments for in-service structures. The only two factors considered for this methodology are different $\mathrm{pH}$ solutions and different temperatures. For more information on sample constraints and preparation, see Chapters

\section{$3.1 .1 \& 3.2 .2$}

2. The aged samples are tested for the degradation of interlaminar shear strength. Throughout the aging process, testing was carried out on specific days with periodic intervals to understand the degradation trends. Under interlaminar shear strength response to composites, most testing occurred within the first thirty days because the severest degradation occurs within that period for polymer composites. Two different trends were analyzed within this project (0-90 days and 150 + days). Data from 0-90 days was collected at West Virginia University. However, test data from 150 + days and above was taken from literature and previous WVU work (Lorenzo et al., 2018). The number of days of aging of samples under different environmental conditions for this research can be found in Appendix A.

3. Once all the data was collected (WVU data and other data from literature (Lorenzo et al., 2018; Dittenber et al., 2012)), retention plots are created for different environments. These degradation curves are presented in a ratio of strength at the day of testing over the original 
strength (retention \%) vs. the aging duration (days aged) for the different temperatures and $\mathrm{pH}$ environments. Plots were separated into 0-90 days aged and 150 + days to compare the different degradation trends with time due to steep variation in rate of degradation. All retention plots of our work are provided in Appendix A.

4. Once retention plots are created for the different $\mathrm{pH}$ environments, Arrhenius plots are created. The Arrhenius plots are transformed logarithmic retention plots into straight lines. Arrhenius plots are composed of lines that represent the amount of time needed to reach a specific strength retention level (i.e. $90 \%, 80 \%$, etc.) vs. the inverse of temperature (kelvin). These lines, in theory, are perfectly parallel for strength degradation-temperature relationship, but that will never be the case in structures under long term service conditions. See Figure 2-1-1 for an example of this perfect parallel behavior. See Appendix C.1 through C.3 for the Arrhenius plots made from the data presented.

5. Once the Arrhenius plots are created, time shift factor (TSF) can be created. Normalizing this data begins with choosing a temperature of constant $\left(\mathrm{t}_{0}\right)$. In this work, room temperature was chosen to be $22^{\circ} \mathrm{C}$. Once this temperature of constant $\left(22^{\circ} \mathrm{C}\right)$ is chosen, time shift factors can be obtained. Following Equation 4-1-1 as given below, the time shift factors are obtained as ratios of the amount of days it takes for the constant temperature samples $\left(22^{\circ} \mathrm{C}\right)$ to reach a retention level over the amount of days it takes the test sample corresponding to a specific temperature group to reach a retention level. Time shift factors can also be found as a ratio of the slopes in the Arrhenius plots, but this process is very tedious and this results in approximate results when compared to the data generated by using Equation 4-1-1. See Appendix D for guidance on creating time shift factors for different environments and temperatures. 


$$
T S F=\frac{t_{1}}{t_{2}}=e^{\frac{E_{a}}{R}\left(\frac{1}{T_{2}}-\frac{1}{T_{1}}\right)}
$$

Note: $t_{1}=$ time in days it takes for the temperature of constant to reach a retention level, $t_{2}=$ time in days it takes for a specific temperature to reach a retention level

The degradation times for each of the strength retention levels are obtained from the retention plots found in Appendix A. After finding time shift factors for the temperatures that were used for testing, normalized time-displacement curves relative to a range of specific temperatures can be found. See Appendix E for the normalized timedisplacement curves created from the data in this report. Once time shift factors are found, averages are made throughout the retention levels and used to create shifted degradation plots for accelerated data.

6. When the shifted plots are obtained using the Time-Temperature Superposition Principle (explained in Chapter 5), naturally aged data correlation can be created. Using the various temperatures in the previous steps, everything gets normalized to room temperature and compared with the naturally aged samples. It is important to understand that only correlation can happen with neutral environment samples due to the fact that there is no naturally aged test data under alkaline or acidic natural data to correlate with. Using the data, prediction on retention values can be made for neutral environment of GFRP composites for a service life of 100 years. This will be explained further in Chapter 6 . 


\subsubsection{Limitations to This Methodology}

There are multiple limitations to this methodology when it comes to correlating data with the naturally aged data. The main limitation is that retention percentages of alkaline and acidic data is based solely on acceleratedly aged data due to the fact that there is no natural aged data to correlate with. Retention percentages for these two environments are lower than expected due to the acceleratedly aged methodology creates a much harsher $\mathrm{pH}$ environment and harsher temperature conditions.

Another limitation is that the only environmental effect taken into account to correlate with is temperature. Temperature is taken as the basis of the normalization process. Other side effects such as moisture absorbed, freeze-thaw cycles, sustained stress, and many other effects that can affect durability of a composite are not taken into account for correlation purposes. We attempted to limit all other environmental factors affecting the natural aged samples. Since the samples came from an aged plate, environmental effects such as sustained stress and other in-service effects are neglected.

\subsection{Arrhenius Plots}

Arrhenius plots provide curves that represent the amount of time it takes for a temperature to reach a retention level. For an ideal Arrhenius plot, all lines should be parallel with similar slopes, but in practice that is not always the case. The plots show how the behavior of material strength in long term sense changes with temperature (dominant degradation mechanism).

As shown in Appendix $\mathrm{C}$, most plots do not have enough degradation to compare lines in the plots. But with plots referring to alkaline environments, they (plots) mostly present a good parallel behavior for the different temperatures. The slope of the lines in the Arrhenius plots are known as 
the activation energy. With multiple lines in an Arrhenius plot, the slopes can be averaged to get an overall activation energy value for certain environments. In section 4.3 , it will be explained how activation energy plays an important role in understanding the degradation of composites.

\subsection{Activation Energy}

Activation energy $\left(E_{a}\right)$ is defined as the minimum quantity of energy which the reacting species must possess in order to undergo a specified reaction. Activation energy also is known as the difference between the reactant and the transition state (energy needed for the reaction to occur).

Using the Arrhenius plots, activation energy can be obtained by recording the average slope of Arrhenius plots. The higher the slope, the more the material is susceptible to temperature changes. Using all the Arrhenius plots in Appendix C, the slopes were recorded to achieve the activation energy values. In Table 4-3, the activation energy over the gas constant (R) is presented for the different aging trends and $\mathrm{pH}$ environments. The higher the activation energy, the more susceptible a composite is to temperature changes rather than the $\mathrm{pH}$ environment.

Table 4-3: Vinyl-ester Interlaminar Shear Strength Activation Energy Values

\begin{tabular}{|c|c|c|}
\hline \multicolumn{2}{|c|}{ Vinyl-Ester Interlaminar Shear Strength Activation Energy Values } \\
\hline Aging Time & $\boldsymbol{p H}$ & $\mathbf{- E a / R ( \boldsymbol { K } ^ { \circ } )}$ \\
\hline \multirow{3}{*}{ Longitudinal (0-90 Days) } & Neutral & 5526.6 \\
\cline { 2 - 3 } & Acidic $(\mathrm{pH}=3-4)$ & 4798.7 \\
\cline { 2 - 3 } & Alkaline $(\mathrm{pH}=13)$ & 3180 \\
\hline \multirow{3}{*}{ Transverse (0-90 Days) } & Neutral & 5286.5 \\
\cline { 2 - 3 } & Acidic $(\mathrm{pH}=3-4)$ & 4112 \\
\cline { 2 - 3 } & Alkaline $(\mathrm{pH}=13)$ & 2910 \\
\hline \multirow{3}{*}{150 + Days } & Neutral & 1682.4 \\
\cline { 2 - 3 } & Acidic $(\mathrm{pH}=3-4)$ & 2350 \\
\cline { 2 - 3 } & Alkaline $(\mathrm{pH}=13)$ & 4236.5 \\
\hline
\end{tabular}


To fully understand the values in Table 4-3, one needs to understand that lower the activation energy values relate to lower temperature requirements for the degradation to initiate and continue. When activation energy value is lower, time shift factors are less dependent on the temperature but reverse is true for higher activation energy values. Alkaline environment does the most damage in the early aging period, then it begins to fade away as aging surpasses 150 days. Also, notice how the $\mathrm{pH}$ environment does not begin to affect the neutral and acidic $\mathrm{pH}$ until $150+$ days. These activation energy values can be used to help determine aging and remaining strength of composites in different environments and how to analyze them.

\subsection{Conclusions}

The methodology behind correlating the accelerated and natural data together is presented in this chapter. This correlation is to be able to obtain long term degradation behavior of FRP composites in the field by correlating the neutral acceleratedly aged data to the naturally aged data in the field. It is important to understand that this correlation can only take place under neutral environment since there is no natural aged data to correlate with for acidic and alkaline

environments. Alkaline and acidic environmental resistance factors are based on the TimeTemperature Superposition principle which will be explained in further detail in Chapter 5. 


\section{Chapter 5: Time-Temperature Superposition (TTS) Principle}

With FRP composites being relatively new into infrastructure, the collection of naturally aged data is very limited and difficult to obtain from literature. Therefore, acceleratedly aged data becomes very important in the studies of degradation of polymer composites. Using the Arrhenius relationship, researchers can extrapolate accelerated data into a longer term $(\sim 75-100$ years $)$ prediction of strength reductions in composites. This principle is used in this study to come up with retention predictions of composites in both the alkaline and acidic environments.

\subsection{Introduction}

The Time-Temperature Superposition (TTS) principle is followed herein to create a prediction of the degradation of composites in a natural setting by using acceleratedly aged data and correlating with the naturally aged data, which is very limited. By using time shift factors (TSF), one can shift acceleratedly aged retention plots to a longer term degradation plot. For example, with approximately one year of acceleratedly aged data in neutral environment, using time shift factors, we can extrapolate the data to roughly 30 years of natural age. This principle is used to correlate data at room temperature setting to data in different temperatures aged higher than room temperature. This implies that the behavior of composites at one temperature can be related to room temperature to create degradation plots with shifts. It is important to understand that this principle is only applicable in materials that are stable or below glass transition temperature. For this research, temperatures have to be about $15-20^{\circ} \mathrm{F}$ less the glass transition temperature, which varies for different resins, but is around $80-100^{\circ} \mathrm{C}$. If one crosses into the glass transition temperature range, rate of degradation is promoted with effects one will not see in the field. 


\subsection{Time Shift Factors}

Time shift factors (TSF) drive the shifting of the acceleratedly aged plots. These factors allow composites to be normalized under different temperature environments to be able to create degradation plots for specific $\mathrm{pH}$ environments. The more different temperatures that the composites are tested under, a higher accuracy of these accelerated plots can be attained. After the time shift factors are obtained, regression curves can be created and then correlated with naturally aged data (if available for specific $\mathrm{pH}$ environments) to predict strength retentions under natural aging over 50 or 75 or 100 years.

\subsubsection{Time Shift Factors (TSF) vs. Temperature}

TSF is defined as the ratio between the times required for a certain decrease in a mechanical property at two different temperatures. The time for a certain reaction to take place is proportional to the inverse of the reaction rate $k$ and the ratio of $t_{1}$, time required for a certain decrease of a property at temperature $T_{1}$ and $t_{2}$, time required for the same decrease at temperature $T_{2}$ can then be written as (Silva et al., 2014):

$$
\mathrm{TSF}=\frac{t_{1}}{t_{2}}=\frac{A e^{\frac{E_{a}}{T_{2} R}}}{A e^{\frac{E_{a}}{T_{1} R}}}=e^{\frac{E_{a}}{R}\left(\frac{1}{T_{2}}-\frac{1}{T_{1}}\right)}
$$

Obtaining time shift factors is very simple if you have a large amount of degradation to get adequate sensitivity under varying environmental conditions, over shorter durations. First, the time of degradation of the acceleratedly aged samples for each retention level $(90 \%, 80 \%, 70 \%$, etc. $)$ is extracted from the retention plots in Appendix A. Using Equation 5-1, $t_{1}$ is taken as the time it takes for room temperature to achieve a strength retention level and $t_{2}$ is taken as the time it takes for a reference temperature to achieve certain strength retention level. A ratio is created to achieve 
these time shift factors for every temperature tested (TSF $=1$ for room temperature). An explanation of obtaining time shift factors is presented in Figure 5-2-1.

\begin{tabular}{|c|c|c|c|c|c|c|c|c|c|c|}
\hline \multicolumn{6}{|c|}{ Neutral Environment (150 + Days) } & \multicolumn{5}{|c|}{ Neutral Environment (150+ Days) } \\
\hline & & \multicolumn{4}{|c|}{ Degradation Times (Days) } & & & \multicolumn{3}{|c|}{ Time Shift Factors } \\
\hline \multicolumn{2}{|c|}{$1 / \mathrm{T}^{\circ} \mathrm{K}^{-1}$} & 0.00400 & 0.00340 & 0.00310 & 0.00295 & \multicolumn{2}{|c|}{$1 / \mathrm{T}^{\circ} \mathrm{K}^{-1}$} & 0.00340 & 0.00310 & 0.00295 \\
\hline \multirow{6}{*}{ 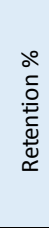 } & $90 \%$ & 360 & 175 & 100 & 6 & \multirow{6}{*}{$\frac{\widehat{\varrho}}{\frac{\breve{b}}{\curvearrowleft}}$} & & & & \\
\hline & $80 \%$ & $\mathrm{~N} / \mathrm{A}$ & 420 & 150 & 15 & & TSF 90\% & 1 & 1.75 & 29.1 \\
\hline & $70 \%$ & N/A & N/A & 210 & 150 & & TCF ८০\% & 1 & 28 & $7 \varsigma$ \\
\hline & $60 \%$ & $\mathrm{~N} / \mathrm{A}$ & $\mathrm{N} / \mathrm{A}$ & $\mathrm{N} / \mathrm{A}$ & 175 & & $15 \mathrm{~F} 80 \%$ & 1 & 2.8 & 28 \\
\hline & $50 \%$ & N/A & N/A & $\mathrm{N} / \mathrm{A}$ & 180 & & TSF AVG & 1 & 23 & 28.6 \\
\hline & $40 \%$ & $\mathrm{~N} / \mathrm{A}$ & $\mathrm{N} / \mathrm{A}$ & $\mathrm{N} / \mathrm{A}$ & 240 & & ISF AVG. & 1 & & \\
\hline
\end{tabular}

Figure 5-2-1: Obtaining TSF Neutral Environment 150 + Days Accelerated Aging

Once time shift factors are calculated for each temperature and retention level, the factors can be averaged over every retention level to obtain an average TSF for every temperature tested. As stated previously, room temperature was taken as the constant temperature for this research which means that the TSF for room temperature is 1 for every retention level. When analyzing degradation rates of higher temperature, it is understood that as temperature increases, the time shift factors also increase. When taking room temperature as the temperature of constant, time shift factors for temperatures less than room temperature will be less than 1 . Temperatures under room temperature is not of concern knowing that lower degradation rates occur. Therefore, time shift factors for $-22^{\circ} \mathrm{C}$ was ignored due to such low degradation values. Average time shift factors for the temperatures and $\mathrm{pH}$ environments tested in this study can be seen in Table 5-2-1. 
Table 5-2-1: Average Time Shift Factors for Given Environment and Aging Protocols

\begin{tabular}{|c|c|c|c|c|}
\hline \multicolumn{5}{|c|}{ Vinylester Interlaminar Shear Strength Time Shift Factors } \\
\hline \multirow{2}{*}{ Sample Size } & \multirow{2}{*}{$p H$} & \multicolumn{3}{|c|}{ Time shift Factors } \\
\cline { 3 - 5 } & & $0.0034\left(1 / \mathrm{T}^{\circ} \mathrm{K}^{-1}\right)$ & $0.0031\left(1 / \mathrm{T}^{\circ} \mathrm{K}^{-1}\right)$ & $0.00295\left(1 / \mathrm{T}^{\circ} \mathrm{K}^{-1}\right)$ \\
\hline \multirow{3}{*}{ Longitudinal (0-90 Days) } & Neutral & 1 & $\mathrm{~N} / \mathrm{A}$ & 7.5 \\
\cline { 2 - 5 } & Acidic $(\mathrm{pH}=3-4)$ & 1 & $\mathrm{~N} / \mathrm{A}$ & 8 \\
\cline { 2 - 5 } & Alkaline $(\mathrm{pH}=13)$ & 1 & $\mathrm{~N} / \mathrm{A}$ & 4.5 \\
\hline \multirow{3}{*}{ Transverse (0-90 Days) } & Neutral & 1 & $\mathrm{~N} / \mathrm{A}$ & 10.7 \\
\cline { 2 - 5 } & Acidic $(\mathrm{pH}=3-4)$ & 1 & $\mathrm{~N} / \mathrm{A}$ & 5.3 \\
\cline { 2 - 5 } & Alkaline $(\mathrm{pH}=13)$ & 1 & $\mathrm{~N} / \mathrm{A}$ & 3.7 \\
\hline \multirow{3}{*}{$150+$ Days } & Neutral & 1 & 2.3 & 28.6 \\
\cline { 2 - 5 } & Acidic $(\mathrm{pH}=3-4)$ & 1 & 2.3 & 11.4 \\
\cline { 2 - 5 } & Alkaline $(\mathrm{pH}=13)$ & 1 & 1.8 & 9.7 \\
\hline
\end{tabular}

\subsubsection{Approximating TSF for Temperature Range}

The relationship of time shift factors vs. temperature can be obtained to achieve time shift factors for different temperatures. It is noticeable that as temperature increases, time shift factors increase in an exponential relationship. Once time shift factors are found for temperatures evaluated in this study, time shift factors in that temperature range can be approximated. For this research, the lowest temperature analyzed was room temperature $\left(\sim 22^{\circ} \mathrm{C}\right)$, and the highest is $71^{\circ} \mathrm{C}$. Therefore, time shift factors for any temperature between $22^{\circ} \mathrm{C}$ to $71^{\circ} \mathrm{C}$ can be approximated as shown in Appendix E. As shown in Figure 5-2-2, an exponential relationship was created using three base points of evaluated temperatures. In this figure, one can see how the time shift factors increase with temperature and how they differentiate between the three different $\mathrm{pH}$ environments. Once these plots are created, the exponential equations and $\mathrm{R}^{2}$ values can be found to understand how accurate the plotted points are to the fitted exponential curves. These equations and $\mathrm{R}^{2}$ values can be found in Table 5-2-2. As one can notice, the degree of accuracy for accelerated age testing of 0-90 days is uncertain with only having two points creating a $R^{2}$ value of $1 . R^{2}$ values for 150 + days of aging range are relatively accurate $(\sim 0.83-0.9)$. Knowing the $\mathrm{R}^{2}$, we conclude that the confidence level of varying TSF with respect to temperature is high. 
Table 5-2-2: TSF vs $\mathbf{T}^{\circ}$ Relationships for Different Environments and Aging Protocols

\begin{tabular}{|c|c|c|c|}
\hline Direction & Environment & \multicolumn{2}{|c|}{ TSF vs T' Relationship } \\
\hline \multirow{3}{*}{ Longitudinal (0-90 Days) } & Neutral & $\mathrm{Y}=2 \mathrm{E}+07 \mathrm{e}^{-5,037 \mathrm{x}}$ & $\mathrm{R}^{2}=1$ \\
\cline { 2 - 4 } & Acidic & $\mathrm{Y}=4 \mathrm{E}+07 \mathrm{e}^{-5,199 \mathrm{x}}$ & $\mathrm{R}^{2}=1$ \\
\cline { 2 - 4 } & Alkaline & $\mathrm{Y}=295566 \mathrm{e}^{-3,76 \mathrm{x}}$ & $\mathrm{R}^{2}=1$ \\
\hline \multirow{3}{*}{ Transverse (0-90 Days) } & Neutral & $\mathrm{Y}=4 \mathrm{E}+08 \mathrm{e}^{-5,926 \mathrm{x}}$ & $\mathrm{R}^{2}=1$ \\
\cline { 2 - 4 } & Acidic & $\mathrm{Y}=1 \mathrm{E}+06 \mathrm{e}^{-4,169 \mathrm{x}}$ & $\mathrm{R}^{2}=1$ \\
\cline { 2 - 4 } & Alkaline & $\mathrm{Y}=57371 \mathrm{e}^{-3,271 \mathrm{x}}$ & $\mathrm{R}^{2}=1$ \\
\hline \multirow{3}{*}{$150+$ Days } & Neutral & $\mathrm{Y}=2 \mathrm{E}+11 \mathrm{e}^{-7,868 \mathrm{x}}$ & $\mathrm{R}^{2}=0.8292$ \\
\cline { 2 - 4 } & Acidic & $\mathrm{Y}=2 \mathrm{E}+08 \mathrm{e}^{-5,803 \mathrm{x}}$ & $\mathrm{R}^{2}=0.8989$ \\
\cline { 2 - 4 } & Alkaline & $\mathrm{Y}=5 \mathrm{E}+07 \mathrm{e}^{-5,341 \mathrm{x}}$ & $\mathrm{R}^{2}=0.8374$ \\
\hline
\end{tabular}

Note: $Y=T S F$ (time shift factors), $x=1 / T\left({ }^{\circ} K^{-1}\right)$

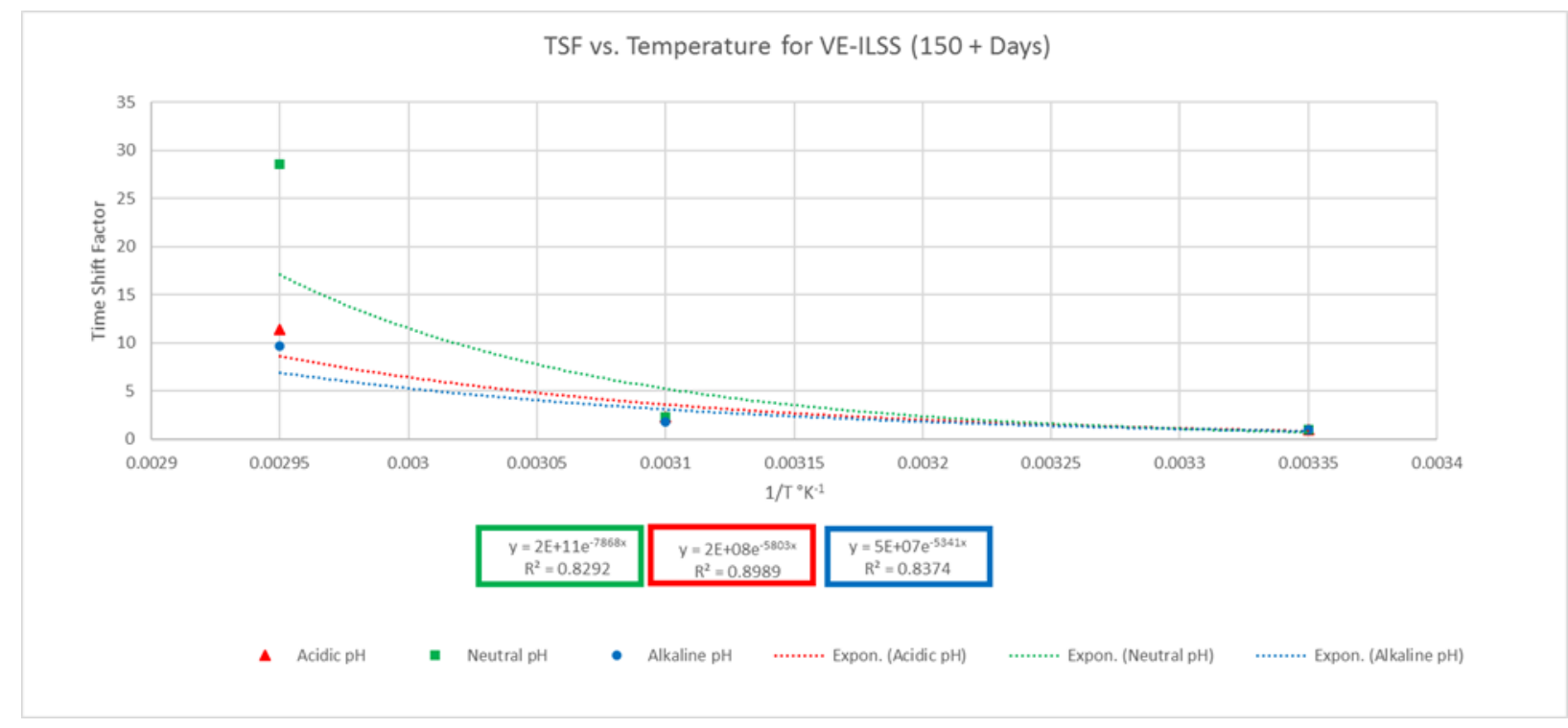

Figure 5-2-2: TSF vs. Temperature for 150 + Days of Accelerated Aging 


\subsection{Accelerated Data Shift for Long Term Degradation Trends}

Once time shift factors are obtained, the time-temperature principle can be contiuned into creating shifted degradation plots. To create these plots, retention plots of the accelerated data from Chapter 3 are used to shift the data. The time shift factors are used as multipliers for the acceleratedly aged time as shown in Equation 5-3.

$$
t_{\text {shift }}=t_{\text {accelerated }} * T S F
$$

Note: $t_{\text {shift }}=$ shifted time in days used to create acceleratedly shifted plots, $t_{\text {accelerated }}=$ accelerated time in days in a specific $p H$ environment, TSF $=$ time shift factors for given temperature and environment

The concept of creating these plots are based on the different time shift factors for the different temperatures and $\mathrm{pH}$ environments. By multiplying the accelerated time by the corresponding time shift factor for the specific temperature and environment, a shifted time can be created for that retention level in a new degradation plot. All shifted degradation curves based solely on the accelerated aged data can be found in Appendix F. These degradation curves are created as a logarithmic function to best represent the data. These logarithmic equations and $\mathrm{R}^{2}$ values can be found in Table 5-3. As stated previously, maximum $\mathrm{R}^{2}$ values are desired for high accuracy of these degradation curves. Knowing that an alkaline environment is the most detrimental $\mathrm{pH}$ environmnet, $\mathrm{R}^{2}$ values for those environments are relatively high for all aging protocols (an average of $\mathrm{R}^{2}=0.88$ ), which provides high confidence level in this analysis. 
Table 5-3: Shifted Degradation Curve Relationships for Different Envionrments and Aged Protocol

\begin{tabular}{|c|c|c|c|}
\hline Direction & Environment & \multicolumn{2}{|c|}{ Degradation Curve Relationship } \\
\hline \multirow{4}{*}{ Longitudinal (0-90 Days) } & Neutral & $\mathrm{Y}=-1.439 \ln (\mathrm{x})+94.855$ & $\mathrm{R}^{2}=0.224$ \\
\cline { 2 - 4 } & Acidic & $\mathrm{Y}=-1.94 \ln (\mathrm{x})+95.425$ & $\mathrm{R}^{2}=0.4109$ \\
\cline { 2 - 4 } & Alkaline & $\mathrm{Y}=-9.285 \ln (\mathrm{x})+87.182$ & $\mathrm{R}^{2}=0.9476$ \\
\hline \multirow{4}{*}{ Transverse (0-90 Days) } & Neutral & $\mathrm{Y}=-3.27 \ln (\mathrm{x})+102.71$ & $\mathrm{R}^{2}=0.8248$ \\
\cline { 2 - 4 } & Acidic & $\mathrm{Y}=-2.377 \ln (\mathrm{x})+99.727$ & $\mathrm{R}^{2}=0.3799$ \\
\cline { 2 - 4 } & Alkaline & $\mathrm{Y}=-10.37 \ln (\mathrm{x})+82.513$ & $\mathrm{R}^{2}=0.8773$ \\
\hline \multirow{3}{*}{ 150 + Days } & Neutral & $\mathrm{Y}=-11.01 \ln (\mathrm{x})+146.27$ & $\mathrm{R}^{2}=0.8027$ \\
\cline { 2 - 4 } & Acidic & $\mathrm{Y}=-11.99 \ln (\mathrm{x})+155.23$ & $\mathrm{R}^{2}=0.721$ \\
\cline { 2 - 4 } & Alkaline & $\mathrm{Y}=-9.129 \ln (\mathrm{x})+91.983$ & $\mathrm{R}^{2}=0.8113$ \\
\hline
\end{tabular}

Note: $Y=$ retention percentage, $x=$ shifted time in days calculated through TSF

When evaluating these degradation plots, it is imporant to understand that the two accelerated aging protocols (0-90 days and $150+$ days $)$ are analyzed seperately. Therefore, two different degradation plots are created for each $\mathrm{pH}$ environment. For the shifted plots using 0-90 days of aging, we can see that the time shifted for up to 3 years in some cases. For the shifted plots using $150+$ days aged, we can see the time shift correlation up to $\sim 30$ years.

Once all shifted degradation curves are obtained, correlation with natural data degradation curves can be created. Without accurate/adequate correlation with natural aged data, it is difficult to reach an accurate representation of aging behaviors in the field. Knock-down factors for alkaline and acidic enviornments are based solely on this shifted data since there is no natural data to correlate with. Therefore, for accuracy, the neutral environment based accelerated shifted degradation trends can only be correlated with the natural data. This methodology of correlation with the natural data can be found in Chapter 6 . 


\section{Chapter 6: Correlation between Neutral Environment Field and}

\section{Accelerated Aged Data}

With the limited amount of naturally aged data that is available in literature, one would like to be able to predict degradation behavior based heavily on the accelerated aged data, albeit, with lower accuracy. Acceleratedly aged environments consist of much harsher $\mathrm{pH}$ and much higher temperatures. Therefore, generating accurate correlations of acceleratedly aged data with naturally aged data is paramount for decent confidence in strength reduction factors for structural designs.

With large amount of naturally aged data coming from structures in service, it is understood that there are other environmental effects that will affect service life of a composite structural system. Some of these effects consist of sustained stress, UV radiation, temperature cycles, humidity cycles, etc. In comparison, acceleratedly aged test data reported herein were only exposed to temperature and $\mathrm{pH}$ solution (absorbed moisture). Therefore correlation with natural aged data consists of items beyond temperature and $\mathrm{pH}$. The data that was most useful consisted of field data from previous research (Dittenber et al., 2012; Lorenzo et al., 2018). This data which was used for analyses, consisted of only glass fiber reinforced vinyl-ester under neutral $\mathrm{pH}$ and approximately room temperature. There is also data recorded for aging that is not exposed to the environment, partial exposed, and full exposed; these classifications are defined in Chapters $4 \&$ 5. Fully exposed data was the data that is used to correlate with. Degradation curves were created based on the neutral environment natural aged data. The plots for the three naturally aged exposed data can be found in Appendix B. The degradation rates in terms of logarithmic equation form can be found in Table 3-2-2. Table 6-1 shows the degradation curves that were used in the correlation 
process. Acidic and alkaline degradation curves are presented in the table, but they were not used for correlation.

Table 6-1: Field and Accelerated Aged Degradation Curves used for Correlation

\begin{tabular}{|c|c|c|c|c|}
\hline Environment & Field Degradation Curves & \multicolumn{3}{|c|}{ Accelerated Aging Curves } \\
\hline & & Longitudinal $(0-90$ Days $)$ & Transverse $(0-90$ Days $)$ & $150+$ Days \\
\hline Neutral & $y=-3.676 \ln (x)+100$ & $Y=-1.439 \ln (x)+94.855$ & $Y=-3.27 \ln (x)+102.71$ & $Y=-11.01 \ln (x)+146.27$ \\
\hline Acidic & N/A & $Y=-1.94 \ln (x)+95.425$ & $Y=-2.377 \ln (x)+99.727$ & $Y=-11.99 \ln (x)+155.23$ \\
\hline Alkaline & N/A & $Y=-9.285 \ln (x)+87.182$ & $Y=-10.37 \ln (x)+82.513$ & $Y=-9.129 \ln (x)+91.983$ \\
\hline
\end{tabular}

Note: $Y=$ retention percentage, $x=$ natural aging time in days for Field Degradation Curves and accelerated shift time for Accelerated Aging Curves

Using the above neutral environment equations, a similar procedure like the TimeTemperature Superposition principle can be used. As shown in Table 6-1, both the accelerated and natural data are represented as a logarithmic equation relating retention $\%$ vs. aging duration. Equations 6-1 and 6-2 are used to collect variable a, b, c, and d to find correlated time shift factors (Equation 6-3). It is assumed that similar expressions can be used to correlate that natural and accelerated shifted degradation curves. Before correlation, assumptions were made in the process. It is assumed that at the beginning of aging $\left(\mathrm{t}_{0}\right)$, the strength retained by the samples is assumed to be $100 \%\left(\sigma_{\text {retention }}=\mathrm{b}=100 \%\right)$. These variables $\mathrm{a}, \mathrm{b}, \mathrm{c}$, and $\mathrm{d}$ are used to create a correlation equations. Equations 6-1 and 6-2 was taken from the thesis of Lorenzo et al., 2018.

$$
\begin{aligned}
& \sigma_{\text {natural }}=a \ln \left(\text { time }_{\text {natural }}\right)+b \\
& \sigma_{\text {accelerated }}=c \ln \left(\text { time }_{\text {acc shifted }}\right)+d
\end{aligned}
$$


Note: $\sigma_{\text {natural }}=$ natural aged retention percentages, time $_{\text {natural }}=$ natural aging time in days, $\sigma_{\text {accelerated }}=$ accelerated shifted retention percentages, time $_{\text {acc shifted }}=$ acceleratedly shifted time in days

Once these four variable are recorded (variable are used from equations in Table 6-1), time shift factors can be created for correlation. The time shift factor is defined as the time taken by a specimen in the field to degrade to a retention level over the time it would take for an accelerated aged sample to degrade to the same retention level. There are two different approaches to calculating these time shift factors. One way is defined in Equation 6-3, and this will give you a more exact, accurate time shift factor. Using Equation 6-4 will give you more of an approximation. In this study, Equation 6-3 was used by using the four variables (a, b, c, and d) to achieve time shift factors. The retention percent being calculated for is used as the " $y$ " variable. Equations 6-3 and 6-4 were taken from the thesis of Maria Martinez et al., 2018.

$$
\begin{gathered}
\text { TSF }=\frac{t_{\text {natural }}}{t_{\text {accelerated }}}=\frac{\exp \left(\frac{y-b}{a}\right)}{\exp \left(\frac{y-d}{c}\right)}=\exp \left(\frac{a d-c b+y(c-a)}{a c}\right) \\
T S F \cong \exp \left(\frac{(y-b)(c-a)}{a c}\right)
\end{gathered}
$$

Note: $t_{\text {natural }}=$ time in days to take natural aged data to reach a specific retention level, $t_{\text {accelerated }}=$ time it takes for accelerated data to reach a specific retention level

As stated before, the time shift factors will be different for different acceleratedly aged protocols, as given in this report. The TSF for up to 3 years was calculated by correlating the 0-90 day accelerated trends with the natural trends. This 3 year range implies that the 3-100 years time 
shift factors were calculated using the $150+$ day accelerated trends with the natural trends. Table 6-2 shows the average TSF used for the two different correlation scenarios.

Table 6-2: TSF for the Accelerated Aged and Natural Aged Correlation

\begin{tabular}{|c|c|c|c|c|c|c|c|}
\hline & & \multicolumn{6}{|c|}{ Natural Aging CORRELATION } \\
\hline & & \multicolumn{3}{|c|}{ Up to 3 Years } & \multicolumn{3}{|c|}{ 3-100 Years } \\
\hline & & Neutral & Acidic & Alkaline & Neutral & Acidic & Alkaline \\
\hline \multirow{4}{*}{ 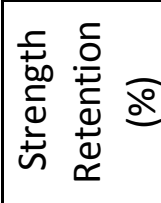 } & 90 & 0.2 & $\mathrm{~N} / \mathrm{A}$ & N/A & 0.2 & N/A & N/A \\
\hline & 80 & 6.2 & $\mathrm{~N} / \mathrm{A}$ & $\mathrm{N} / \mathrm{A}$ & 0.6 & $\mathrm{~N} / \mathrm{A}$ & $\mathrm{N} / \mathrm{A}$ \\
\hline & 70 & $\mathrm{~N} / \mathrm{A}$ & $\mathrm{N} / \mathrm{A}$ & $\mathrm{N} / \mathrm{A}$ & 3.4 & $\mathrm{~N} / \mathrm{A}$ & $\mathrm{N} / \mathrm{A}$ \\
\hline & Average & 3.2 & N/A & N/A & 1.4 & N/A & N/A \\
\hline
\end{tabular}

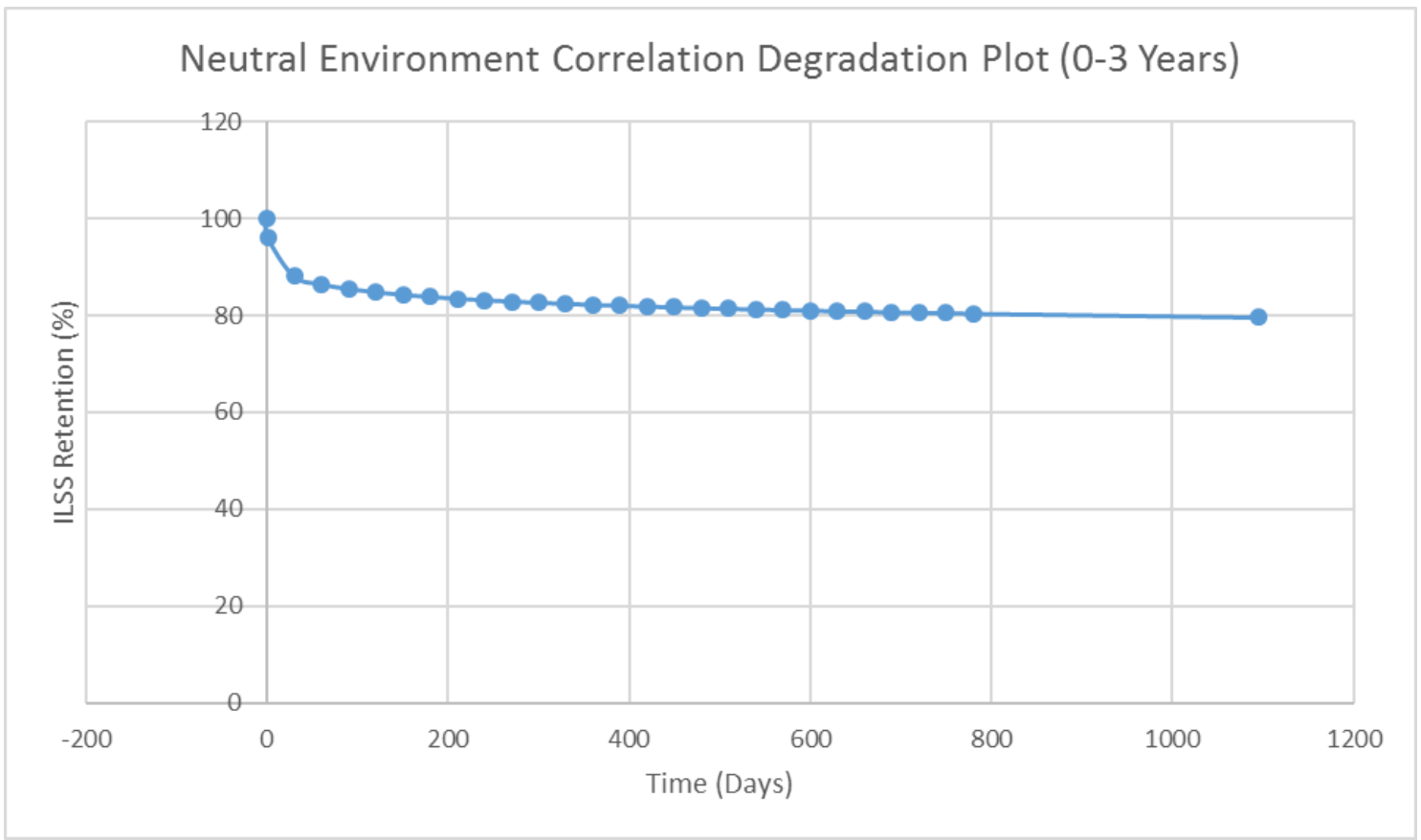

Figure 6-1: Neutral Environment Correlation Degradation Plot 0-3 Years Prediction 


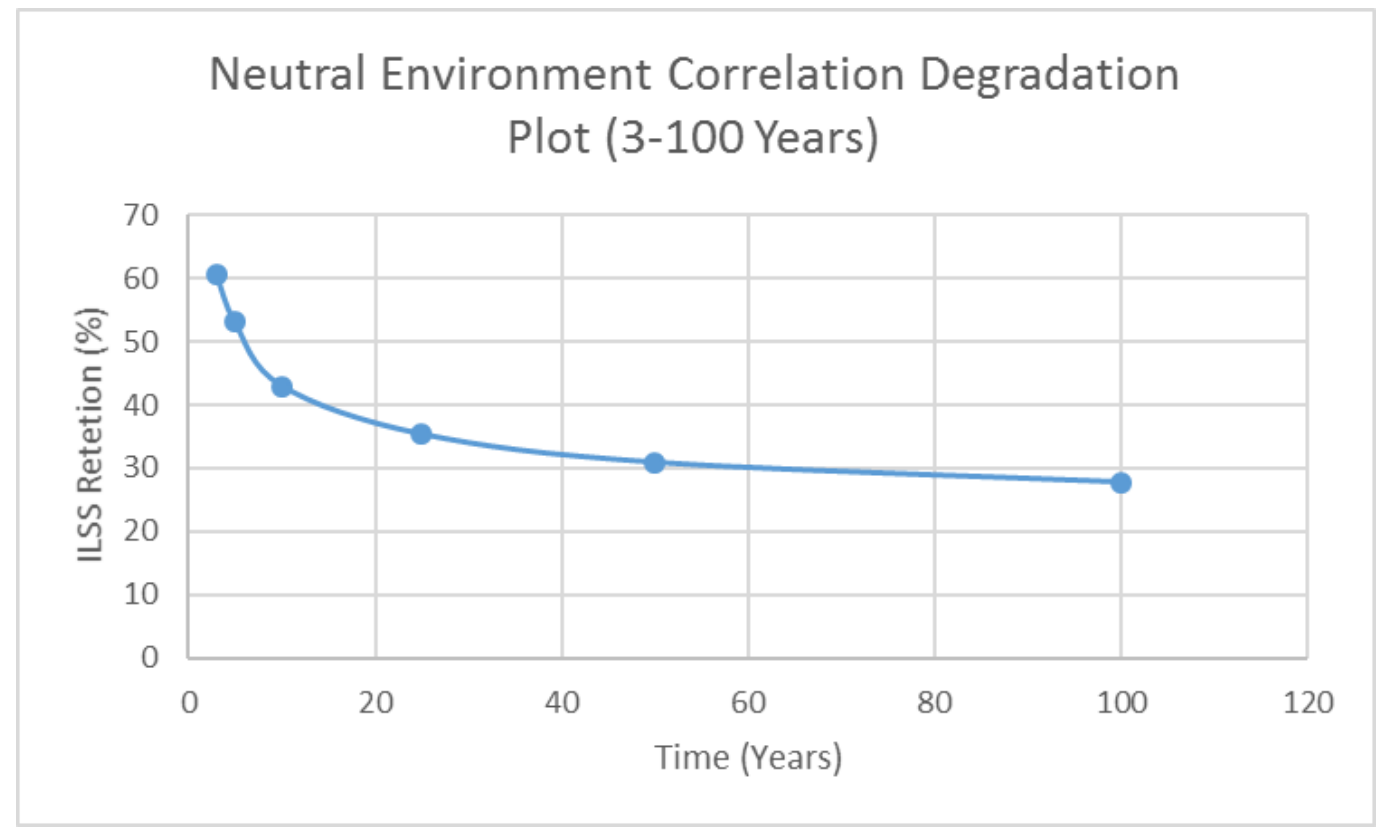

Figure 6-2: Neutral Environment Correlation Degradation Plot 3-100 Years Prediction

Correlated degradation curves are presented in Figures 6-1 and 6-2. Figure 6-1 represents the correlation for a neutral environment analyzed with only the 0-90 day accelerated aged data. Figure 6-2 represents the correlation for a neutral envrionment analyzed with the $150+$ day accelerated aged data. As previously stated, these correlated graphs are only applicable for interlaminar shear strength of glass fiber reinforced vinyl-ester in a neutral $\mathrm{pH}$ environment. These degradation plots were created using Equations 6-5 and 6-6. Understanding that the initial strength is $100 \%$ retention, we can replace the $b$ term in Equations 6-3 and 6-4 with 100 to create a more accurate degradation curve. Equation 6-7 shows how this correlated time is calculated with respect to the time shift factor and accelerated time. Equations 6-5, 6-6, and 6-7 were taken from the thesis of Lorenzo et al., 2018.

$$
\sigma_{\text {natural }}=a_{\text {accelerated }} * \ln \left(T S F * \text { time } e_{\text {accelerated }}\right)+b_{\text {accelerated }}
$$




$$
\begin{aligned}
& \sigma_{\text {natural }}=a_{\text {accelerated }} * \ln \left(T S F * \text { time }_{\text {accelerated }}\right)+100 \\
& t_{\text {natural }}=T S F * t_{\text {accelerated }}
\end{aligned}
$$

With the time shift factors being relatively low in Table 6-2, it represents the acceleratedly aged environment of neutral $\mathrm{pH}$ is not as detrimental as the other accleratedly aged environments (i.e. alkaline environment). With the TSF being only 1.3 for neutral environment for $150+$ days, it shows that most of the degradation already occurred withing the first three years of aging. This is very consistant with how composites degrade with respect to interlaminar shear strength retentions with time.

There are some limitations to these results in relation to the long term degradation of composites in terms of natural aging beyond 3 years. With only having natural aged samples of up to eleven years, the correlated curve for more than three years is not as accurate without long term naturally aged data (50-100 years). The correlation data, in terms of natural data, for Figure 6-2 only has correlated natural data of up to eleven years. This limits the accuracy of the correlation because of the absence of the naturally aged data for (11-100 years). With more data available for longer degradation of these natural aged composites, the correlation of using accelerated data 150 + days becomes more accurate. Without this data, the confidence level is not as high as it should be when it comes to predicting the service life of more than three years in a neutral environment. The confidence level is very high with reference to Figure 6-1. There was plenty of data to support this correlated degradation plot (accelerated and natural). Estimated values of strength retention after correlation using acclerated aged data (0-90 days) for up to 3 years in field is shown in Table 6-3. Estimated values of strength retention after correlation using accelerated aged data $(150+$ days) for 3-100 years in field is shown in Table 6-4. 
Table 6-3: Estimated Strength Retention in the Field for Vinyl-ester and Neutral pH after Correlation (0-3

Years)

\begin{tabular}{|c|c|}
\hline \multicolumn{2}{|c|}{ Up to 3 Years Retention \% - Neutral Environment } \\
\hline Days & Stength Retention (\%) \\
\hline 1 & 96 \\
\hline 30 & 88 \\
\hline 60 & 86 \\
\hline 120 & 85 \\
\hline 240 & 83 \\
\hline 365 & 80 \\
\hline 730 & 77 \\
\hline 1095 & 76 \\
\hline
\end{tabular}

Table 6-4: Estimated Strength Retention in the Field for Vinyl-ester and Neutral pH after Correlation (3-100 Years)

\begin{tabular}{|c|c|}
\hline \multicolumn{2}{|c|}{ 3-100 Year Retention \% - Neutral Environment } \\
\hline Years & Retention\% \\
\hline 3 & 61 \\
\hline 5 & 53 \\
\hline 10 & 43 \\
\hline 25 & 35 \\
\hline 50 & 31 \\
\hline 100 & 28 \\
\hline
\end{tabular}




\section{Chapter 7: Conclusions/Recommendations and Knock-Down}

\section{Factors}

\subsection{Summary}

Recently, Fiber Reinforced Polymer composites are being integrated into infrastructure construction and rehabilitation more often because of their inherent material and system advantages. In the recent years, use of FRPs as substitute construction materials, replacing or reinforcing concrete and steel, has grown. Composites have high strength to weight ratio and also are more economical to rehabilitate in-service structures compared to conventional construction material usage. Durability is one aspect that is still getting studied, but understanding of the degradation mechanisms of FRP composites under different environments has been improving. These composites are susceptible to degradation under both physical and chemical aging. To be able to increase the implementation of composites into engineering applications, aging responses of these composites have to be better understood to ensure that they can withstand a 100-year service life.

With the research and development work (Lorenzo et. al, 2018; Mahato et. al, 2015; Mishra et. al, 2010; Ratna et. al, 2004), we understand that interlaminar shear strength is the most sensitive parameter with respect to durability. Degradation, in terms of ILSS (interlaminar shear strength), has two major trends in GFRP composites. Most degradation occurs within the first ten years of its (FRP) service life (3 years for alkaline environments). Knowing this, the focus of the study was to understand the degradation rate of the initial service life and compare it to the 100 year service life. Therefore to understand these different degradation trends, aging and mechanical property evaluation testing was conducted under controlled lab environments by varying temperatures and 
$\mathrm{pH}$ solutions. Once retention percentages are recorded, Arrhenius relationship is used to correlate the accelerated aged data with the natural aged data to create knock-down factors for different environments.

Accelerated aged data for days 0-90 was evaluated after aging and testing FRP samples under laboratory environment at West Virginia University. Accelerated aged data from $150+$ days was take from literature sources and previous reports (Lorenzo et al., 2018). Naturally aged data came from literature sources and samples tested at West Virginia University. All data consisted of only glass fiber reinforced vinyl-ester for comparisons. Testing was only for interlaminar shear strength (ILSS) since it is the most sensitive to aging in terms of mechanical properties. Alkaline environments showed the largest strength degradation compared to other environments including other $\mathrm{pH}$ variations. Losses as high as $70 \%$ were noticed within the first thirty days of aging of the GFRP composite coupon samples. Such high losses of composite strengths in alkaline environments (i.e. concrete reinforcement) lead to major concerns on durability; hence several schemes such as chemical modification of resins have to be developed to retard the strength degradation trends.

Naturally aged data (field data) was the main concern in this research. The collection of data for natural aged samples was very difficult due to its unavailability or limited availability. With composites being relatively new, naturally aged data is limited in exposure time in terms of field data. The main limitation to the data collection was that there was no naturally aged data in acidic and alkaline environments to correlate the accelerated aged laboratory data. Even with natural data collected in neutral environment, data was only available for up to eleven years of natural aging. 
After collecting data (accelerated and natural aged) for different environments and temperatures, accelerated plots were created through shifting, using the Time-Temperature Superposition principle. This principle can be used once the Arrhenius relationship and time shift factors (TSF) were found. These shifts were based off time shift factor ratios using constant room temperature $\left(22^{\circ} \mathrm{C}\right)$, as a base-line value.

Once TTS plots are created from the acceleratedly aged data, correlation with natural aged data trends can be created. Using the naturally aged data, long-term behavior of the composites can be understood and knock-down factors can be created. A new set of time shift factors are created using a ratio of the amount of time it takes for acceleratedly aged data to reach a retention level over the amount of time it takes for the naturally aged samples to reach the same retention level (Equation 6-3).

The main considerations for future research should deal with large collection of naturally data for accurate correlation with the accelerated from the lab. To be able to create an accurate correlation, naturally aged data needs to be aged longer. Also, accurate knock-down factors for alkaline and acidic environments cannot be created until there is enough naturally aged data collected on a systematic basis. Therefore, it is important to note that large investment of dollars and efforts are needed to obtain additional natural aged data under multiple $\mathrm{pH}$ environments for improved data correlations and also for enhanced confidence levels in strength reduction factor correlations.

\subsection{Conclusions}

After completion of the durability behavior for GFRP composites focusing on interlaminar shear strength (ILSS) to failure, following conclusions can be made: 
1. Interlaminar shear strength of GFRP composites degrade in two distinctly different rates of degradation. One trend is analyzed within the first 90 days of accelerated aging. The other trend is analyzed with 150 or more days of accelerated aged data.

2. An Arrhenius type relationship was chosen to be the best model to represent the degradation of GFRP composites for the two different interlaminar shear strength trends. It is important to understand that with this relationship, only $\mathrm{pH}$ variations and different temperatures were taken into account, while generating laboratory based data.

3. Up to $70 \%$ degradation is observed within the first thirty days in an alkaline environment at $71^{\circ} \mathrm{C}$ for accelerated aged testing. It is important to remember that accelerated environments are much harsher than in service conditions.

4. $1 / 8$ " thick GFRP samples degraded in alkaline solution at a higher rate than the $1 / 4$ " thick samples, which implies moisture/chemical diffusion rate is affecting the mechanical properties directly and more severe for smaller thicknesses. Decrease in strength of approximately $90 \%$ occurred within the first 14 days for $1 / 8$ " thick samples exposed to an alkaline environment at $71^{\circ} \mathrm{C}$.

5. Pure resin/matrix was acceleratedly aged to be able to analyze the degradation rates. Samples were tested under alkaline environment at room temperature and $71^{\circ} \mathrm{C}$. No degradation was noted for samples aged at room temperature, but up to $80 \%$ shear strength loss was seen in samples aged at $71^{\circ} \mathrm{C}$. Sizing of the resin was not in issue in $\mathrm{pH}$ and temperature environments. To slower rate of degradation in GFRP composites, resin needs to be modified to prevent losses in an alkaline environments under high temperatures. 
6. In this study, all coupons tested for 0-90 days testing consisted of the same dimensions and environmental exposure for proper comparisons. Stiffness was assumed to stay nearly constant over the aging period.

7. Good parallel fits for Arrhenius plots were found, as presented in alkaline environments (Appendix C.2.3). Arrhenius plots were very limited with respect to acidic and neutral environments since the rate of degradation of the composite was much slower compared to the neutral environment.

8. Low activation energy values were observed from test data for alkaline solutions compared to acidic and neutral environments.

9. Room temperature $\left(22^{\circ} \mathrm{C}\right)$ was used as the temperature of reference when analyzing time shift factors and shifting of the acceleratedly aged data using the TimeTemperature Superposition principle.

10. Time shift factors increased with respect to temperature. This is expected due to lower amount of time to reach retention levels in higher temperature environments. Higher time shift factors for neutral environments and acidic environments are expected compared to alkaline environments.

11. With very limited naturally aged data, correlation with neutral $\mathrm{pH}$ environment only are developed, herein. The time shift factors for 3-100 year service life were low due to no long term natural aged data to correlate with (11-100 years). The lack of naturally aged data in all $\mathrm{pH}$ environments creates a low confidence level in knock-down factors.

12. The Arrhenius relationship and Time-Temperature Superposition principle yielded great data and accurate accelerated shifted plots. Without the quantity and quality of 
naturally aged data, correlation with these highly accurate accelerated plots does not yield good correlations.

13. Strength reduction factors (knock-down factors) for a 100 year service life is presented in Table 7-1. Keep in mind that the neutral environment reduction factor is based on correlating naturally aged data. The reduction factors for alkaline and acidic $\mathrm{pH}$ environments are based solely on the accelerated shifted plots from using the TimeTemperature Superposition principle. The confidence level in these reduction factors are low due to the small amount of natural data.

Table 7-1: 100 Year Service Life Knock-Down Factors for ILSS GFRP Vinyl-ester Under Different Environments

\begin{tabular}{|c|c|c|c|}
\hline \multicolumn{4}{|c|}{ 100 Year Service Life Knock-Down Factors } \\
\hline Time (Years) & Neutral & Alkaline & Acidic \\
\hline 5 & 0.58 & 0.37 & 0.63 \\
\hline 10 & 0.54 & 0.32 & 0.59 \\
\hline 25 & 0.49 & 0.24 & 0.54 \\
\hline 50 & 0.45 & 0.18 & 0.51 \\
\hline 75 & 0.43 & 0.15 & 0.49 \\
\hline 100 & 0.42 & 0.12 & 0.48 \\
\hline
\end{tabular}

\subsection{Limitations of the Research}

There were not many limitation in this study since it was solely focused on a single type of resin, type of fiber, and type of failure. Some improvements in terms of data collection could be noticed. With respect to accelerated data, a large amount (in-lab and literature) of data was collected for analysis. Natural aged data needs to be a concern due to its limited volume of availability, in literature. 
With the main focus on aging of $1 / 4$ " thick samples, there was testing conducted on $1 / 8$ " thick samples. With limited time and samples, a noticeable change was seen in the rate of degradation of composites with varying thicknesses. With increased temperatures, the degradation rates were much higher in $1 / 8$ " thick samples compared to $1 / 4$ " thick samples, due to higher diffusion rate per unit thickness.

The available data is limited in terms of temperature $\left(-22^{\circ}\right.$ to $\left.71^{\circ} \mathrm{C}\right)$ and $\mathrm{pH}(3,7,13)$ ranges. The need for more temperature groups would be able to create a more accurate TSF vs. temperature plots to be able to predict time shift factors for all temperature with greater accuracy.

These limitations could lead to deviations in the proposed results than expected. The main limitation of this study is the need for additional natural aged data, to generate ILSS reduction factors with high levels of confidence in a 100-year service life.

\subsection{Recommendations}

As stated previously, to be able to achieve accurate knock-down factors, more natural aged data needs to be available. Implementation of composites or just aged laminate plates placed in different $\mathrm{pH}$ environments over longer periods of exposure time is important to obtain the natural aged data.

More studies at West Virginia University are recommended to provide a more complete overview of the durability of composites and their application into engineering applications. To be able to create a broader understanding, different environmental factors need to be studied (UV radiation, thermal fatigue, freeze-thaw cycles, sustained stress, etc.) to create more accurate knockdown factor to be incorporated in design computations. 


\section{$\underline{\text { References }}$}

Bankim, C.R., Dinesh, R. (2014). Durability and Integrity Studies of Environmentally Conditioned Interfaces in Fibrous Polymeric Composites: Critical Concepts and Comments, Advances in Colloid and Interface Science, 209, 68-83.

Bankim, C.R., Dinesh, R. (2015). Environmental Damage and Degradation of FRP Composites: A Review Report, Department of Metallurgical and Materials Engineering, National Institute of Technology, Rourkela, Odisha, India.

Brahim, B., Peng, W., Tan Minh, T., Habib, R., Jean-Francois, R. (2002). Durability of GlassFiber Reinforced Polymer Reinforcing Bars in Concrete Environment, Journal of Composites for Construction, 6(3), 143-153.

Carra, G., Carvelli, V. (2013). Ageing of Pultruded Glass Fibre Reinforced Polymer Composites Exposed to Combined Environmental Agents, Composite Structures, 108, 1019-1026.

Carra, G., Carvelli, V. Effects of Combined Environmental Agents on Pultruded GFRP Composites for Building Constuctions, The $19^{\text {th }}$ International Conference on Composite Materials, Department of Architecture, Built Environment and Construction Engineering, Milano, Italy.

Ceroni, F., Cosenza, E., Gaetano, M., Pecce, P. (2006). Durability Issues of FRP Rebars in Reinforced Concrete Members, Cement \& Concrete Composites, 28, 857-868.

Chen, Y. (2007). Accelerated Ageing Tests and Long-Term Prediction Models for Durability of FRP Bars in Concrete, Dissertation Submitted to the College of Engineering and Mineral Resources at West Virginia University.

Chen, Y., Davalos, J.F., Indrajit, R. (2006). Durability Prediction for GFRP Reinforcing Bars Using Short-Term Data of Accelerated Aging Tests, Journal of Composites for Construction, ASCE, 10(4), 279-286.

Chin, J.W., Hughes, W.L., Signor, A. Elevated Temperature Aging of Glass Fiber Reinforced Vinyl Ester and Isophthalic Polyester Composites in Water, Salt Water and Concrete Pore Solution, Building Material Division, National Institute of Standards and Technology, Gaithersburg, MD.

Dejke, V. (1996). Durability and Service Life Prediction of GFRP for Concrete Reinforcement, Department of Building Materials SE-412, Chalmers University of Technology, Sweden.

Dittenber, D., Gangarao, H., Liang R. (2012). Durability and Life Cycle Performance of Pultruded and Infused FRPs for Infrastructure: Baseline Aging Effects on Mechanical Properties, Submitted to National Science Foundation IIP - IUCRC Fundamental Research, NSF Proposal Number 1230351, West Virginia University, Morgantown, WV.

Gautier, L., Mortaigne, B., Bellenger, V. (1999). Interface Damage Study of Hydrothermally Aged Glass-Fibre-Reinforced Polyester Composites, Composites Science and Technology, 59, 2329-2337. 
Hammami, A., Al-Ghuilani, N. (2004). Durability and Environmental Degradation of GlassVinylester Composites, Department of Mechanical Engineering, College of Engineering United Arab Emirates University.

Hyeong-Yeol, K., Young-Hwan, P., Young-Jun, Y., Chang-Kwon, M. (2007). Short-Term Durability Test for GFRP Rods under Various Environmental Conditions, Composite Structures, 83, 37-47.

Kamal, A.S.M., Boulfiza, M. (2011). Durability of GFRP Rebars in Simulated Concrete Solutions under Accelerated Aging Conditions, Journal of Composites for Construction, 15(4), 473-481.

Karbhari, V.M., Chu, W. (2005). Degradation Kinetics of Pultruded E-Glass/Vinylester in Alkaline Media, ACI Materials Journal, V.102, No.1.

Kemp, R. L. (2017). D for Deterioration: The High Cost of Low Infrastructure Spending. National Civic Review, 106(2), 25-28.

Liao, K., Schultheisz, C.R., Hunston, D.L. (1999). Effects of Environmental Aging on the Properties of Pultruded GFRP, Composites: Part B, 30, 485-493.

Lorenzo, M., Gangarao, H., Liang, R., Gupta, R., Agaarwal, S. (2018). Durability of GFRP composites under Harsh environments: Effect of $p H$ and Temperature, Submitted to the College of Engineering And Mineral Resources, West Virginia University, Morgantown, WV.

Mahato, K.K., Shukla, M.J., Kumar, D.S., Ray, B.C. (2015). In-service Performance of Fiber Reinforced Polymer Composite in Different Environmental Conditions: A Review, Composite Materials Group, Metallurgical and Materials Engineering Department, National Institute of Technology, Rourkela, India.

Mathieu, R., Brahim, B. (2010). Effect of Aging on Bond of GFRP Bars Embedded In Concrete, Cement and Concrete Composites, 32, 461-467.

Micelli, F., Nanni, A. (2004). Durability of FRP Rods for Concrete Structures, Construction and Building Materials, 18, 491-503.

Mishra, G., Mohapatra, S.R., Behera, P.R., Dash, B., Mohanty, U.K., Ray, B.C. (2010). Environmental Stability of GFRP Laminated Composites: An Emphasis on Mechanical Behaviour, Aircraft Engineering and Aerospace Technology: An International Journal, Department of Metallurgical and Materials Engineering, National Institute of Technology, Rourkela, India, 82/4, 258-266.

Mula, S., Bera, T., Ray, P.K., Ray, B.C. (2006). Effects of Hydrothermal Aging on Mechanical Behavior of Sub-zero Weathered GFRP Composites, Department of Metallurgical and Materials Engineering National Institute of Technology, Rourkela, India, Journal of Reinforced Plastics and Composites, Vol. 25, No.6/2006.

Nkurunziza, G., Debaiky, A., Cousin, P., Benmokrane, B. (2005). Durability of GFRP Bars: A Critical Review of the Literature, Program Structural Engineering Materials, 7, 194-209.

Pearce, J. (2001). Stress Corrosion Cracking - Metallic Corrosion, AZO Materials. 
Ratna, D., Chongdar, T.K., Chakraborty, B.C. (2004). Mechanical Characterization of New Glass Fiber Reinforced Epoxy Composites, Polymer Composites, Naval Materials Research Laboratory, Maharashtra, India, 25(2), 165-171.

Sethi, S., Rathore, D.K., Ray, B.C. (2015). Effects of Temperature and Loading Speed on Interface-Dominated Strength in Fibre/Polymer Composites: An Evaluation for In-situ Environment, Materials and Design, 65, 617-626.

Sethi, S., Ray, B.C. (2015). Environmental Effects on Fibre Reinforced Polymeric Composites: Evolving Reasons and Remarks on Interfacial Strength and Stability, Advances in Colloid and Interface Science, 217, 43-67.

Shilpa, K., Panda, G., Mamta, K. (2010). Damage and Degradation Study of FRP Composite, A Thesis of Bachelor in Technology in Metallurgical and Materials Engineering, Department of Metallurgical and Materials Engineering National Institute of Technology Rourkela.

Silva, M.A.G., Biscaia, H. (2008). Degradation of Bond between FRP and RC Beams, Composite Structures, 85, 164-174.

Silva, M.A.G., Fonseca, B.S., Biscaia, H. (2014). On Estimates of Durability of FRP Based on Accelerated Tests, Composite Structures, 116, 377-387.

Surendra, K.M., Sharma, N., Ray, B.C. (2007). Acidic Degradation of FRP Composites, Department of Metallurgical \& Materials Engineering, National Institute of Technology, Rourkela, India.

Vijay, P.V., Hota, V.S.G., Woraphot, P. (2003). Durability of Reinforced Concrete Members Wrapped With FRP Fabrics, Constructed Facilities Center.

Vijay, P. (1999). Aging and design of concrete members reinforced with GFRP bars. $\mathrm{PhD}$ dissertation : West Virginia University.

Wang, J., GangaRao, H., Liang, R., \& Liu, W. (2015). Durability and prediction models of fiberreinforced polymer composites under various environmental conditions: A critical review. Journal of Reinforced Plastic \& Composites, 179-211. 


\section{Appendix A: Accelerated Aging Retention Data}

The data analyzed from 0-150 days of accelerated aging tests is presented in this appendix. Also, accelerated aged data 150 + days from previous work (Lorenzo et al., 2018) is also presented in this appendix. The presented tables and plots are a result for the different collected samples under the conditions specified in the title of each figure. The plots are presented for different temperatures and $\mathrm{pH}$.

The terms used in the figures presented are described in Table A-1.

Table A-1: Notation for Terms Presented in Degradation Plots and Tables

\begin{tabular}{|c|c|}
\hline T1 & $-23^{\circ} \mathrm{C}-15^{\circ} \mathrm{C}$ \\
\hline T2 & $15^{\circ} \mathrm{C}-40^{\circ} \mathrm{C}$ \\
\hline T3 & $40^{\circ} \mathrm{C}-60^{\circ} \mathrm{C}$ \\
\hline T4 & $60^{\circ} \mathrm{C}-71^{\circ} \mathrm{C}$ \\
\hline ILSS & Interlaminar Shear Strength \\
\hline
\end{tabular}

Note: All accelerated data for days greater than 150 days is used from the thesis of Maria Martinez de Lahidalga de Lorenzo in 2018. (See References for full reference of thesis).

The original shear strengths of the different size and oriented composites for accelerated testing is presented in Table A-2.

Table A-2: Original Shear Strengths for Acceleratedly Aged Data

\begin{tabular}{|c|c|}
\hline Size and Orientation & Original Shear Strength (psi) \\
\hline $1 / 4 "$ Longitudinal & 4972 \\
\hline $1 / 4 "$ "Transverse & 4285 \\
\hline $1 / 8$ " Longitudinal & 6486 \\
\hline
\end{tabular}




\section{A.1 Vinyl-ester Interlaminar Shear Strength Retention \% Tables (0-150 Days)}

\section{A.1.1 Longitudinal Retention \%}

\begin{tabular}{|c|c|c|c|c|c|c|c|c|c|}
\hline \multicolumn{9}{|c|}{ Longitudinal Strength Retention (\%) } \\
\hline Days & \multicolumn{3}{|c|}{ Neutral $\mathrm{pH}$} & \multicolumn{3}{c|}{$\mathrm{pH}=3$} & \multicolumn{3}{c|}{$\mathrm{pH}=13$} \\
\hline & $-23.33^{\circ} \mathrm{C}$ & $22^{\circ} \mathrm{C}$ & $71^{\circ} \mathrm{C}$ & $-23.33^{\circ} \mathrm{C}$ & $22^{\circ} \mathrm{C}$ & $71^{\circ} \mathrm{C}$ & $-23.33^{\circ} \mathrm{C}$ & $22^{\circ} \mathrm{C}$ & $71^{\circ} \mathrm{C}$ \\
\hline 1 & $100 \%$ & $89 \%$ & $94 \%$ & $97 \%$ & $95 \%$ & $93 \%$ & $94 \%$ & $85 \%$ & $69 \%$ \\
\hline 4 & $92 \%$ & $91 \%$ & $87 \%$ & $97 \%$ & $94 \%$ & $81 \%$ & $93 \%$ & $78 \%$ & $62 \%$ \\
\hline 7 & $94 \%$ & $88 \%$ & $95 \%$ & $90 \%$ & $91 \%$ & $94 \%$ & $89 \%$ & $74 \%$ & $50 \%$ \\
\hline 9 & $\mathrm{~N} / \mathrm{A}$ & $\mathrm{N} / \mathrm{A}$ & $\mathrm{N} / \mathrm{A}$ & $\mathrm{N} / \mathrm{A}$ & $\mathrm{N} / \mathrm{A}$ & $83 \%$ & $\mathrm{~N} / \mathrm{A}$ & $\mathrm{N} / \mathrm{A}$ & $\mathrm{N} / \mathrm{A}$ \\
\hline 10 & $\mathrm{~N} / \mathrm{A}$ & $\mathrm{N} / \mathrm{A}$ & $\mathrm{N} / \mathrm{A}$ & $\mathrm{N} / \mathrm{A}$ & $\mathrm{N} / \mathrm{A}$ & $\mathrm{N} / \mathrm{A}$ & $\mathrm{N} / \mathrm{A}$ & $\mathrm{N} / \mathrm{A}$ & $55 \%$ \\
\hline 14 & $96 \%$ & $92 \%$ & $91 \%$ & $95 \%$ & $91 \%$ & $85 \%$ & $82 \%$ & $67 \%$ & $53 \%$ \\
\hline 21 & $96 \%$ & $94 \%$ & $92 \%$ & $93 \%$ & $84 \%$ & $86 \%$ & $78 \%$ & $57 \%$ & $43 \%$ \\
\hline 30 & $97 \%$ & $85 \%$ & $81 \%$ & $94 \%$ & $90 \%$ & $77 \%$ & $80 \%$ & $50 \%$ & $38 \%$ \\
\hline 60 & $96 \%$ & $92 \%$ & $86 \%$ & $92 \%$ & $91 \%$ & $86 \%$ & $84 \%$ & $51 \%$ & $36 \%$ \\
\hline 90 & $97 \%$ & $92 \%$ & $83 \%$ & $96 \%$ & $93 \%$ & $82 \%$ & $73 \%$ & $48 \%$ & $32 \%$ \\
\hline 150 & $94 \%$ & $\mathrm{~N} / \mathrm{A}$ & $86 \%$ & $97 \%$ & $91 \%$ & $\mathrm{~N} / \mathrm{A}$ & $79 \%$ & $52 \%$ & $\mathrm{~N} / \mathrm{A}$ \\
\hline
\end{tabular}

\section{A.1.2 Transverse Retention \%}

\begin{tabular}{|c|c|c|c|c|c|c|c|c|c|}
\hline \multicolumn{7}{|c|}{ Transverse Strength Retention (\%) } \\
\hline Days & \multicolumn{3}{|c|}{ Neutral pH } & \multicolumn{3}{c|}{$\mathrm{pH}=3$} & \multicolumn{3}{c|}{$\mathrm{pH}=13$} \\
\hline & $-23.33^{\circ} \mathrm{C}$ & $22^{\circ} \mathrm{C}$ & $71^{\circ} \mathrm{C}$ & $-23.33^{\circ} \mathrm{C}$ & $22^{\circ} \mathrm{C}$ & $71^{\circ} \mathrm{C}$ & $-23.33^{\circ} \mathrm{C}$ & $22^{\circ} \mathrm{C}$ & $71^{\circ} \mathrm{C}$ \\
\hline 1 & $97 \%$ & $98 \%$ & $94 \%$ & $97 \%$ & $101 \%$ & $93 \%$ & $93 \%$ & $89 \%$ & $69 \%$ \\
\hline 4 & $95 \%$ & $97 \%$ & $93 \%$ & $99 \%$ & $99 \%$ & $90 \%$ & $93 \%$ & $69 \%$ & $45 \%$ \\
\hline 7 & $95 \%$ & $97 \%$ & $88 \%$ & $96 \%$ & $97 \%$ & $91 \%$ & $90 \%$ & $68 \%$ & $43 \%$ \\
\hline 10 & $\mathrm{~N} / \mathrm{A}$ & $\mathrm{N} / \mathrm{A}$ & $\mathrm{N} / \mathrm{A}$ & $\mathrm{N} / \mathrm{A}$ & $\mathrm{N} / \mathrm{A}$ & $\mathrm{N} / \mathrm{A}$ & $\mathrm{N} / \mathrm{A}$ & $\mathrm{N} / \mathrm{A}$ & $\mathrm{N} / \mathrm{A}$ \\
\hline 14 & $92 \%$ & $95 \%$ & $85 \%$ & $98 \%$ & $93 \%$ & $87 \%$ & $79 \%$ & $55 \%$ & $39 \%$ \\
\hline 21 & $100 \%$ & $97 \%$ & $85 \%$ & $96 \%$ & $83 \%$ & $80 \%$ & $80 \%$ & $46 \%$ & $34 \%$ \\
\hline 30 & $93 \%$ & $92 \%$ & $80 \%$ & $102 \%$ & $96 \%$ & $86 \%$ & $80 \%$ & $41 \%$ & $29 \%$ \\
\hline 60 & $100 \%$ & $95 \%$ & $83 \%$ & $97 \%$ & $95 \%$ & $86 \%$ & $73 \%$ & $44 \%$ & $26 \%$ \\
\hline 90 & $100 \%$ & $89 \%$ & $83 \%$ & $102 \%$ & $101 \%$ & $86 \%$ & $65 \%$ & $50 \%$ & $29 \%$ \\
\hline 150 & $94 \%$ & $90 \%$ & $80 \%$ & $97 \%$ & $93 \%$ & $82 \%$ & $66 \%$ & $47 \%$ & $27 \%$ \\
\hline
\end{tabular}




\section{A.2 Vinyl-ester Interlaminar Shear Strength Retention \% Plots (0-90 Days)}

\section{A.2.1 Longitudinal Neutral Environment}

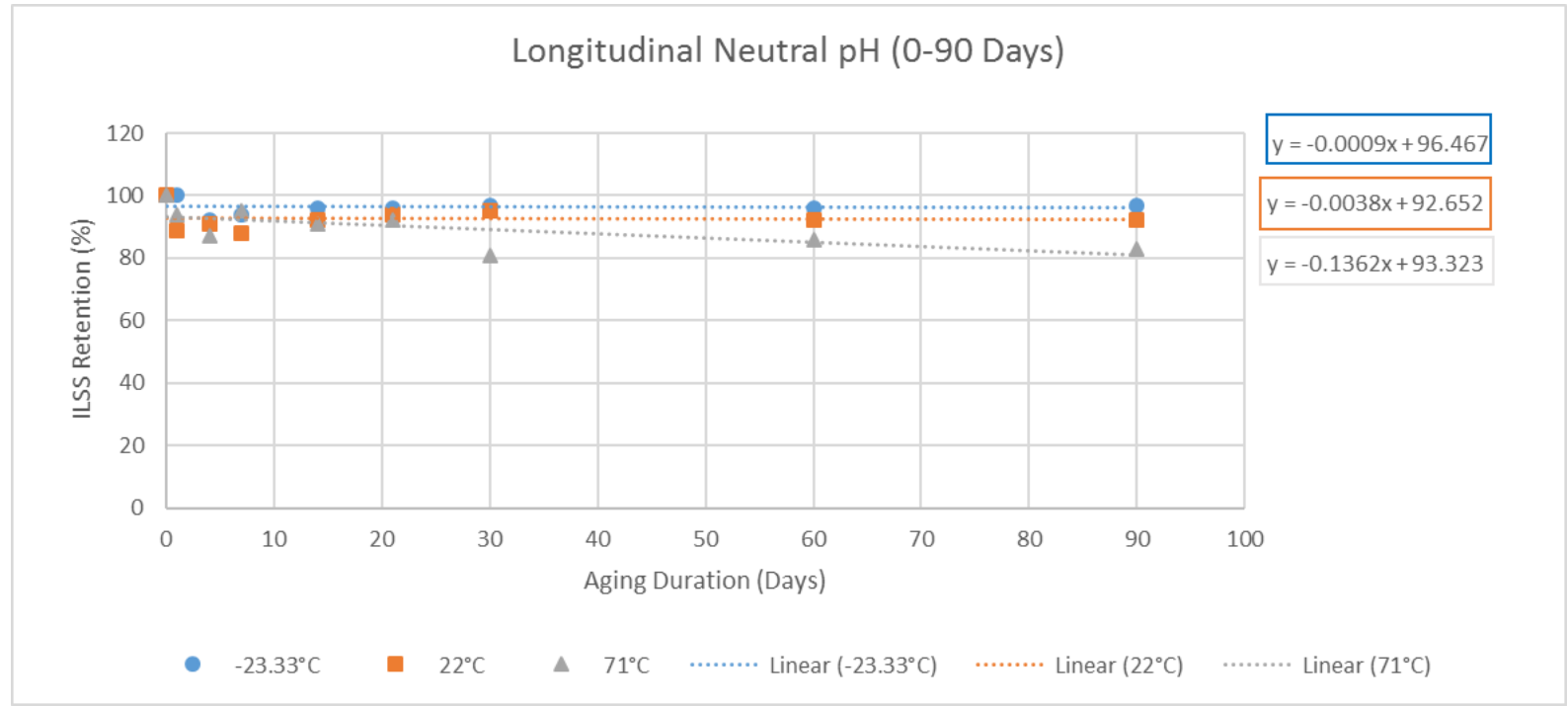

A.2.2 Longitudinal Acidic Environment

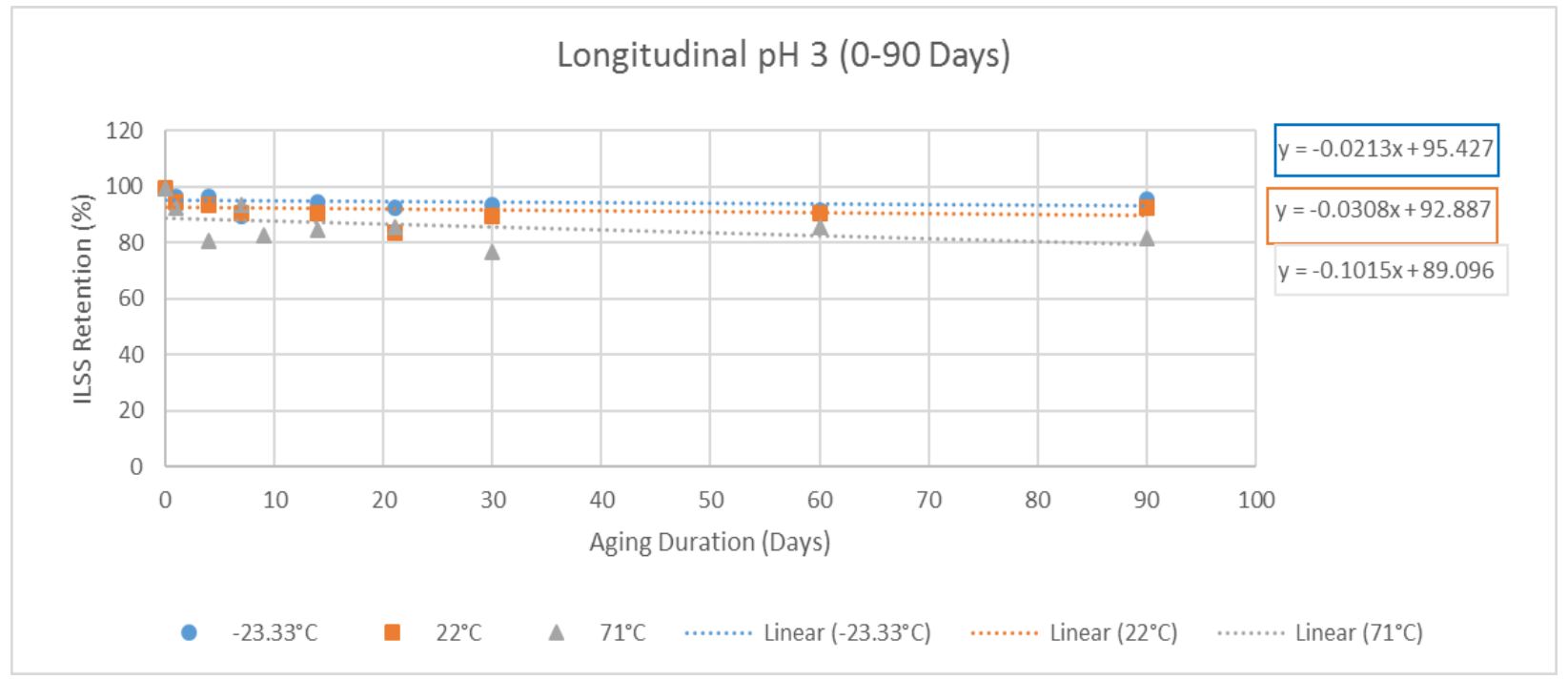




\section{A.2.3 Longitudinal Alkaline Environment}

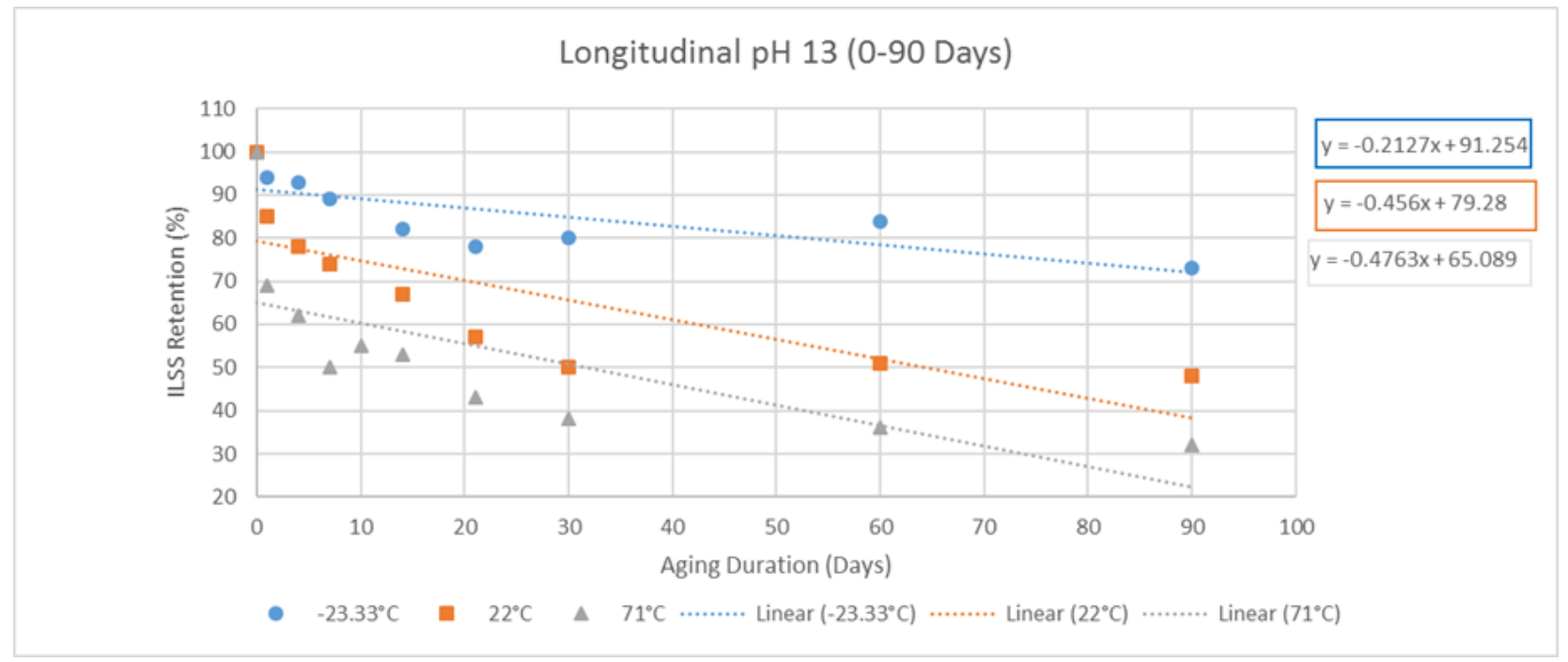

\section{A.2.4 Transverse Neutral Environment}

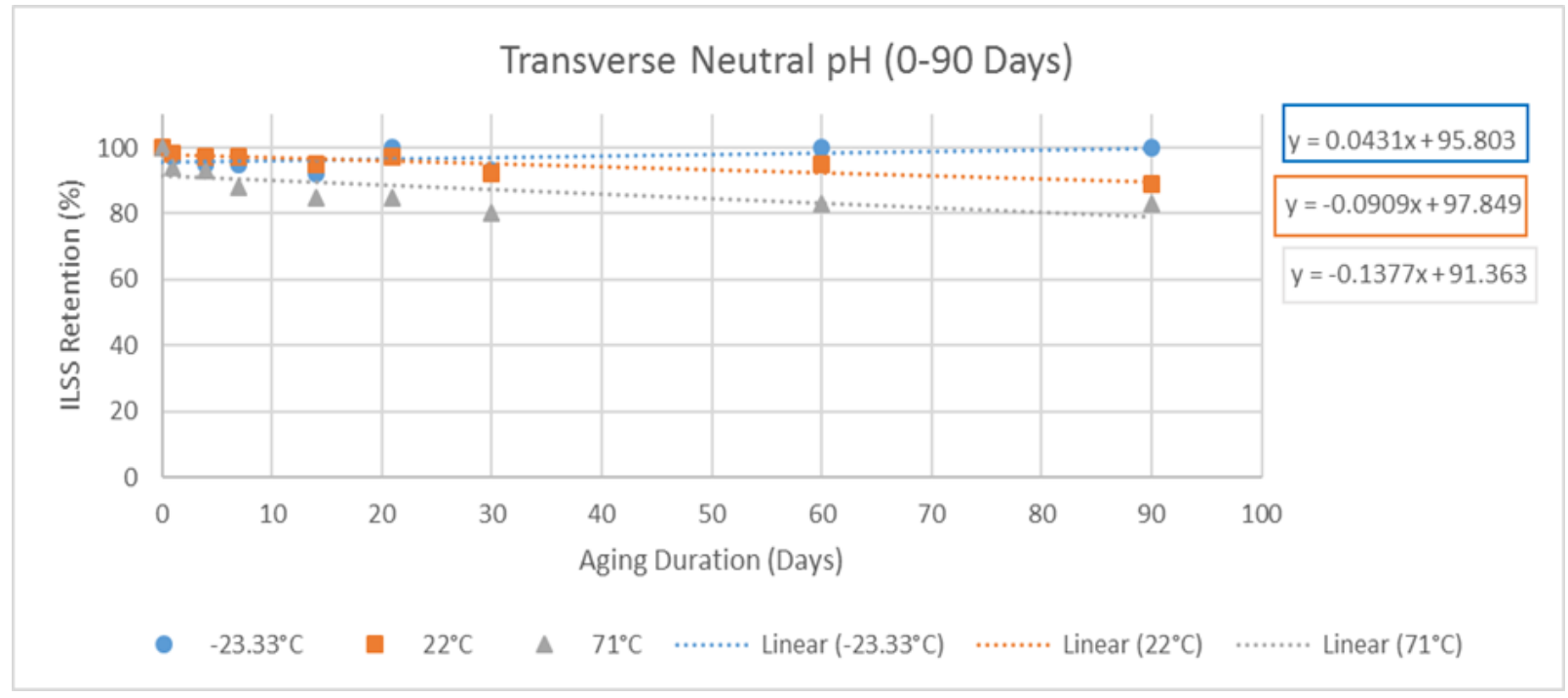




\section{A.2.5 Transverse Acidic Environment}

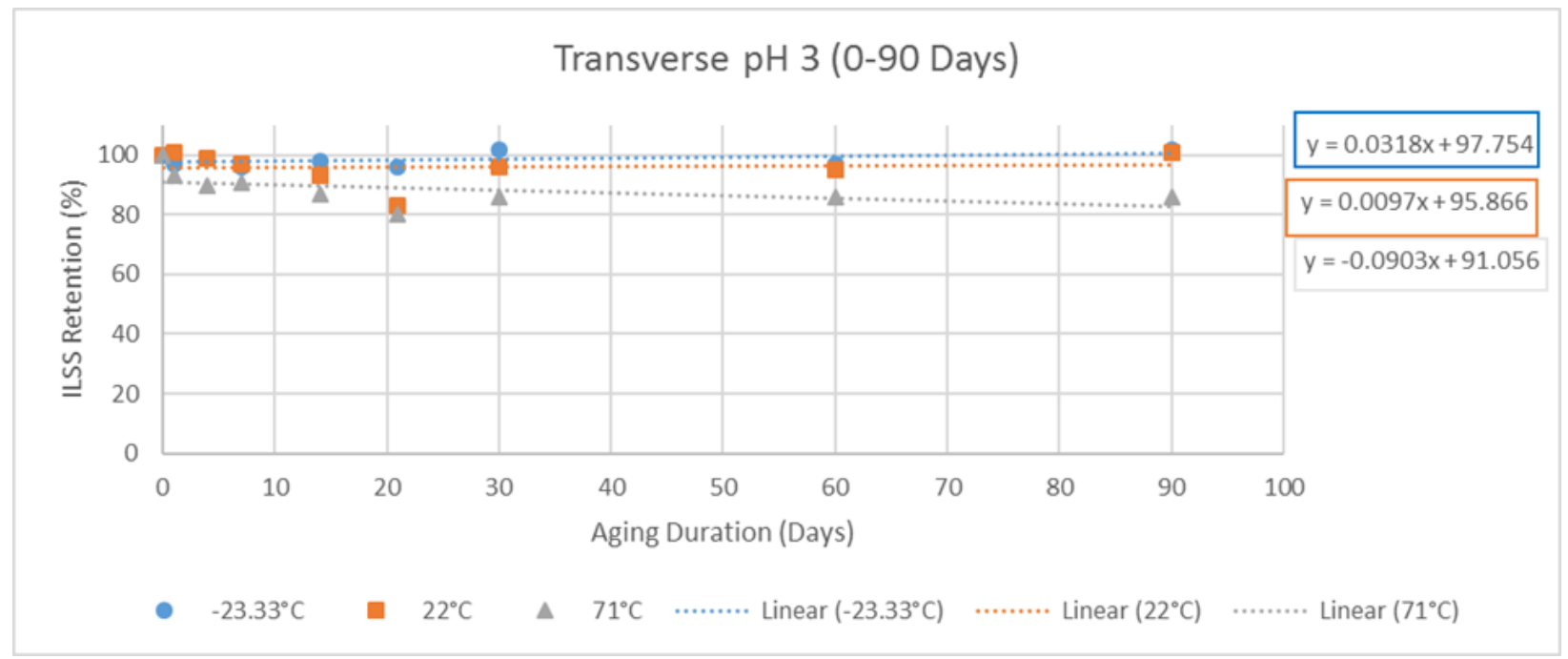

\section{A.2.6 Transverse Alkaline Environment}

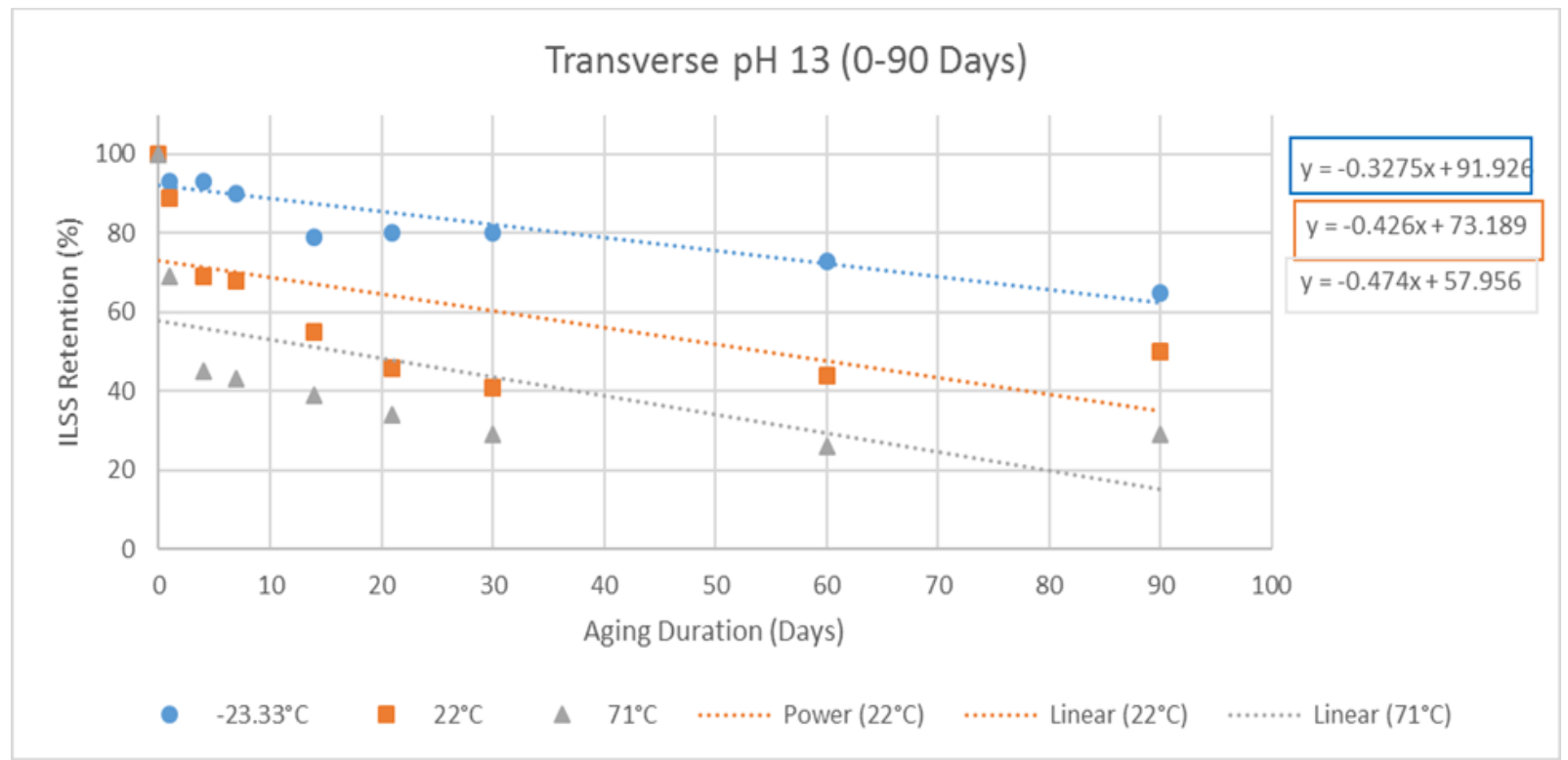




\section{A.3 Vinyl-ester Interlaminar Shear Strength Retention \% Tables (150 + Days)}

\section{A.3.1 Neutral Environment}

\begin{tabular}{|c|c|c|c|c|c|c|c|c|}
\hline \multicolumn{9}{|c|}{ Retention (\%) Neutral Environment 150 Days + } \\
\hline \multirow[b]{2}{*}{ Temp. } & \multicolumn{8}{|c|}{ Time in Days } \\
\hline & 150 & 180 & 210 & 240 & 270 & 360 & 420 & 540 \\
\hline T1 & 94 & 95 & 94 & 94 & 92 & 89 & 87 & 86 \\
\hline $\mathrm{T} 2$ & 92 & 88 & 98 & 94 & 84 & 91 & 75 & $\mathrm{~N} / \mathrm{A}$ \\
\hline T3 & 80 & 73 & 70 & 70 & 64 & 76 & 74 & $\mathrm{~N} / \mathrm{A}$ \\
\hline $\mathrm{T} 4$ & 69 & 47 & 43 & 39 & 49 & 56 & $\mathrm{~N} / \mathrm{A}$ & $\mathrm{N} / \mathrm{A}$ \\
\hline
\end{tabular}

\section{A.3.2 Acidic Environment}

\begin{tabular}{|c|c|c|c|c|c|}
\hline \multicolumn{5}{|c|}{ Retention (\%) Acidic Environment 150 Days + } \\
\hline & \multicolumn{5}{|c|}{ Time in Days } \\
\hline Temp. & $\mathbf{1 5 0}$ & $\mathbf{2 4 0}$ & $\mathbf{2 7 0}$ & $\mathbf{3 6 0}$ & $\mathbf{4 2 0}$ \\
\hline T2 & 88 & 92 & 89 & 100 & 80 \\
\hline T3 & & 66 & 75 & 87 & 71 \\
\hline T4 & & 53 & 63 & 65 & 45 \\
\hline
\end{tabular}

\section{A.3.3 Alkaline Environment}

\begin{tabular}{|c|c|c|c|c|}
\hline \multicolumn{5}{|c|}{ Retention (\%) Alkaline Environment 150 Days + } \\
\hline & \multicolumn{5}{|c|}{ Time in Days } \\
\hline Temp. & $\mathbf{1 5 0}$ & $\mathbf{1 8 0}$ & $\mathbf{2 4 0}$ & $\mathbf{4 2 0}$ \\
\hline T2 & 52 & 50 & 35 & 40 \\
\hline T3 & & 31 & 37 & 30 \\
\hline T4 & & 20 & 25 & 18 \\
\hline
\end{tabular}




\section{A.4 Vinyl-ester Interlaminar Shear Strength Retention \% Plots (150 + Days)}

\section{A.4.1 Neutral Environment}

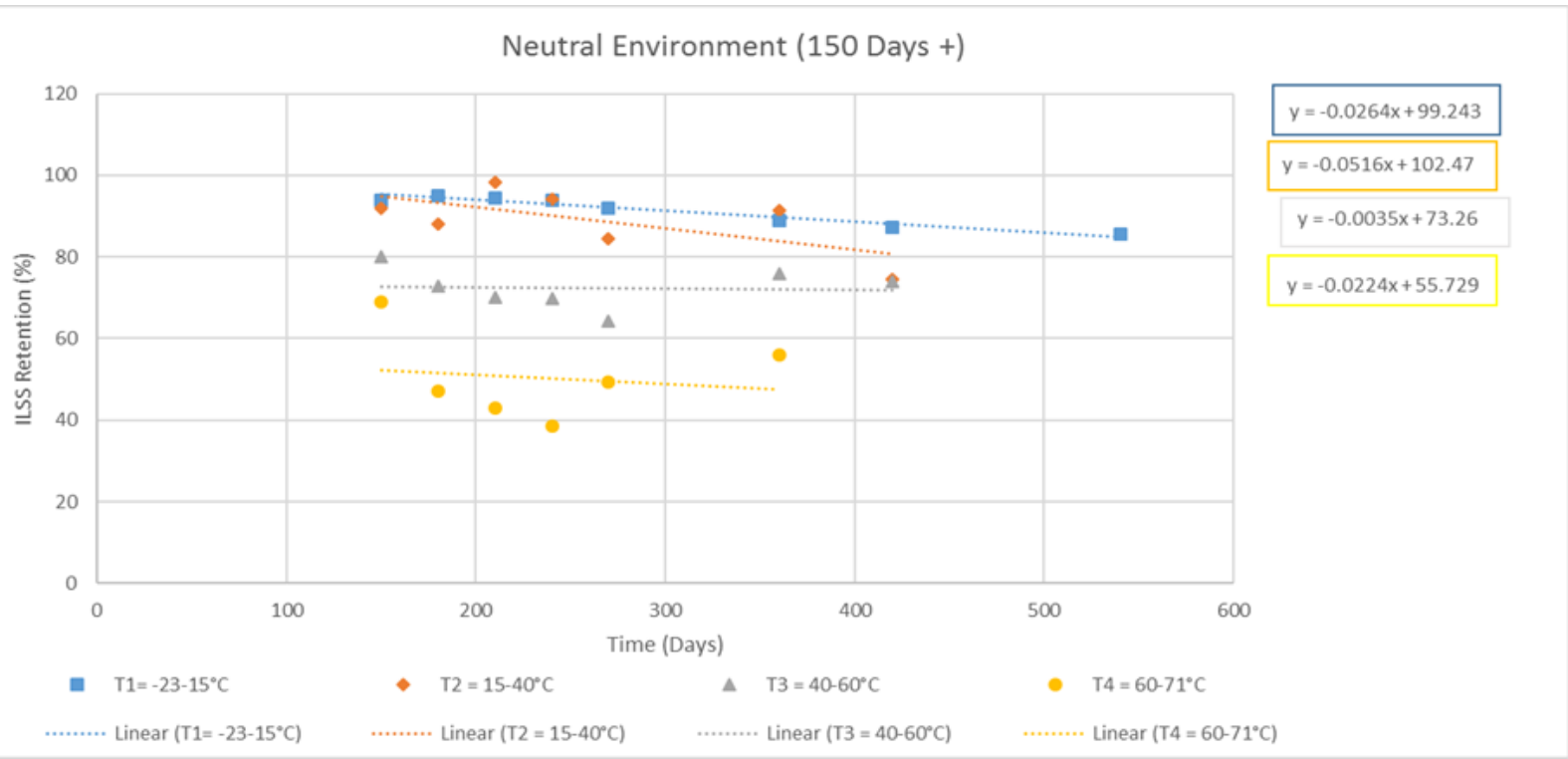

\section{A.4.2 Acidic Environment}

Acidic Environment (150 Days +)

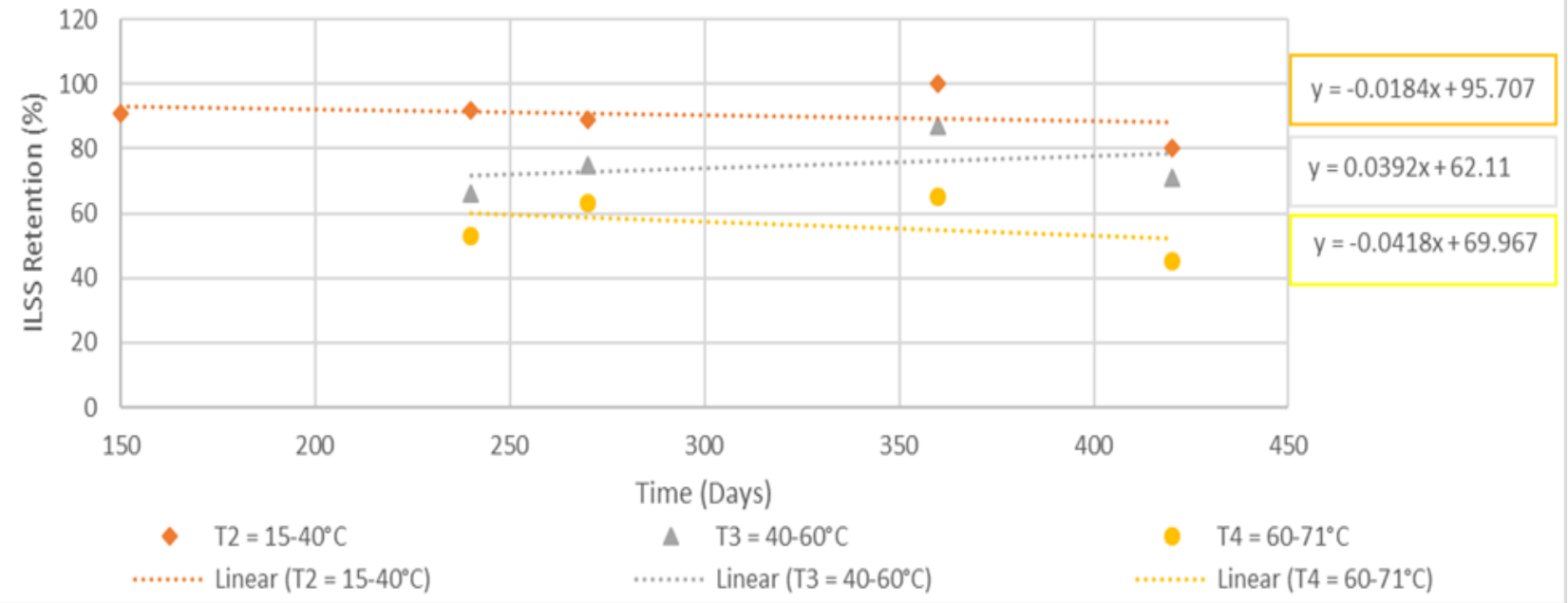




\section{A.4.3 Alkaline Environment}

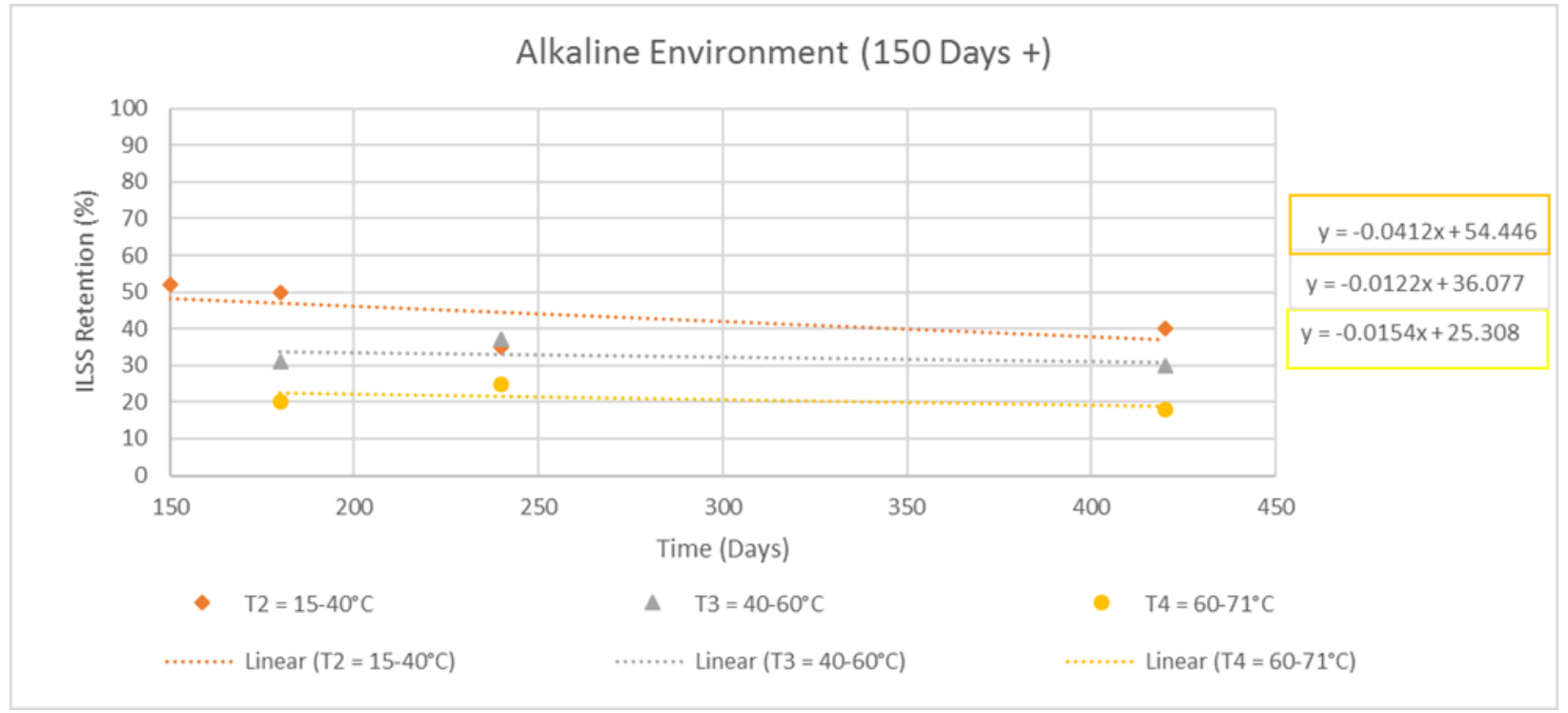

\section{A.5 Vinyl-ester Interlaminar Shear Strength Data (1/8” Thick Samples)}

\section{A.5.1 Retention (\%) Table}

\begin{tabular}{|c|c|c|c|}
\hline \multicolumn{4}{|c|}{$1 / 8^{\prime \prime}$ Thick Retention \% } \\
\hline \multicolumn{4}{|c|}{$\mathrm{pH}=13$} \\
\hline Days & $-22^{\circ} \mathrm{C}$ & $22^{\circ} \mathrm{C}$ & $71^{\circ} \mathrm{C}$ \\
\hline 0 & 100 & 100 & 100 \\
\hline 1 & 91 & 79 & 70 \\
\hline 4 & 93 & 74 & 27 \\
\hline 7 & 92 & 67 & 21 \\
\hline 14 & 93 & 66 & 11 \\
\hline
\end{tabular}




\section{A.5.2 Retention (\%) Plot}

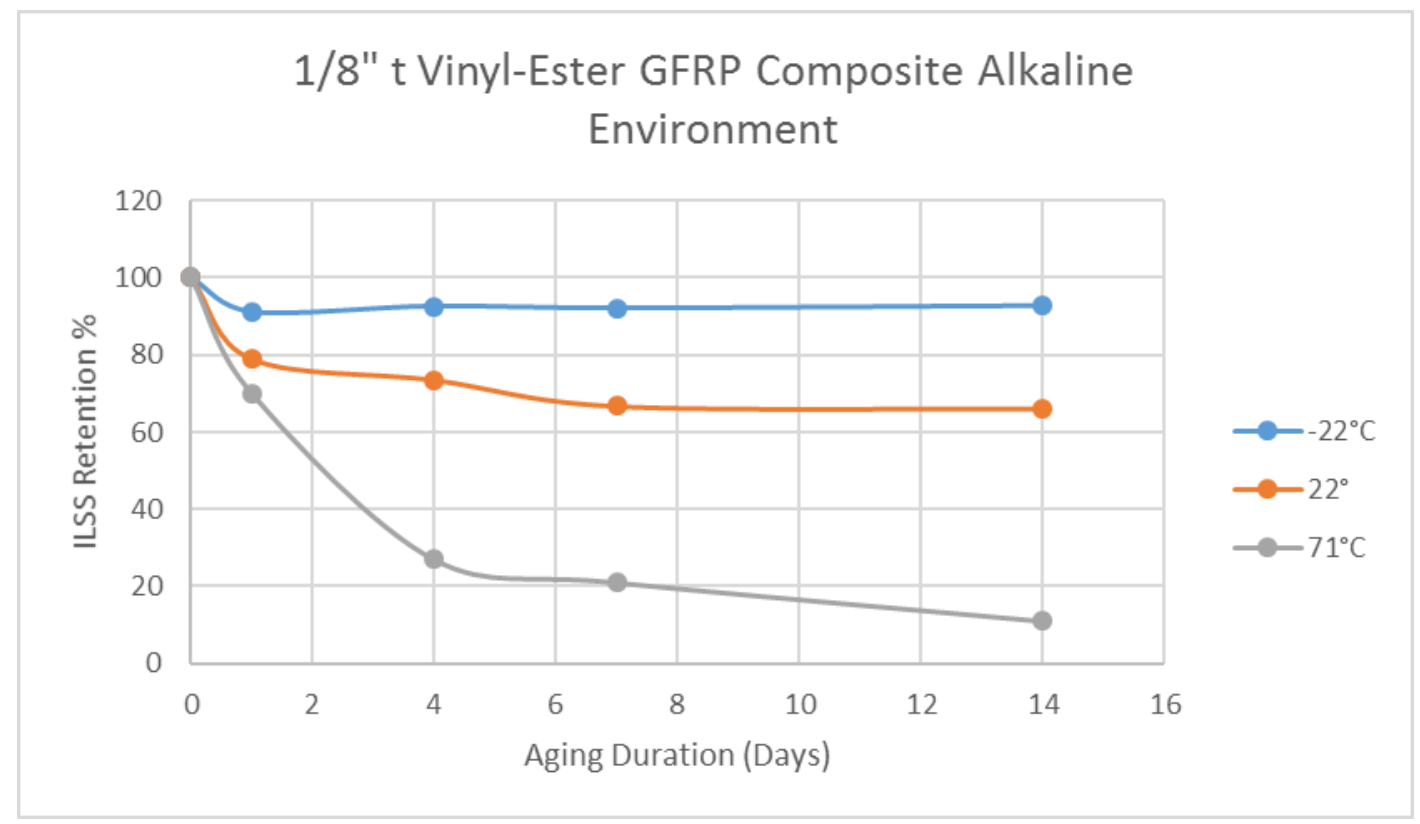




\section{Appendix B: Field Data (Natural Data)}

All natural data being used for this analyses is presented in this Appendix. As stated previously, the only natural data gathered was neutral environment data. There will also be some

plots showing aging indoors in a laboratory with no environmental influences, plots aging with some environmental exposure, and plots exposed fully to the environment. These plots will reflect how the natural environment influences degradation of FRP composites.

Note: Plate 1 composite properties is similar to Plate 2, therefore the original strength was assumed to be the same original strength as Plate 1.

\section{B.1 Natural Aging Information Tables}

\section{B.1.1 Natural Aging Material Information}

\begin{tabular}{|c|c|c|}
\hline Material & 2018 Aging Location & Year Manufactured \\
\hline$\# 1$ & Inside Morgantown Lab & 1993 \\
\hline \#1 transverse & Inside Morgantown Lab & 1993 \\
\hline$\# 2$ & Inside Morgantown Lab & 1992 \\
\hline \#2 web & Inside Morgantown Lab & 1992 \\
\hline \#2 web/trans & Inside Morgantown Lab & 1992 \\
\hline \#3 & Inside Morgantown Lab & 2004 \\
\hline \#3 web & Inside Morgantown Lab & 2004 \\
\hline \#3 web/trans & Inside Morgantown Lab & 2004 \\
\hline$\# 4$ & Inside Morgantown Lab & 2002 \\
\hline \#4 Transverse & Inside Morgantown Lab & 2002 \\
\hline \#4 web/trans & Inside Morgantown Lab & 2002 \\
\hline \#6 & Inside Morgantown Lab & 2002 \\
\hline \#6 transverse & Inside Morgantown Lab & 2002 \\
\hline \#7 & Inside Morgantown Lab & 2005 \\
\hline$\# 8$ & Inside Morgantown Lab & 2002 \\
\hline \#8 transverse & Inside Morgantown Lab & 2002 \\
\hline$\# 9$ & Inside Morgantown Lab & 2005 \\
\hline \#9 web/trans & Inside Morgantown Lab & 2005 \\
\hline \#12 & Inside Morgantown Lab & 2003 \\
\hline \#12 transverse & Inside Morgantown Lab & 2003 \\
\hline \#13 & Inside Morgantown Lab & 2009 \\
\hline \#13 transverse & Inside Morgantown Lab & 2009 \\
\hline \#15 & Inside Morgantown Lab & $\mathrm{N} / \mathrm{A}$ \\
\hline \#15 transverse & Inside Morgantown Lab & $\mathrm{N} / \mathrm{A}$ \\
\hline Plate $1 \mathrm{~L}$ & Outdoor Morgantown Lab & 2007 \\
\hline Plate $1 \mathrm{~T}$ & Outdoor Morgantown Lab & 2007 \\
\hline Plate $2 \mathrm{~L}$ & Outdoor Morgantown, WV & 2007 \\
\hline Plate $2 \mathrm{~T}$ & Outdoor Morgantown, WV & 2007 \\
\hline
\end{tabular}




\section{B.1.2 Natural Age Strength \& Sample Size}

\begin{tabular}{|c|c|c|c|c|}
\hline Material & \# Samples & Original Strength (psi) & 2013 Strength (psi) & 2018 Strength (psi) \\
\hline$\# 1$ & 1 & 4876 & 4237 & 4320 \\
\hline \#1 transverse & 1 & 2139 & 1859 & 2889 \\
\hline$\# 2$ & 5 & 3225 & 3330 & 3426 \\
\hline$\# 2$ web & 1 & 2974 & 2615 & 2826 \\
\hline \#2 web/trans & 1 & 2213 & 1946 & 1872 \\
\hline \#3 & 1 & 8177 & 5049 & 5735 \\
\hline$\# 3$ web & 1 & 8177 & 5003 & 5223 \\
\hline \#3 web/trans & 1 & 2534 & 2829 & 3225 \\
\hline$\# 4$ & 3 & 5230 & 4339 & 5117 \\
\hline \#4 Transverse & 1 & 2786 & 2814 & 3279 \\
\hline \#4 web/trans & 1 & 2583 & 2389 & 2955 \\
\hline$\# 6$ & 5 & 5509 & 4172 & 4184 \\
\hline \#6 transverse & 3 & 2454 & 2417 & 2036 \\
\hline$\# 7$ & 5 & 4754 & 5148 & 5207 \\
\hline$\# 8$ & 1 & 7310 & 4338 & 4766 \\
\hline \#8 transverse & 1 & 2424 & 2172 & 1879 \\
\hline$\# 9$ & 1 & 5040 & 4502 & 4033 \\
\hline \#9 web/trans & 1 & 2220 & 2507 & 2758 \\
\hline$\# 12$ & 2 & 5605 & 4179 & 5193 \\
\hline$\# 12$ transverse & 3 & 4502 & 4498 & 4815 \\
\hline$\# 13$ & 4 & 3045 & 3205 & 3520 \\
\hline \#13 transverse & 5 & 1339 & 1409 & 1539 \\
\hline$\# 15$ & 4 & 4403 & 4332 & 4746 \\
\hline$\# 15$ transverse & 3 & 2824 & 2778 & 2879 \\
\hline Plate $1 \mathrm{~L}$ & 7 & 6700 & $\mathrm{~N} / \mathrm{A}$ & 5320 \\
\hline Plate $1 \mathrm{~T}$ & 7 & $\mathrm{~N} / \mathrm{A}$ & $\mathrm{N} / \mathrm{A}$ & 3174 \\
\hline Plate $2 \mathrm{~L}$ & 8 & 6700 & $\mathrm{~N} / \mathrm{A}$ & 4032 \\
\hline Plate 2T & 6 & $\mathrm{~N} / \mathrm{A}$ & $\mathrm{N} / \mathrm{A}$ & 3641 \\
\hline
\end{tabular}


B.1.3 Natural Aging Strength Retention \% (Samples used for Degradation Plots)

\begin{tabular}{|c|c|c|c|c|}
\hline Material & 2013 Age (Days) & 2018 Age (Days) & 2013 Strength Retention & 2018 Strength Retention \\
\hline$\# 1$ & 7300 & 9125 & $87 \%$ & $89 \%$ \\
\hline$\# 2$ web & 7665 & 9490 & $88 \%$ & $95 \%$ \\
\hline$\# 2$ web/trans & 7665 & 9490 & $88 \%$ & $85 \%$ \\
\hline$\# 3$ & 3285 & 5110 & $62 \%$ & $70 \%$ \\
\hline$\# 3$ web & 3285 & 5110 & $61 \%$ & $64 \%$ \\
\hline$\# 4$ & 4015 & 5840 & $83 \%$ & $98 \%$ \\
\hline$\# 6$ & 4015 & 5840 & $76 \%$ & $76 \%$ \\
\hline$\# 6$ transverse & 4015 & 5840 & $98 \%$ & $83 \%$ \\
\hline$\# 7$ & 4745 & 6570 & $108 \%$ & $110 \%$ \\
\hline$\# 9$ & 4745 & 6570 & $89 \%$ & $80 \%$ \\
\hline$\# 12$ & 3650 & 5475 & $75 \%$ & $93 \%$ \\
\hline Plate 1L & N/A & 4015 & N/A & $79 \%$ \\
\hline Plate 2L & N/A & 4015 & N/A & $60 \%$ \\
\hline
\end{tabular}

\section{B.2 Natural Aging Plots}

\section{B.2.1 Indoor Environment}

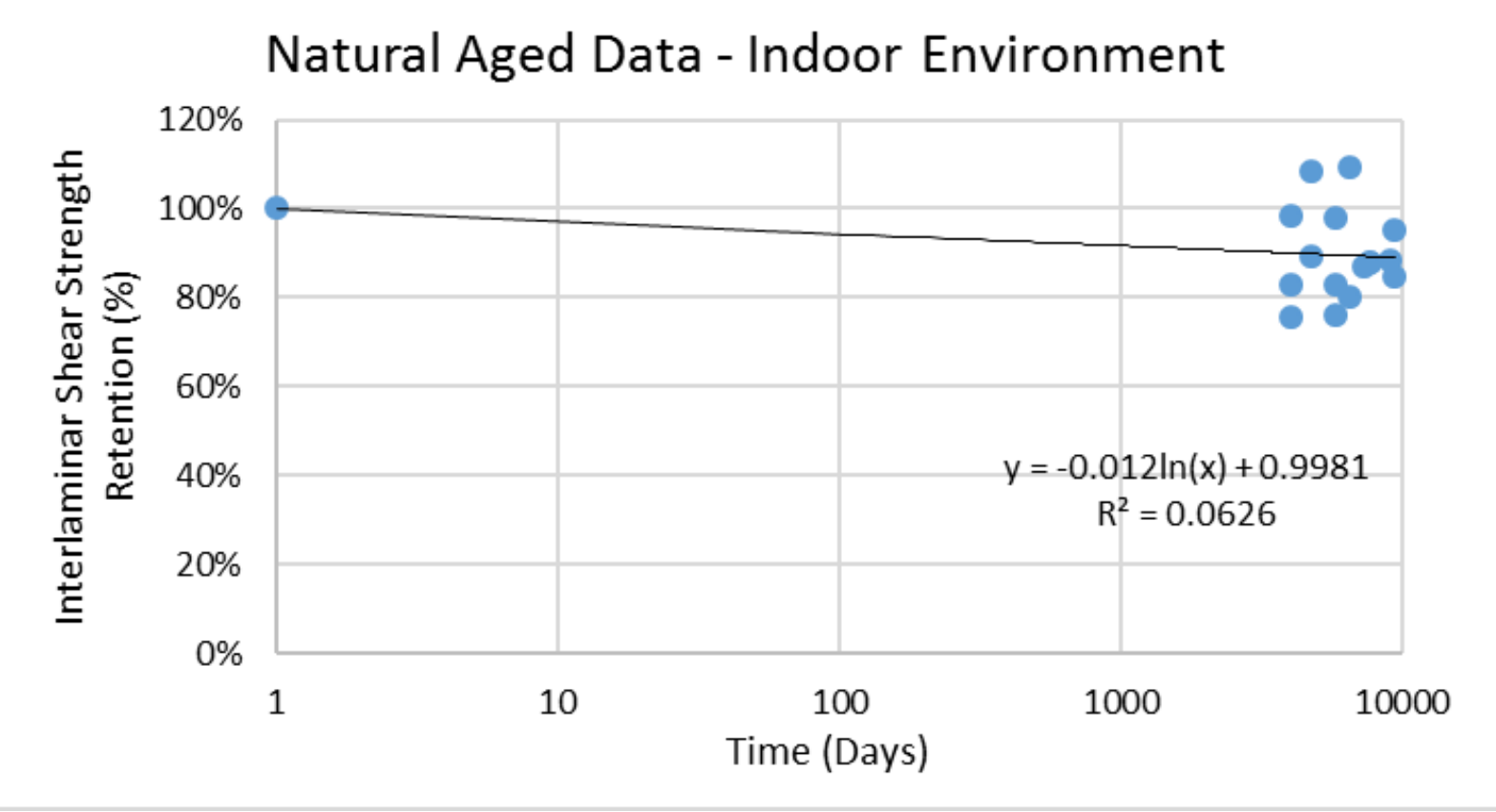




\section{B.2.2 Partially Exposed Environment}

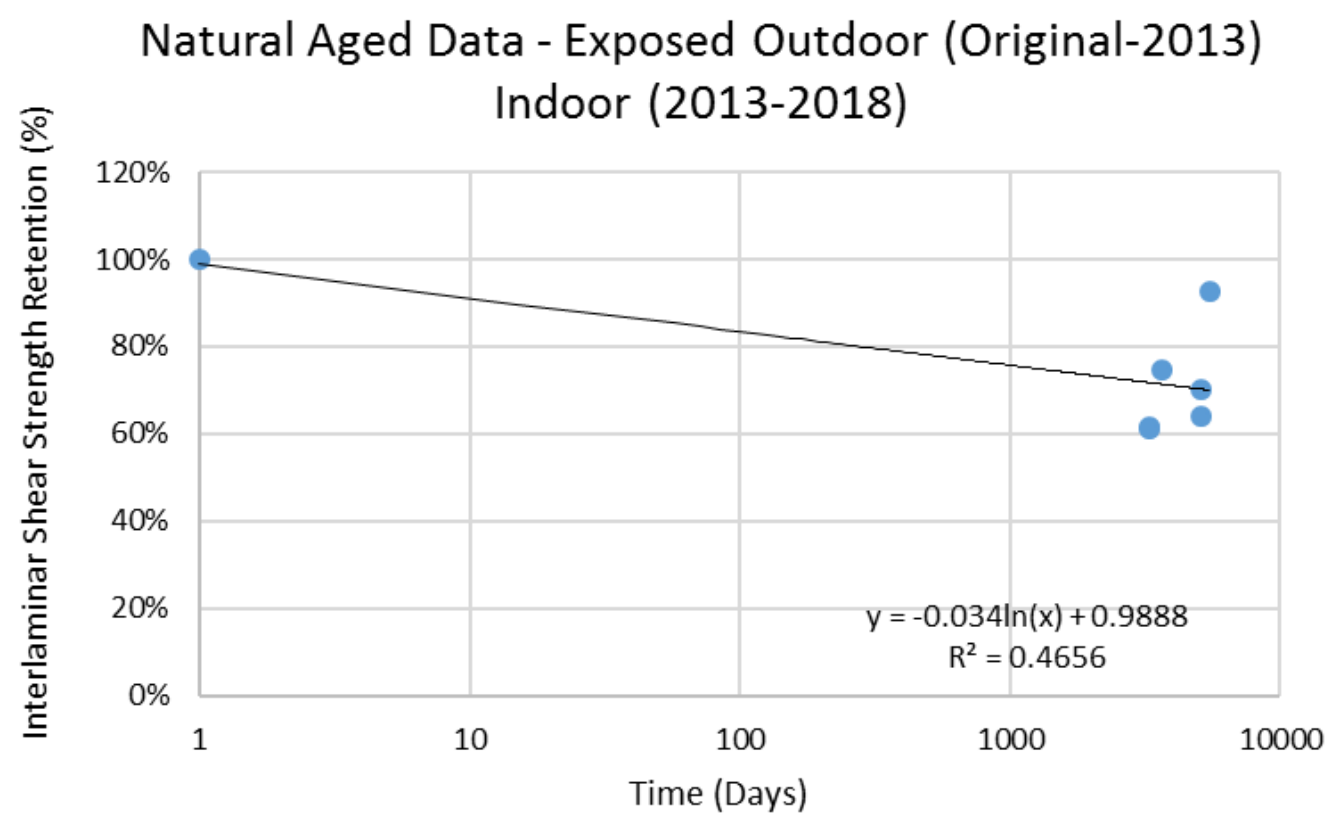

\section{B.2.3 Fully Exposed Environment}

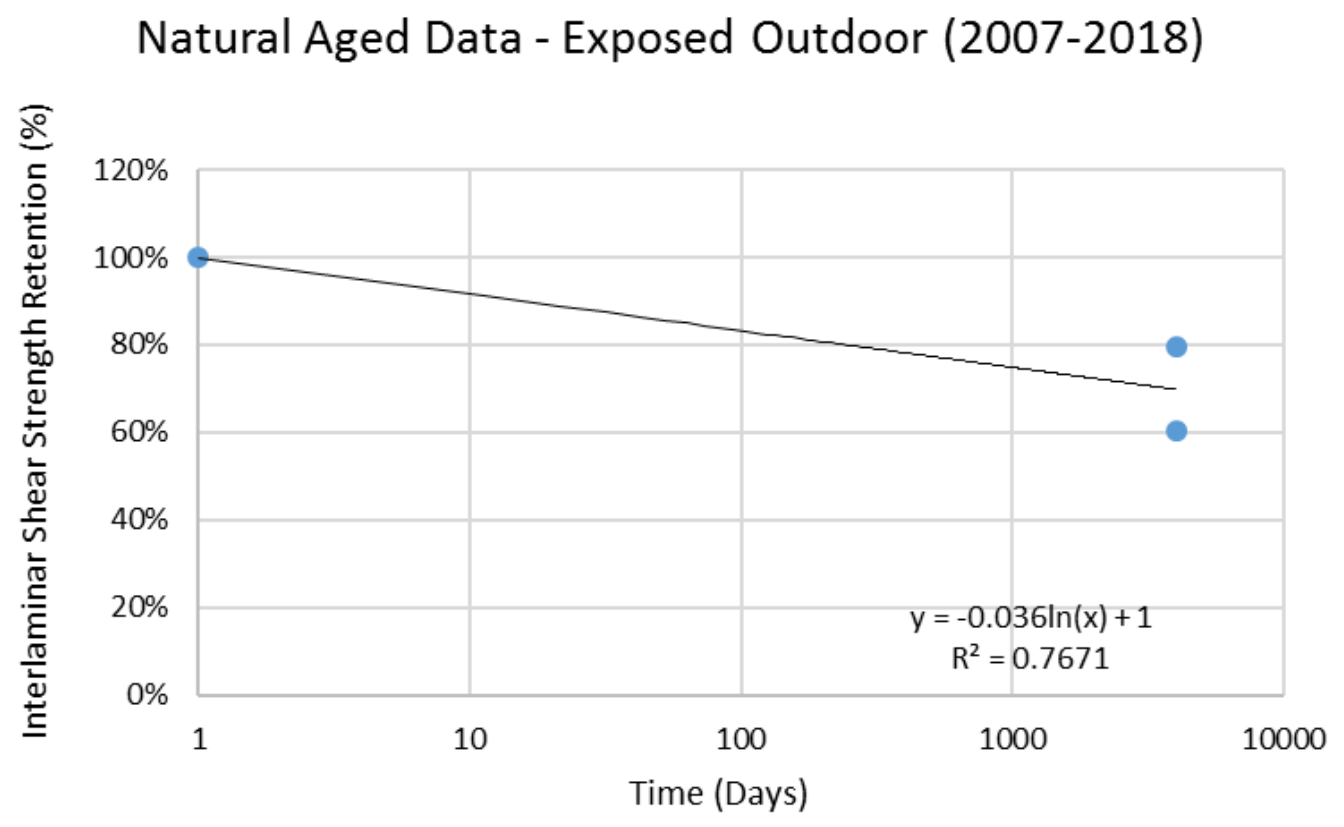




\section{Appendix C: Arrhenius Plots}

Shown below in this Appendix are the Arrhenius plots created from the retention percentages from plots and tables in Appendix A. These plots consists of data with the 1/4" thick composite plate.

\section{C.1 Arrhenius Plots Longitudinal (0-90 Days)}

\section{C.1.1 Neutral Environment}

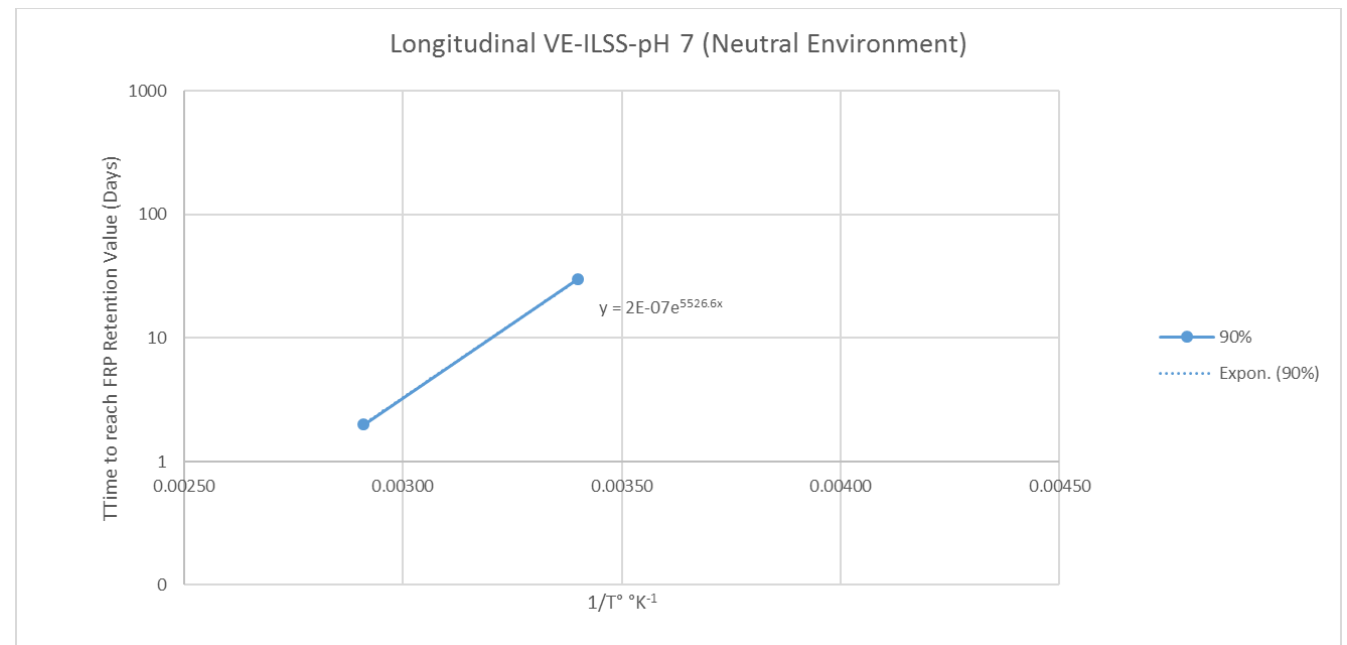

\section{C.1.2 Acidic Environment}

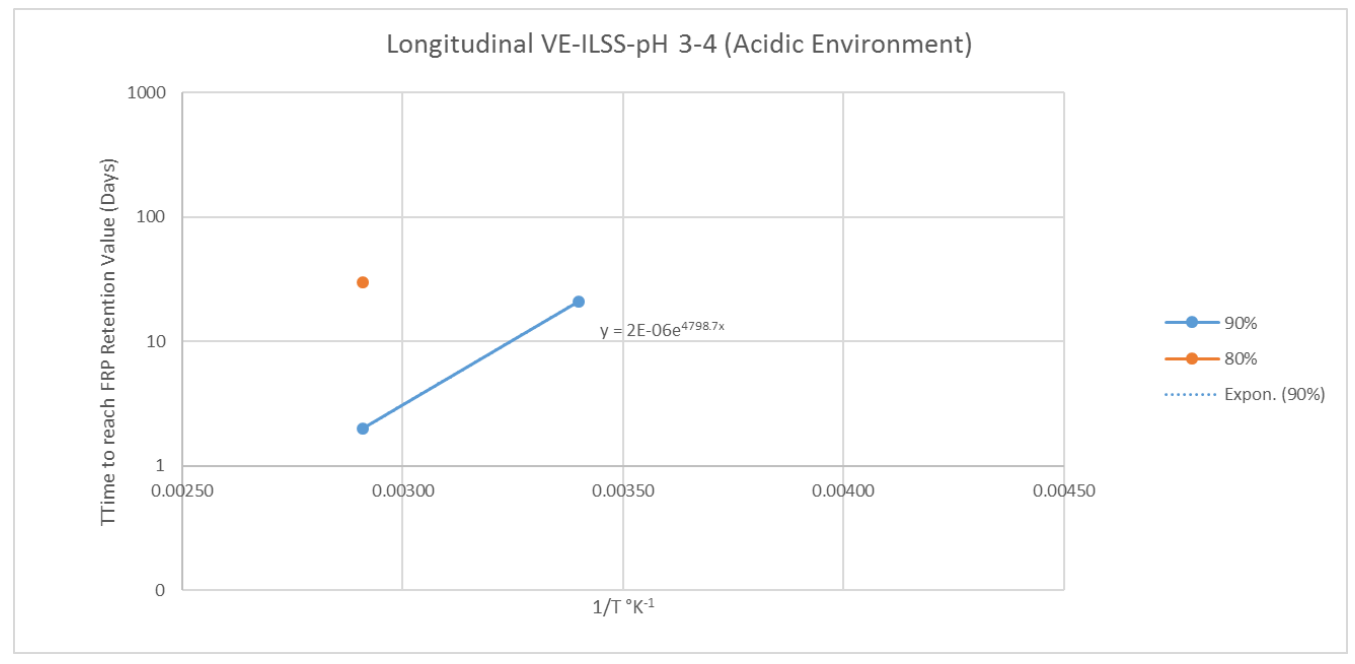




\section{C.1.3 Alkaline Environment}

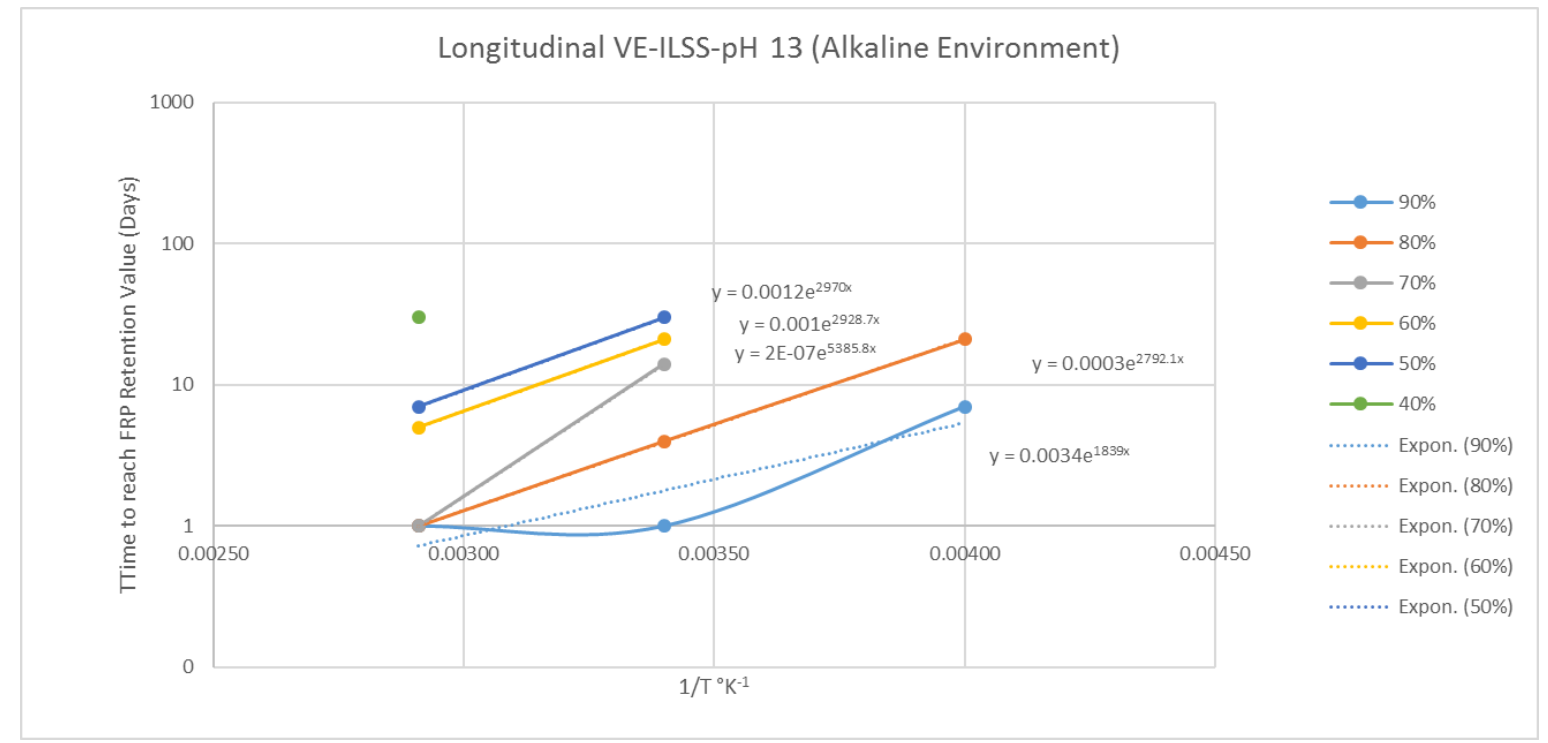

\section{C.2 Arrhenius Plots Transverse (0-90 Days)}

\section{C.2.1 Neutral Environment}

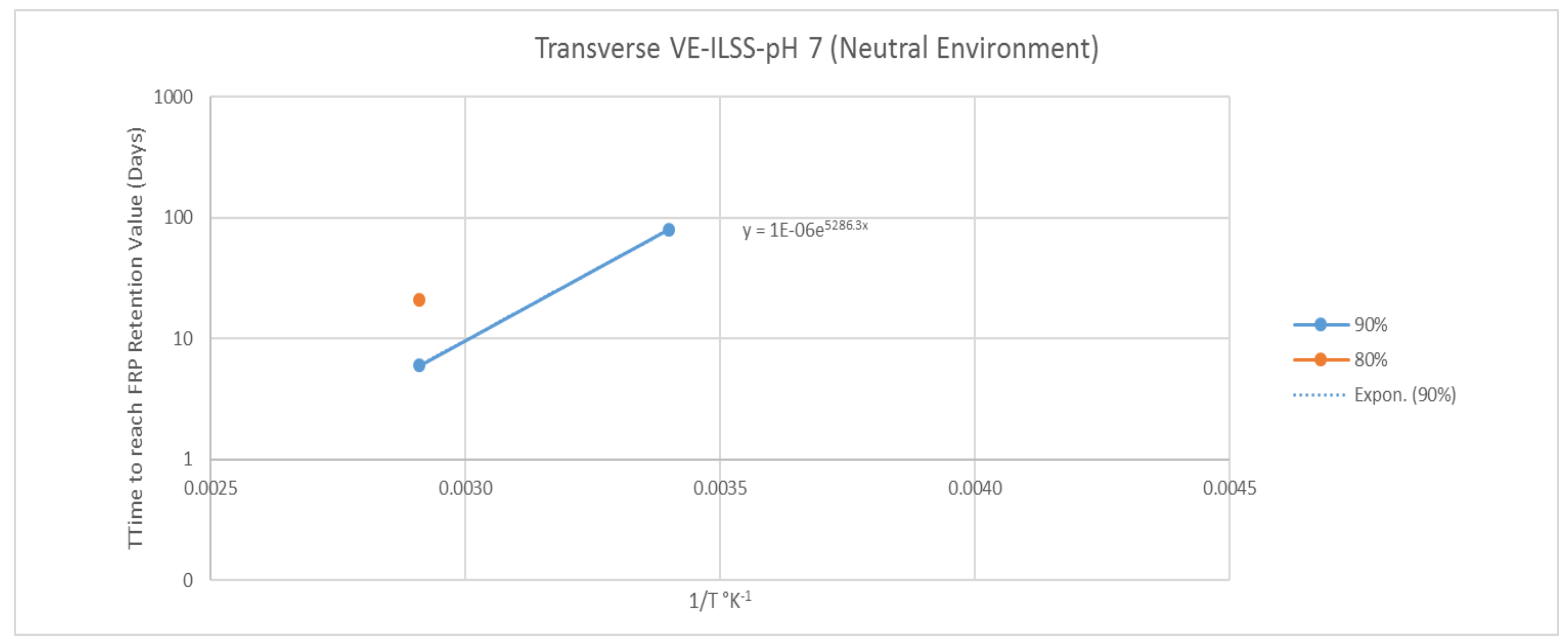




\section{C.2.2 Acidic Environment}

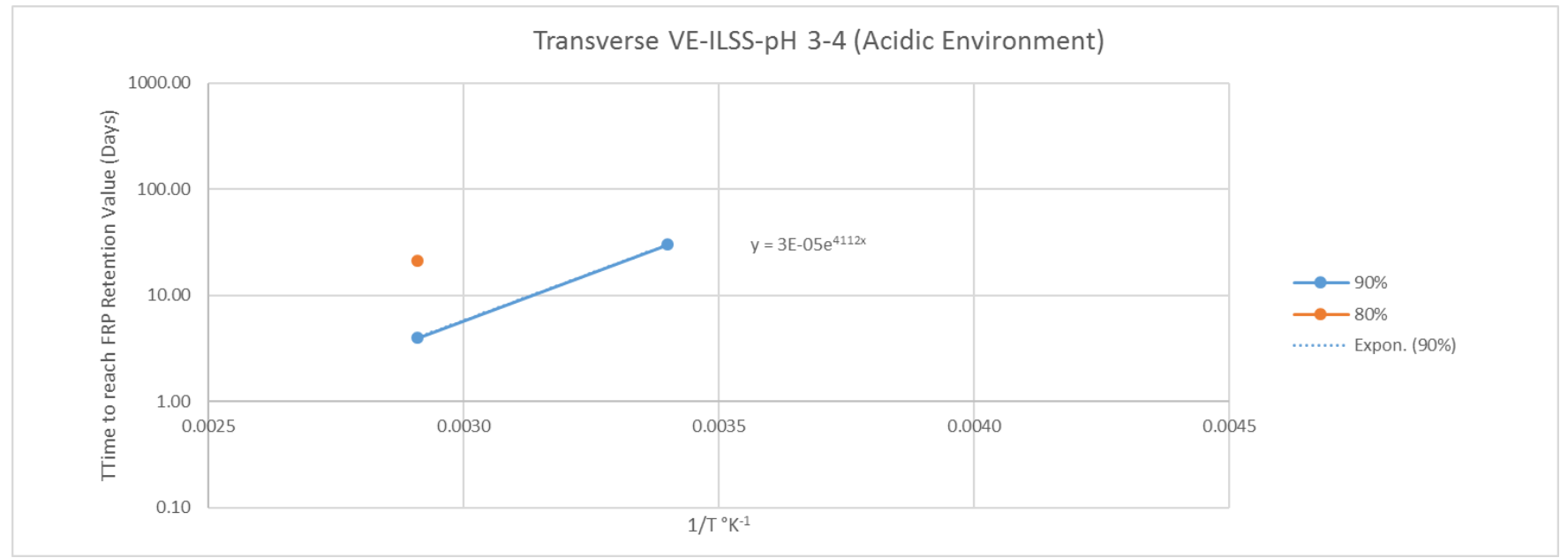

\section{C.2.3 Alkaline Environment}

Transverse VE-ILSS-pH 13 (Alkaline Environment)

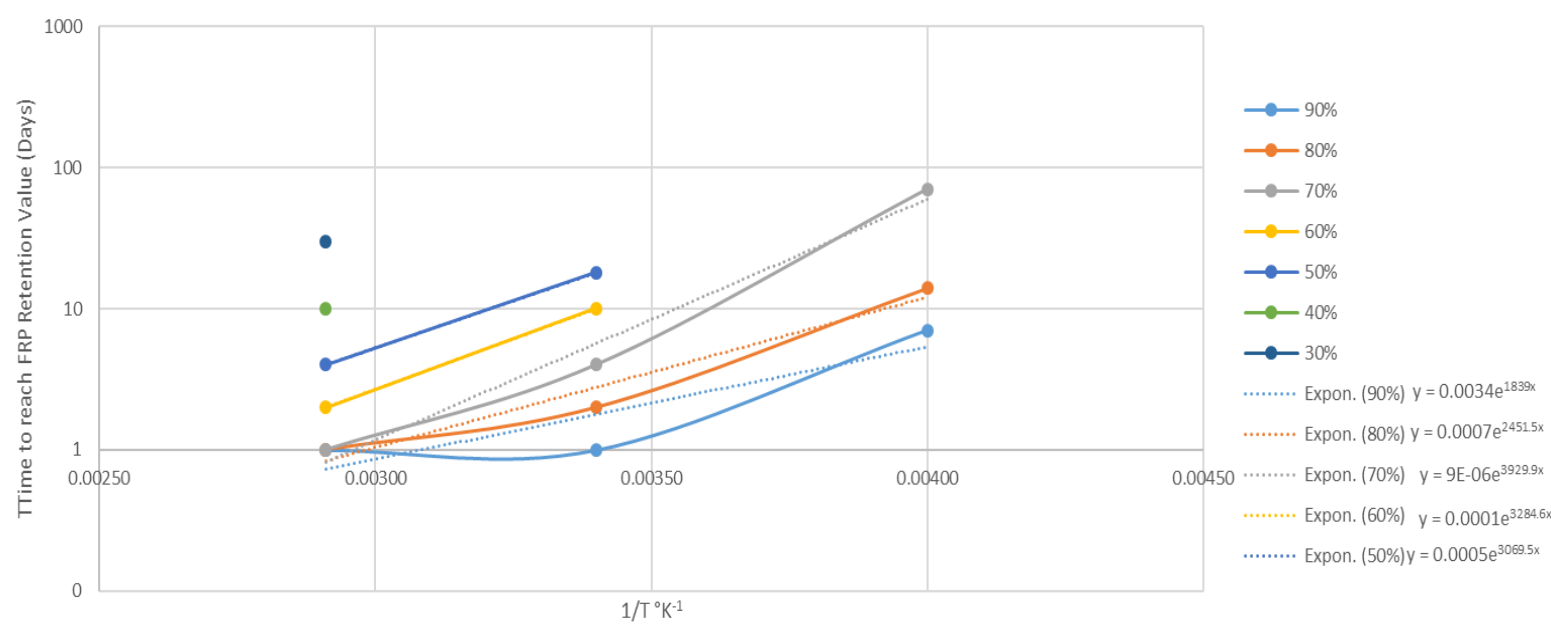




\section{C.3 Arrhenius Plots (150 + Days)}

\section{C.3.1 Neutral Environment}

Neutral Environment (150 + Days)
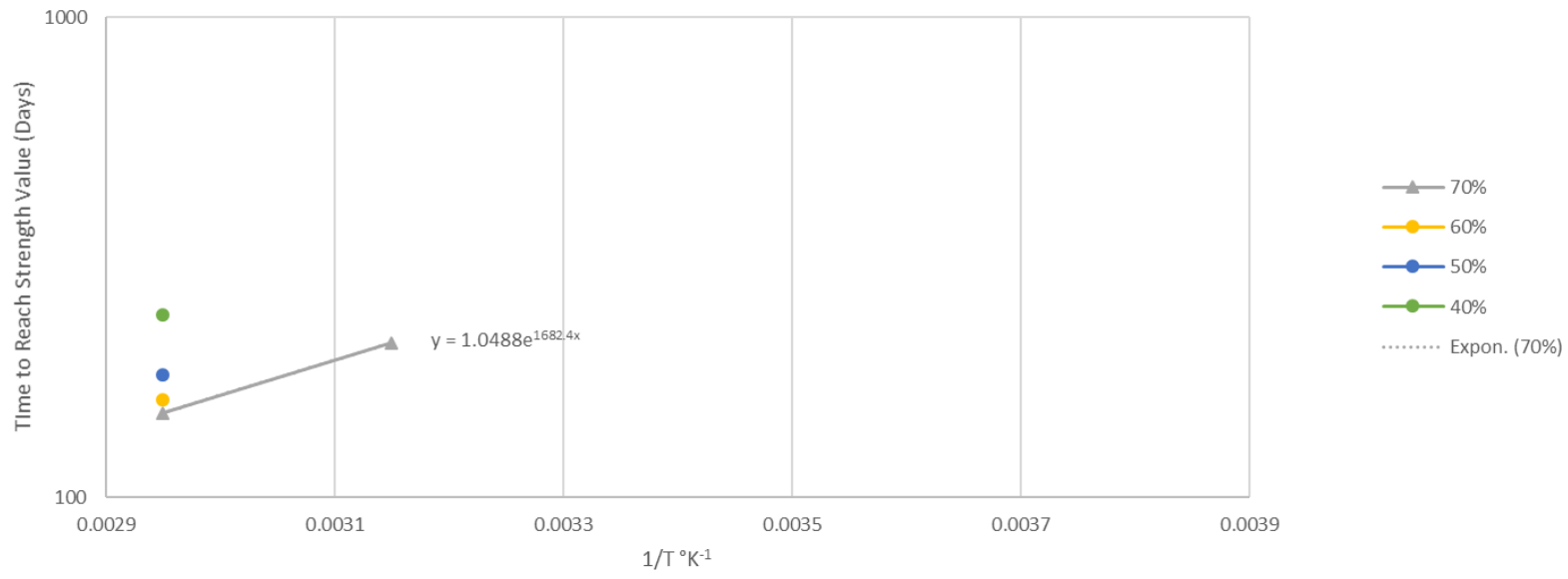

C.3.2 Acidic Environment

Acidic Environment (150 + Days)

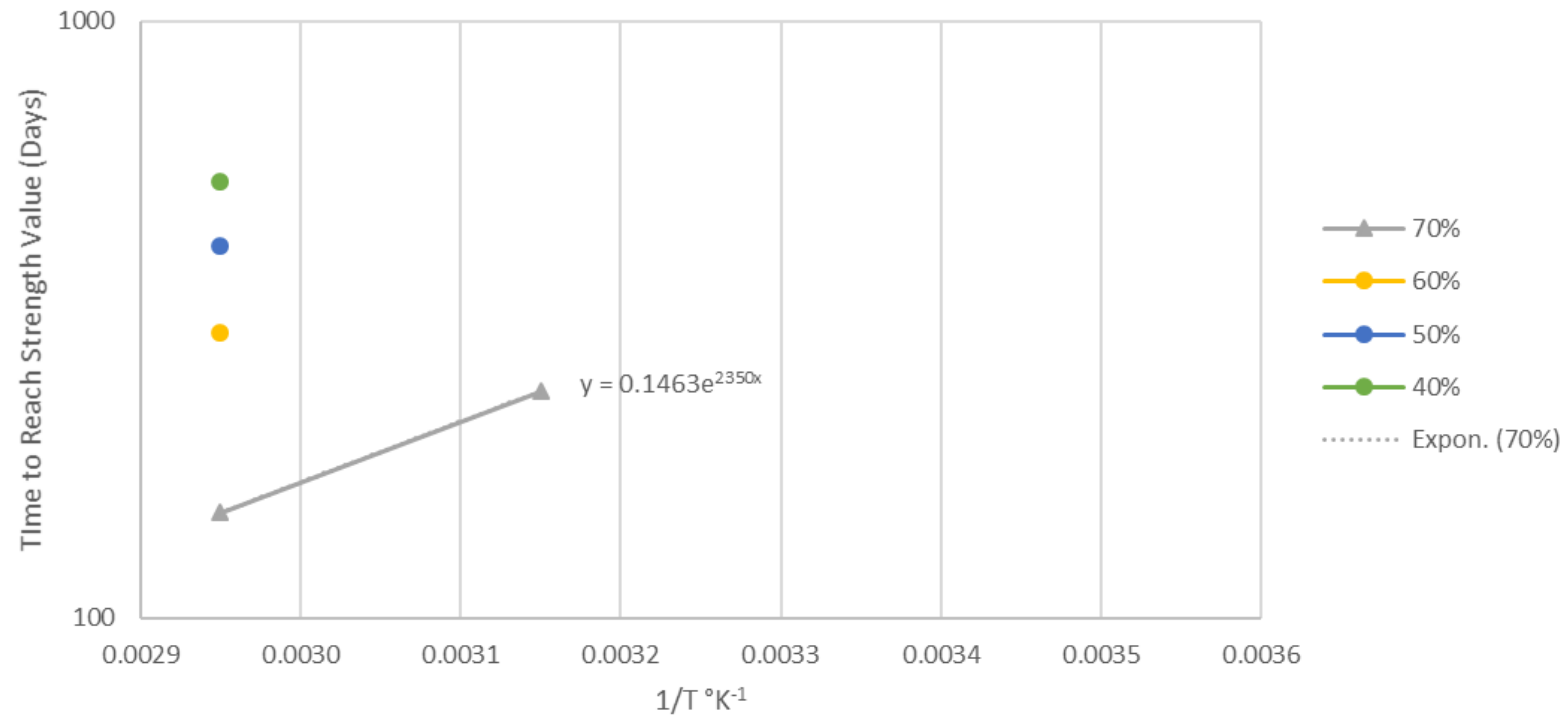




\section{C.3.3 Alkaline Environment}

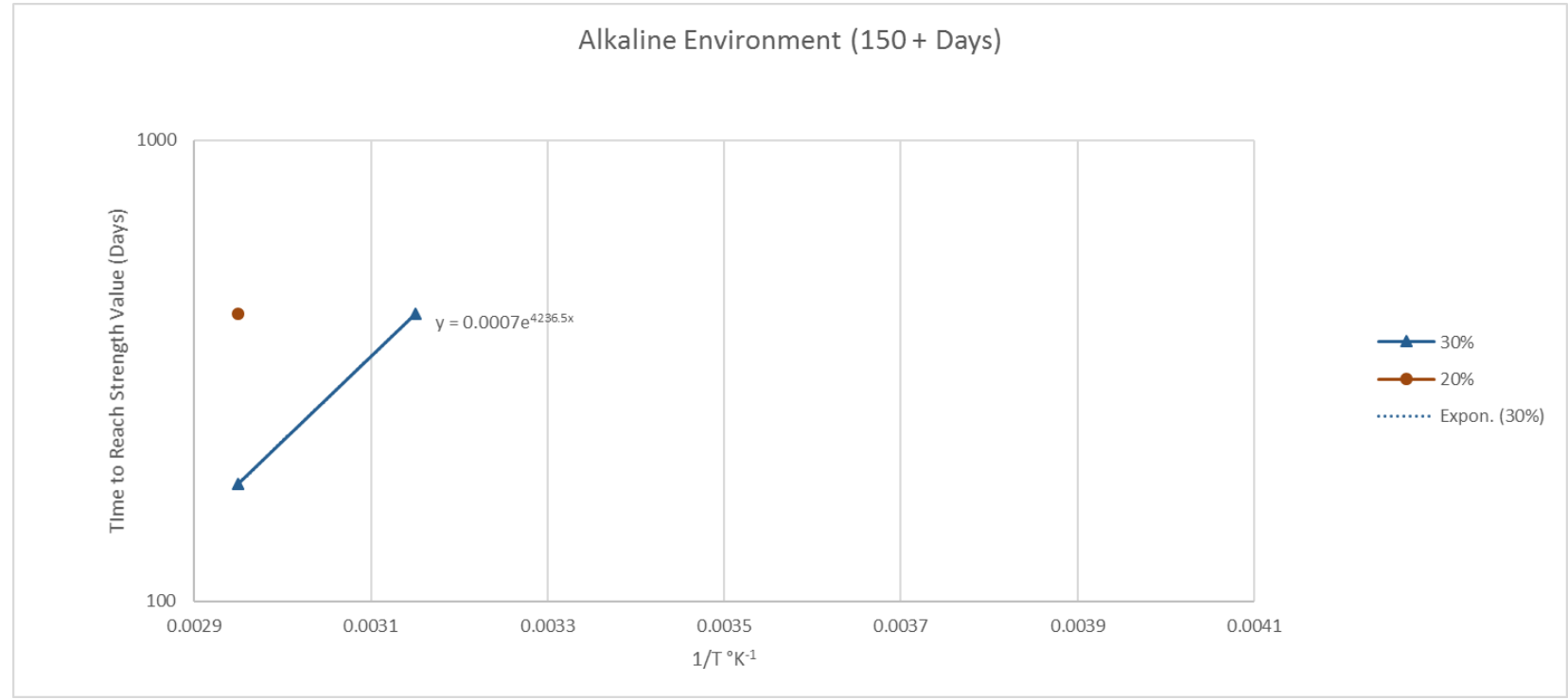




\section{Appendix D: Obtaining TSF}

Shown in this Appendix is tables and plots on obtaining Time Shift Factors (TSF) and how TSF changes with reference to temperature and $\mathrm{pH}$ environments. These figures consist of data with the $1 / 4$ " thick composite plate.

\section{D.1 Obtaining TSF Longitudinal (0-90 Days)}

\section{D.1.1 Neutral Environment}

\begin{tabular}{|c|c|c|c|c|c|c|c|}
\hline \multicolumn{4}{|c|}{ Longitudinal Neutral Environment } & \multicolumn{4}{|c|}{ Longitudinal Neutral Environment } \\
\hline & & \multicolumn{2}{|c|}{ Time Shift Factors } & \multirow{2}{*}{\multicolumn{2}{|c|}{$1 / \mathrm{T}^{\circ} \mathrm{K}^{-1}$}} & Degrada & Times (Days) \\
\hline \multicolumn{2}{|c|}{$1 / T^{\circ} K^{-1}$} & 000510 & 000305 & & & 0.00340 & 0.00295 \\
\hline \multirow{2}{*}{$\frac{\widehat{d}}{\frac{1}{n}}$} & TSF $90 \%$ & 1 & 7.5 & \multirow{2}{*}{ 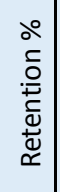 } & \multirow[t]{2}{*}{$90 \%$} & \multirow{2}{*}{30} & \multirow[t]{2}{*}{4} \\
\hline & TSF AVG. & 1 & 7.5 & & & & \\
\hline
\end{tabular}

\section{D.1.2 Acidic Environment}

\begin{tabular}{|c|c|c|c|c|c|c|c|}
\hline \multicolumn{4}{|c|}{ Longitudinal Acidic Environment } & \multicolumn{4}{|c|}{ Longitudinal Acidic Environment } \\
\hline & & \multicolumn{2}{|c|}{ Degradation Times (Days) } & & & \multicolumn{2}{|c|}{ Time Shift Factors } \\
\hline \multicolumn{2}{|c|}{$1 / \mathrm{T}^{\circ} \mathrm{K}^{-1}$} & 0.00340 & 0.00295 & \multicolumn{2}{|c|}{$1 / \mathrm{T}^{\circ} \mathrm{K}^{-1}$} & 0.00340 & 0.00295 \\
\hline \multirow{2}{*}{ 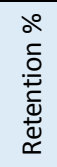 } & $90 \%$ & 16 & 2 & \multirow{2}{*}{$\frac{\widehat{a}}{\frac{\tilde{d}}{n}}$} & TSF $90 \%$ & 1 & 8.0 \\
\hline & $80 \%$ & $\mathrm{~N} / \mathrm{A}$ & 30 & & TSF AVG. & 1 & 8.0 \\
\hline
\end{tabular}

\section{D.1.3 Alkaline Environment}

\begin{tabular}{|c|c|c|c|c|c|c|c|c|}
\hline \multicolumn{5}{|c|}{ Longitudinal Alkaline Environment } & \multicolumn{4}{|c|}{ Longitudinal Alkaline Environment } \\
\hline & & \multicolumn{3}{|c|}{ Degradation Time (Days) } & & & \multicolumn{2}{|c|}{ Time Shift Factors } \\
\hline \multicolumn{2}{|c|}{$1 / \mathrm{T}^{\circ} \mathrm{K}^{-1}$} & 0.00400 & 0.00340 & 0.00295 & \multicolumn{2}{|c|}{$1 / \mathrm{T}^{\circ} \mathrm{K}^{-1}$} & 0.00340 & 0.00295 \\
\hline \multirow{6}{*}{ 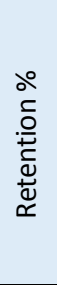 } & $90 \%$ & 7 & 1 & 1 & \multirow{6}{*}{$\frac{\widehat{\partial}}{\frac{u}{\hbar}}$} & TSF $90 \%$ & 1 & 1 \\
\hline & $\frac{80 \%}{70 \%}$ & $\frac{21}{N / A}$ & $\frac{4}{9}$ & 1 & & TSF $80 \%$ & 1 & 4 \\
\hline & $\begin{array}{l}70 \% \\
60 \%\end{array}$ & $\frac{N / A}{N / A}$ & $\frac{9}{21}$ & $\frac{1}{5}$ & & TSF $70 \%$ & 1 & 9 \\
\hline & $50 \%$ & N/A & 30 & 7 & & TSF $60 \%$ & 1 & 4.2 \\
\hline & $40 \%$ & N/A & N/A & 30 & & TSF $50 \%$ & 1 & 4.3 \\
\hline & $30 \%$ & N/A & N/A & $\mathrm{N} / \mathrm{A}$ & & TSF AVG. & 1 & 4.5 \\
\hline
\end{tabular}




\section{D.2 Obtaining TSF Transverse (0-90 Days)}

\section{D.2.1 Neutral Environment}

\begin{tabular}{|c|c|c|c|c|c|c|c|}
\hline \multicolumn{4}{|c|}{ Transverse Neutral Environment } & \multicolumn{4}{|c|}{ Transverse Neutral Environment } \\
\hline & & \multicolumn{2}{|c|}{ Degradation Times (Days) } & & & \multicolumn{2}{|c|}{ Time Shift Factors } \\
\hline \multicolumn{2}{|c|}{$1 / \mathrm{T}^{\circ} \mathrm{K}^{-1}$} & 0.00340 & 0.00295 & \multicolumn{2}{|c|}{$1 / \mathrm{T}^{\circ} \mathrm{K}^{-1}$} & 0.00340 & 0.00295 \\
\hline \multirow{2}{*}{ 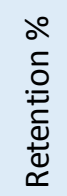 } & $90 \%$ & 75 & 7 & \multirow{2}{*}{$\frac{\widehat{a}}{\frac{u}{n}}$} & TSF 90\% & 1 & 10.7 \\
\hline & $80 \%$ & $\mathrm{~N} / \mathrm{A}$ & 30 & & TSF AVG. & 1 & 10.7 \\
\hline
\end{tabular}

\section{D.2.2 Acidic Environment}

\begin{tabular}{|c|c|c|c|}
\hline \multicolumn{4}{|c|}{ Transverse Acidic Environment } \\
\hline & & \multicolumn{2}{|c|}{ Degradation Times (Days) } \\
\hline \multicolumn{2}{|c|}{$1 / \mathrm{T}^{\circ} \mathrm{K}^{-1}$} & 0.00340 & 0.00295 \\
\hline \multirow{2}{*}{ 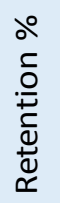 } & $90 \%$ & 21 & 4 \\
\hline & $80 \%$ & N/A & 21 \\
\hline
\end{tabular}

\begin{tabular}{|c|c|c|c|}
\hline \multicolumn{4}{|c|}{ Transverse Acidic Environment } \\
\hline & & Time Shi & t Factors \\
\hline \multicolumn{2}{|c|}{$1 / \mathrm{T}^{\circ} \mathrm{K}^{-1}$} & 0.00340 & 0.00295 \\
\hline \multirow{2}{*}{$\frac{\widehat{a}}{\frac{1}{n}}$} & TSF $90 \%$ & 1 & 5.3 \\
\hline & TSF AVG. & 1 & 5.3 \\
\hline
\end{tabular}

\section{D.2.3 Alkaline Environment}

\begin{tabular}{|c|c|c|c|c|c|c|c|c|}
\hline \multicolumn{5}{|c|}{ Transverse Alkaline Environment } & \multicolumn{4}{|c|}{ Transverse Alkaline Environment } \\
\hline & & \multicolumn{3}{|c|}{ Degradation Time (Days) } & & & \multicolumn{2}{|c|}{ Time Shift Factors } \\
\hline \multicolumn{2}{|c|}{$1 / \mathrm{T}^{\circ} \mathrm{K}^{-1}$} & 0.00400 & 0.00340 & 0.00295 & \multicolumn{2}{|c|}{$1 / \mathrm{T}^{\circ} \mathrm{K}^{-1}$} & 0.00340 & 0.00295 \\
\hline \multirow{6}{*}{ 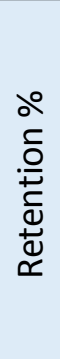 } & $90 \%$ & 7 & 1 & 1 & \multirow{6}{*}{$\frac{\widehat{a}}{\frac{\dot{w}}{\mathfrak{n}}}$} & TSF $90 \%$ & 1 & 1 \\
\hline & $80 \%$ & 14 & $\frac{1}{1}$ & $\frac{1}{1}$ & & TSF $80 \%$ & 1 & 1 \\
\hline & $\begin{array}{l}70 \% \\
60 \%\end{array}$ & $\frac{90}{N / A}$ & $\frac{4}{14}$ & $\frac{1}{2}$ & & TSF $70 \%$ & 1 & 4 \\
\hline & $50 \%$ & N/A & $\frac{14}{17}$ & 3 & & TSF $60 \%$ & 1 & 7 \\
\hline & $40 \%$ & $\mathrm{~N} / \mathrm{A}$ & $\mathrm{N} / \mathrm{A}$ & 14 & & TSF $50 \%$ & 1 & 5.7 \\
\hline & $30 \%$ & $\mathrm{~N} / \mathrm{A}$ & $\mathrm{N} / \mathrm{A}$ & 30 & & TSF AVG. & 1 & 3.7 \\
\hline
\end{tabular}




\section{D.3 Obtaining TSF (150 + Days)}

\section{D.3.1 Neutral Environment}

\begin{tabular}{|c|c|c|c|c|c|c|c|c|c|c|}
\hline \multicolumn{6}{|c|}{ Neutral Environment (150 + Days) } & \multicolumn{5}{|c|}{ Neutral Environment (150+ Days) } \\
\hline & & \multicolumn{4}{|c|}{ Degradation Times (Days) } & & & \multicolumn{3}{|c|}{ Time Shift Factors } \\
\hline \multicolumn{2}{|c|}{$1 / \mathrm{T}^{\circ} \mathrm{K}^{-1}$} & 0.00400 & 0.00340 & 0.00310 & 0.00295 & \multicolumn{2}{|c|}{$1 / \mathrm{T}^{\circ} \mathrm{K}^{-1}$} & 0.00340 & 0.00310 & 0.00295 \\
\hline \multirow{6}{*}{ 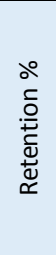 } & $90 \%$ & 360 & 175 & 100 & 6 & \multirow{6}{*}{$\frac{\widehat{d}}{\stackrel{\breve{s}}{\curvearrowleft}}$} & & & & \\
\hline & $80 \%$ & $\mathrm{~N} / \mathrm{A}$ & 420 & 150 & 15 & & TSF 90\% & 1 & 1.75 & 29.1 \\
\hline & $70 \%$ & N/A & N/A & 210 & 150 & & & & & \\
\hline & $60 \%$ & $\mathrm{~N} / \mathrm{A}$ & N/A & $\mathrm{N} / \mathrm{A}$ & 175 & & TSF $80 \%$ & 1 & 2.8 & 28 \\
\hline & $50 \%$ & $\mathrm{~N} / \mathrm{A}$ & $\mathrm{N} / \mathrm{A}$ & $\mathrm{N} / \mathrm{A}$ & 180 & & & & & 20 \\
\hline & $40 \%$ & $\mathrm{~N} / \mathrm{A}$ & $\mathrm{N} / \mathrm{A}$ & $\mathrm{N} / \mathrm{A}$ & 240 & & TSF AVG. & 1 & 2.3 & 28.6 \\
\hline
\end{tabular}

\section{D.3.2 Acidic Environment}

\begin{tabular}{|c|c|c|c|c|}
\hline \multicolumn{5}{|c|}{ Acidic Environment (150 + Days) } \\
\hline & & \multicolumn{3}{|c|}{ Degradation Times (Days) } \\
\hline \multicolumn{2}{|c|}{$1 / \mathrm{T}^{\circ} \mathrm{K}^{-1}$} & 0.00340 & 0.00310 & 0.00295 \\
\hline \multirow{4}{*}{ 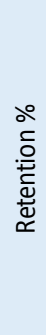 } & $90 \%$ & 18 & 10 & 3 \\
\hline & $80 \%$ & 420 & 150 & 25 \\
\hline & $70 \%$ & N/A & 420 & 150 \\
\hline & $60 \%$ & N/A & $\mathrm{N} / \mathrm{A}$ & 420 \\
\hline
\end{tabular}

\begin{tabular}{|c|c|c|c|c|}
\hline \multicolumn{5}{|c|}{ Acidic Environment (150 + Days) } \\
\hline & & \multicolumn{3}{|c|}{ Time Shift Factors } \\
\hline \multicolumn{2}{|c|}{$1 / \mathrm{T}^{\circ} \mathrm{K}^{-1}$} & 0.00340 & 0.00310 & 0.00295 \\
\hline \multirow{3}{*}{$\frac{\widehat{d}}{\frac{u}{n}}$} & TSF $90 \%$ & 1 & 1.8 & 6 \\
\hline & TSF $80 \%$ & 1 & 2.8 & 16.8 \\
\hline & TSF AVG. & 1 & 2.3 & 11.4 \\
\hline
\end{tabular}

\section{D.3.3 Alkaline Environment}

\begin{tabular}{|c|c|c|c|c|c|c|c|c|c|}
\hline \multicolumn{5}{|c|}{ Alkaline Environment (150 + Days) } & \multicolumn{5}{|c|}{ Alkaline Environment (150 + Days) } \\
\hline & & \multicolumn{3}{|c|}{ Degradation Time (Days) } & & & \multicolumn{3}{|c|}{ Time Shift Factors } \\
\hline \multicolumn{2}{|c|}{$1 / \mathrm{T}^{\circ} \mathrm{K}^{-1}$} & 0.00340 & 0.00310 & 0.00295 & \multicolumn{2}{|c|}{$1 / \mathrm{T}^{\circ} \mathrm{K}^{-1}$} & 0.00340 & 0.00310 & 0.00295 \\
\hline \multirow{7}{*}{ 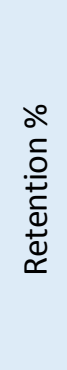 } & $90 \%$ & 1 & $\mathrm{~N} / \mathrm{A}$ & 1 & \multirow{7}{*}{$\frac{\widehat{d}}{\frac{u}{\curvearrowleft}}$} & TSF $90 \%$ & 1 & $\mathrm{~N} / \mathrm{A}$ & 1 \\
\hline & $80 \%$ & 4 & $\mathrm{~N} / \mathrm{A}$ & 1 & & TSF $80 \%$ & 1 & $\mathrm{~N} / \mathrm{A}$ & 4 \\
\hline & $\frac{10 \%}{60 \%}$ & $\frac{9}{21}$ & $\frac{N / A}{N / A}$ & $\frac{1}{5}$ & & TSF $70 \%$ & 1 & $\mathrm{~N} / \mathrm{A}$ & 9 \\
\hline & $50 \%$ & 180 & $\mathrm{~N} / \mathrm{A}$ & 7 & & TSF $60 \%$ & 1 & $\mathrm{~N} / \mathrm{A}$ & 4.2 \\
\hline & $40 \%$ & 420 & 240 & 30 & & TSF $50 \%$ & 1 & $\mathrm{~N} / \mathrm{A}$ & 25.7 \\
\hline & $30 \%$ & $\mathrm{~N} / \mathrm{A}$ & 420 & 180 & & TSF $40 \%$ & 1 & 1.8 & 14 \\
\hline & $20 \%$ & $\mathrm{~N} / \mathrm{A}$ & $\mathrm{N} / \mathrm{A}$ & 420 & & TSF AVG. & 1 & 1.8 & 9.7 \\
\hline
\end{tabular}




\section{Appendix E: Time Shift Factor vs. Temperature Relationships}

Time shift factors (TSF) change with respect to temperature and $\mathrm{pH}$ environment. Therefore, to be able to get these factors with respect to different temperatures, TSF can be extrapolated and graphed to obtain these. The plots shown below present the TSF with varying temperatures and $\mathrm{pH}$ environments. These plots consists of data with the $1 / 4$ " thick composite plate.

\section{E.1 Longitudinal TSF vs. Temperature (0-90 Days)}

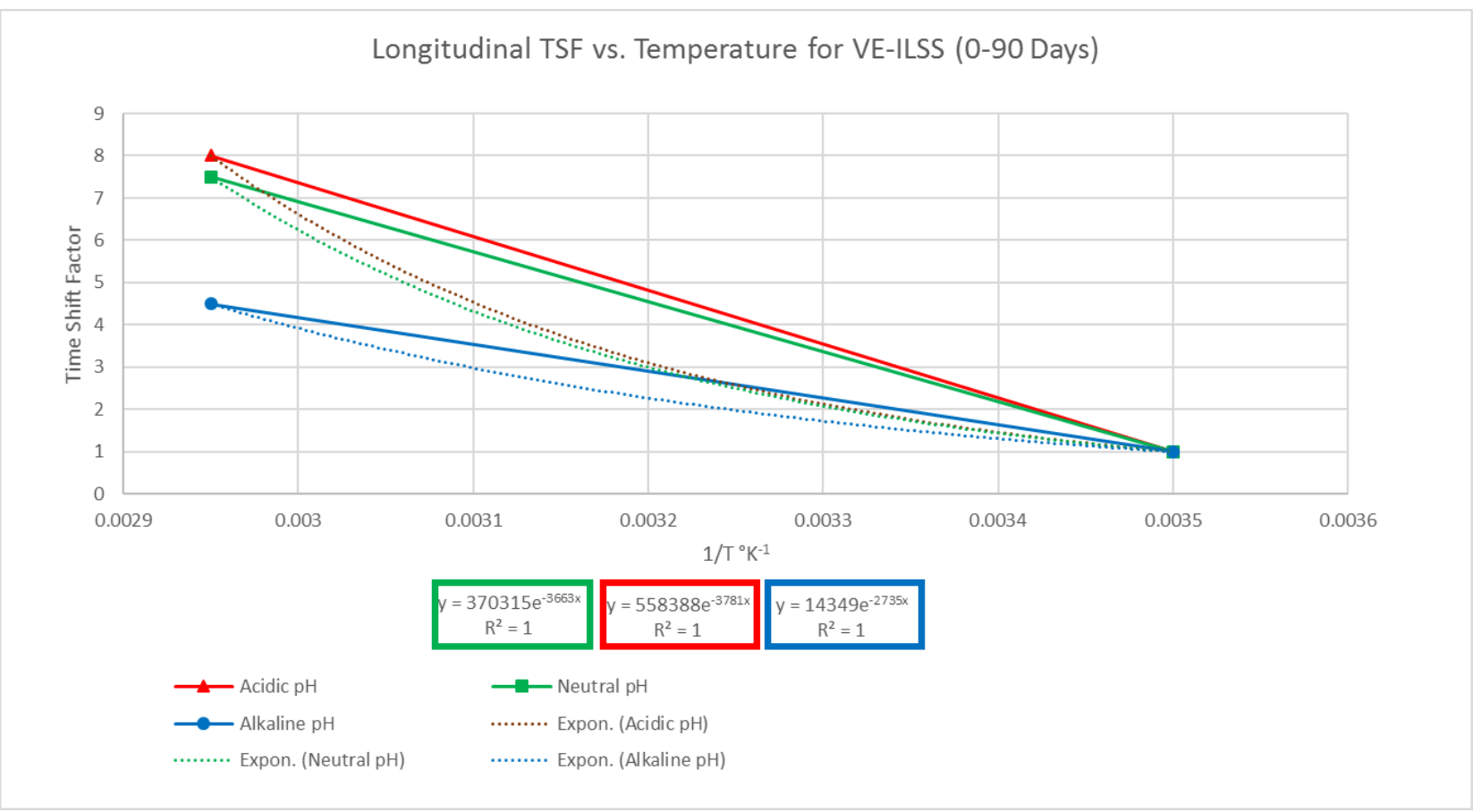




\section{E.2 Transverse TSF vs. Temperature (0-90 Days)}

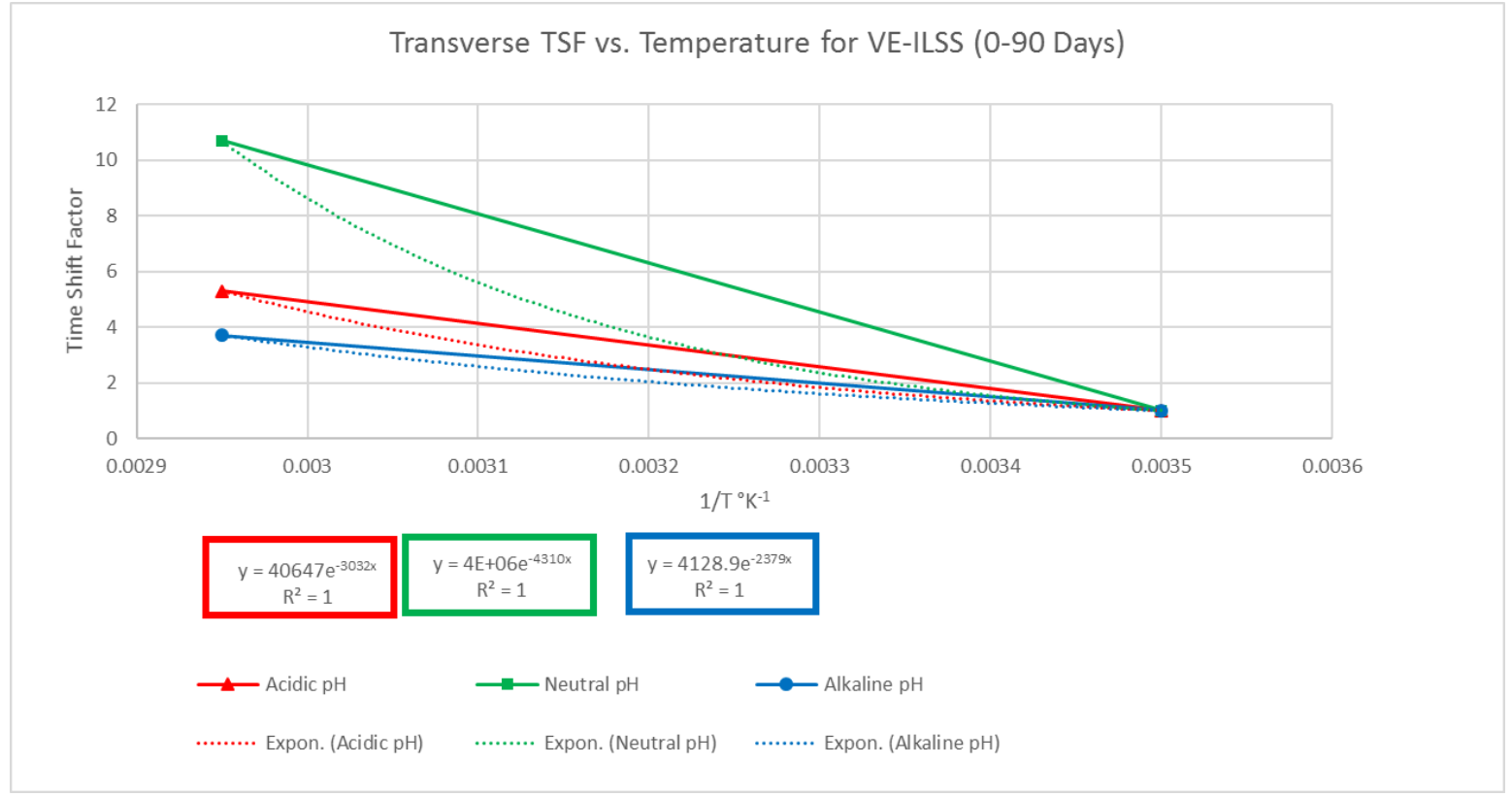

E.3 TSF vs. Temperature (150 + Days)

TSF vs. Temperature for VE-ILSS (150 + Days)

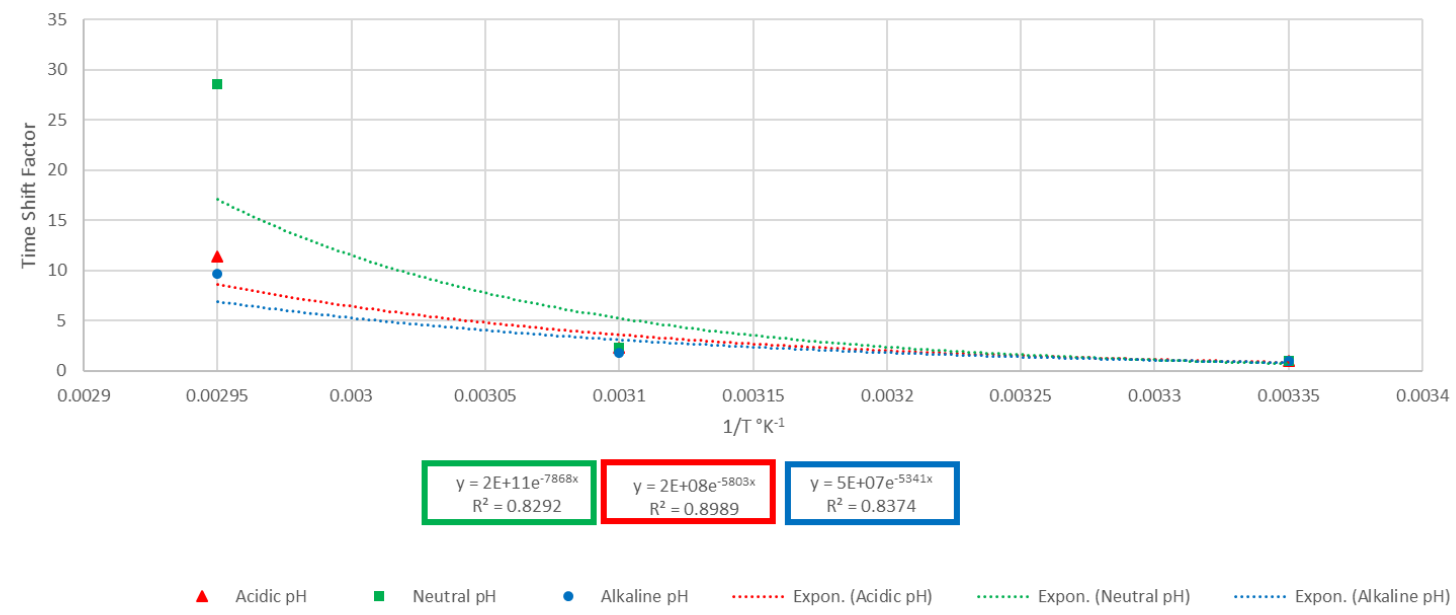




\section{Appendix F: Accelerated Shifted Data for Long-Term Degradation}

\section{Trends}

Once the Time Shift Factors are obtained, degradation curves are extrapolated from the accelerated aging data. The plots for the given $\mathrm{pH}$ environments are shown below. These plots consists of data with the $1 / 4$ " thick composite plate.

\section{F.1 Longitudinal Degradation Plots (0-90 Days)}

\section{F.1.1 Neutral Environment}

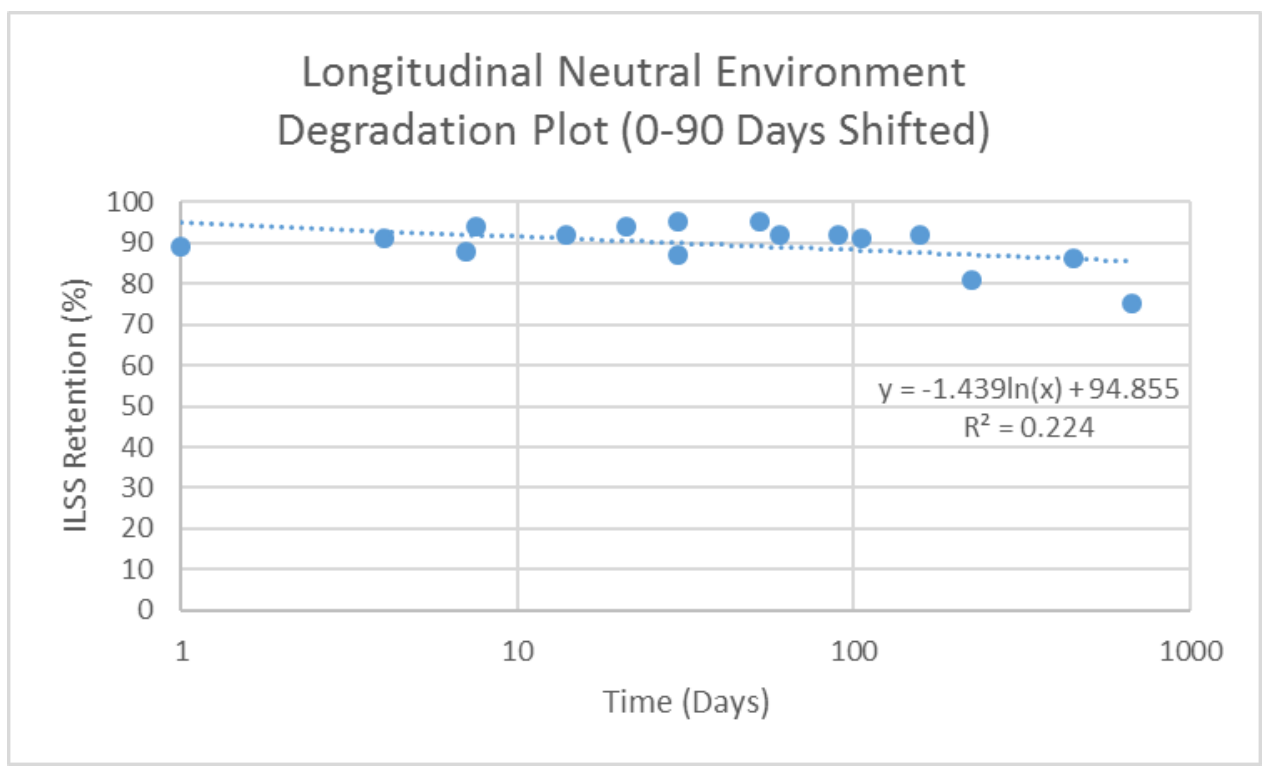




\section{F.1.2 Acidic Environment}

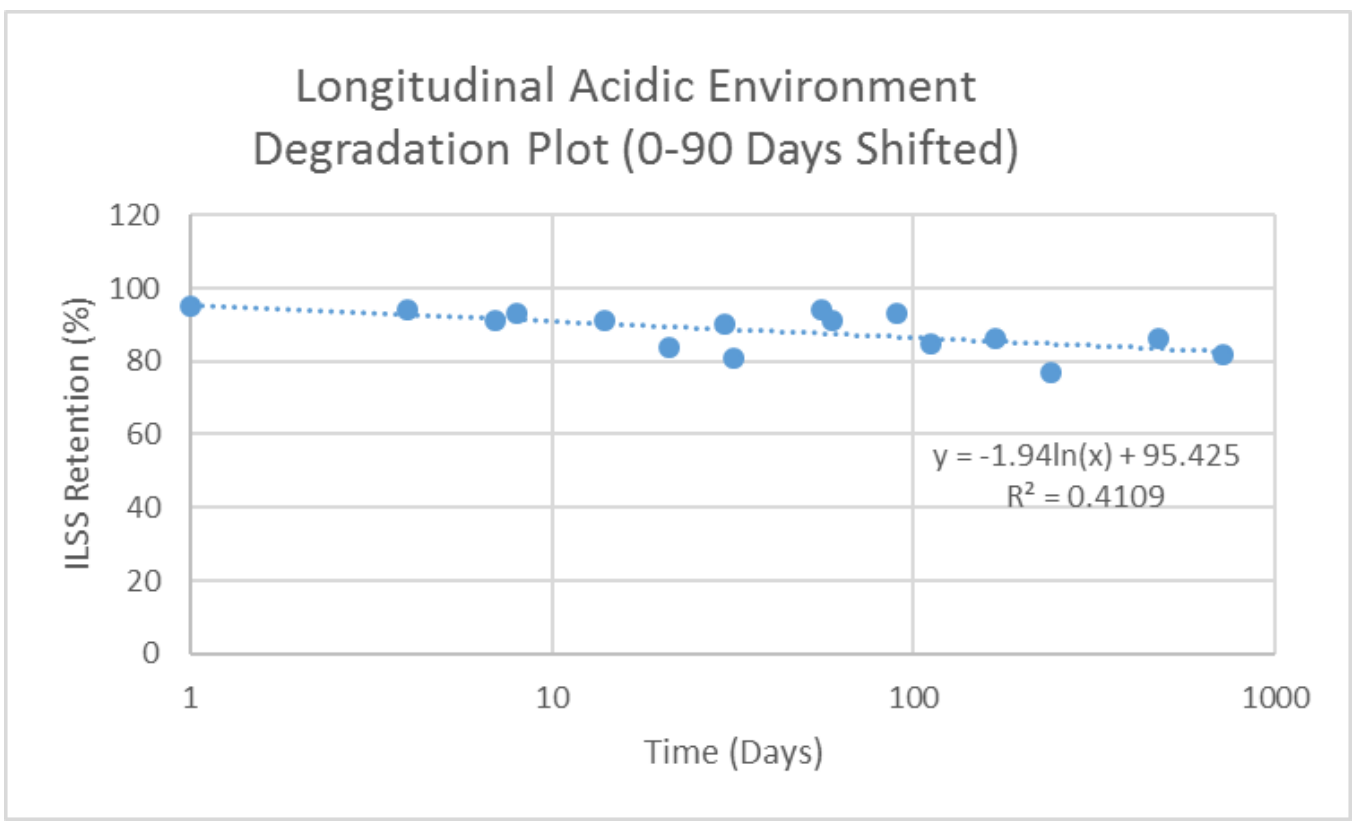

\section{F.1.3 Alkaline Environment}

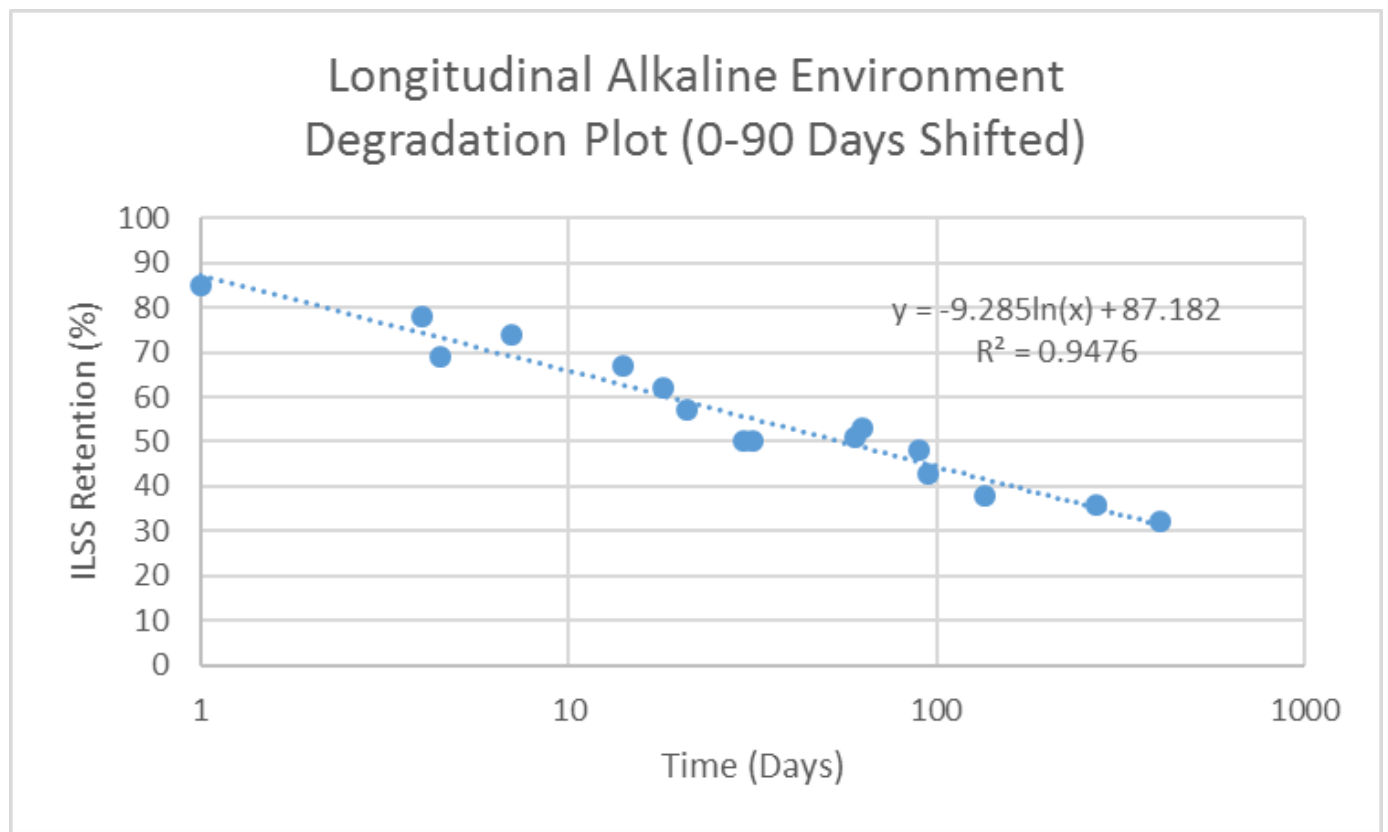


F.2 Transverse Degradation Plots (0-90 Days)

\section{F.2.1 Neutral Environment}

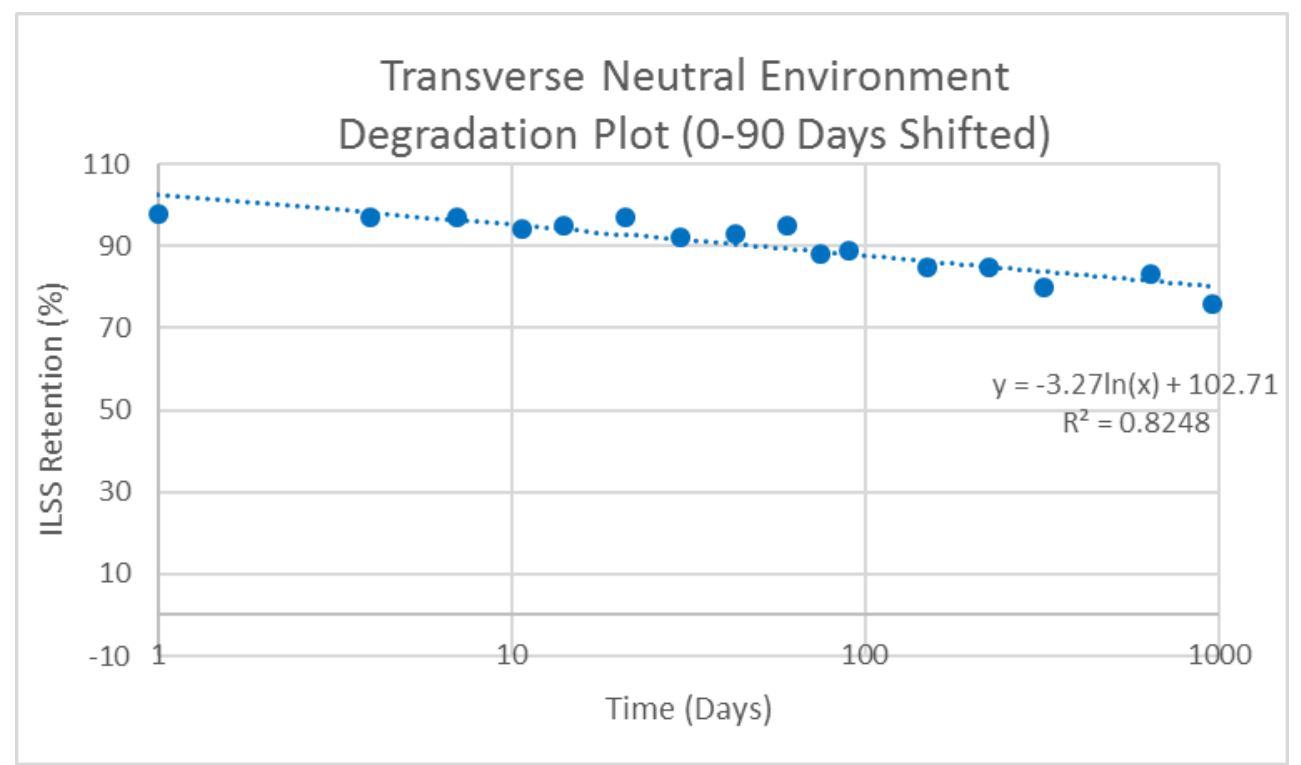

\section{F.2.2 Acidic Environment}

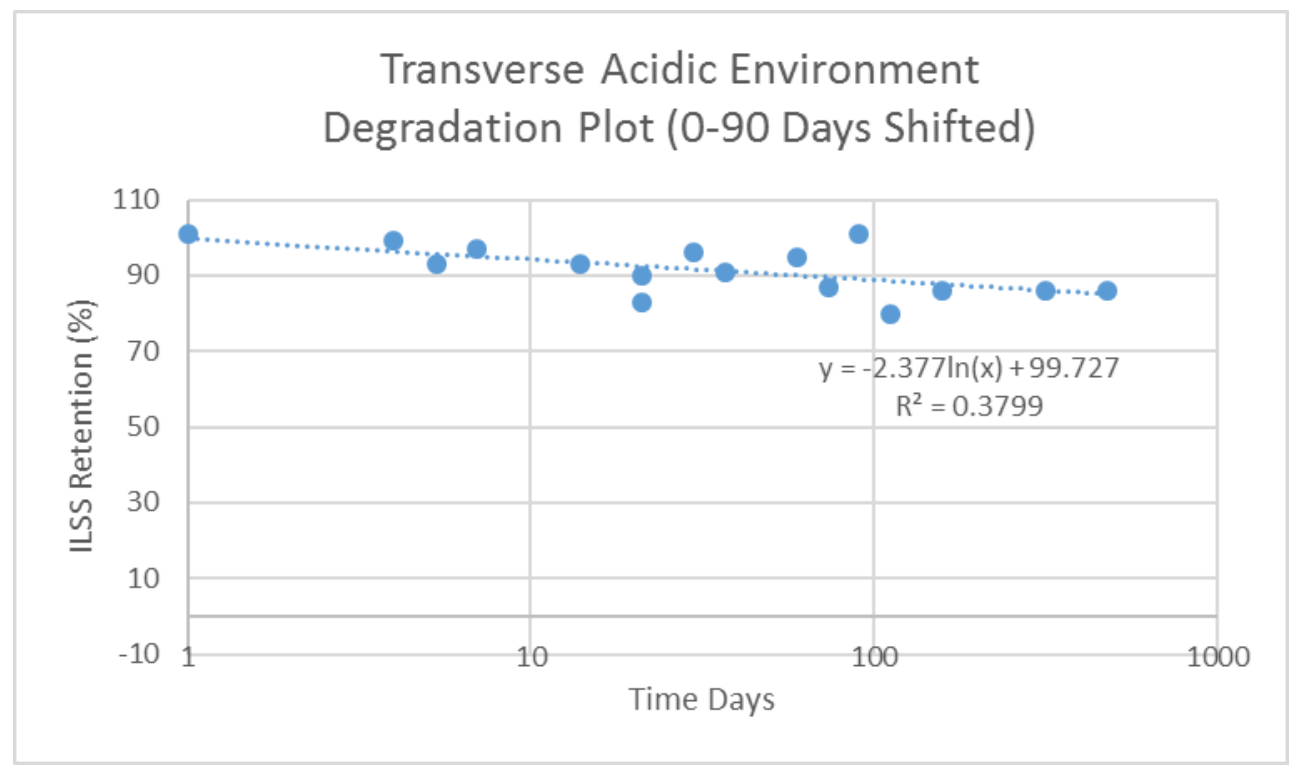


F.2.3 Alkaline Environment

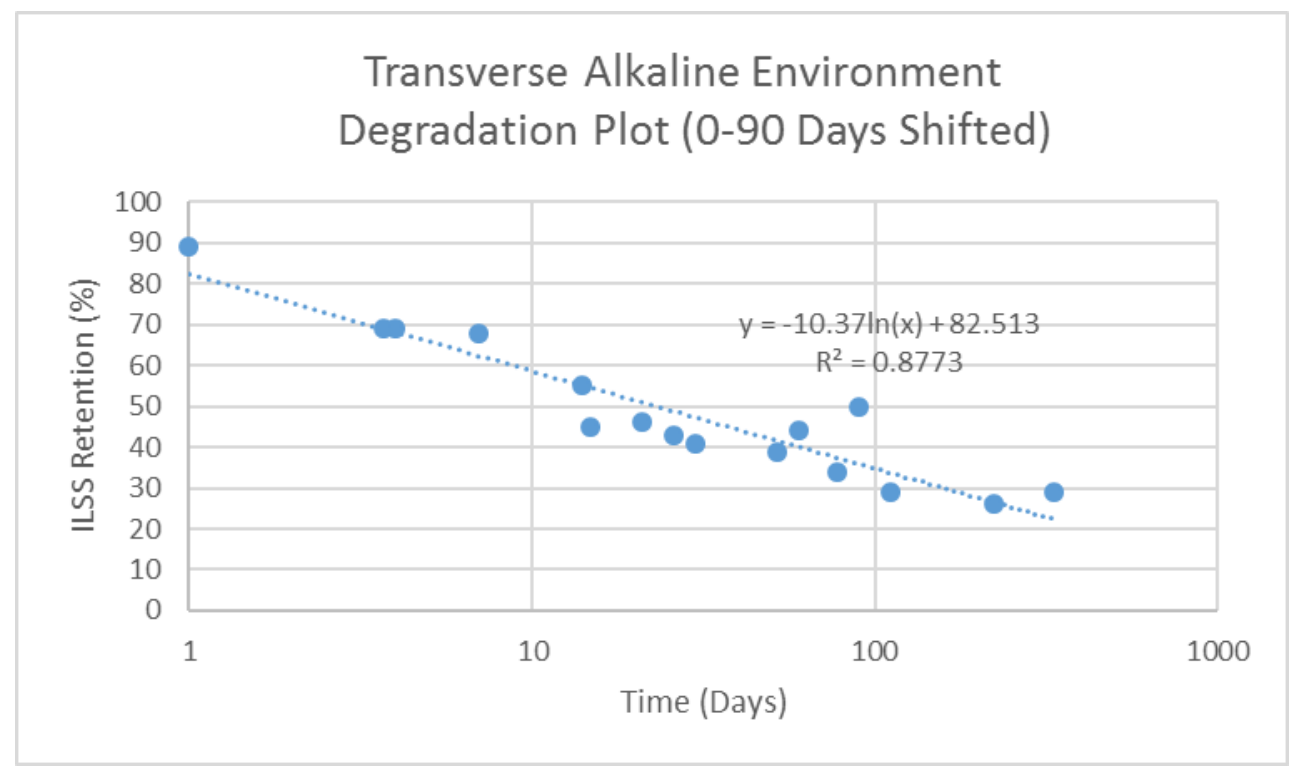

\section{F.3 Degradation Plots (150 + Days)}

\section{F.3.1 Neutral Environment}

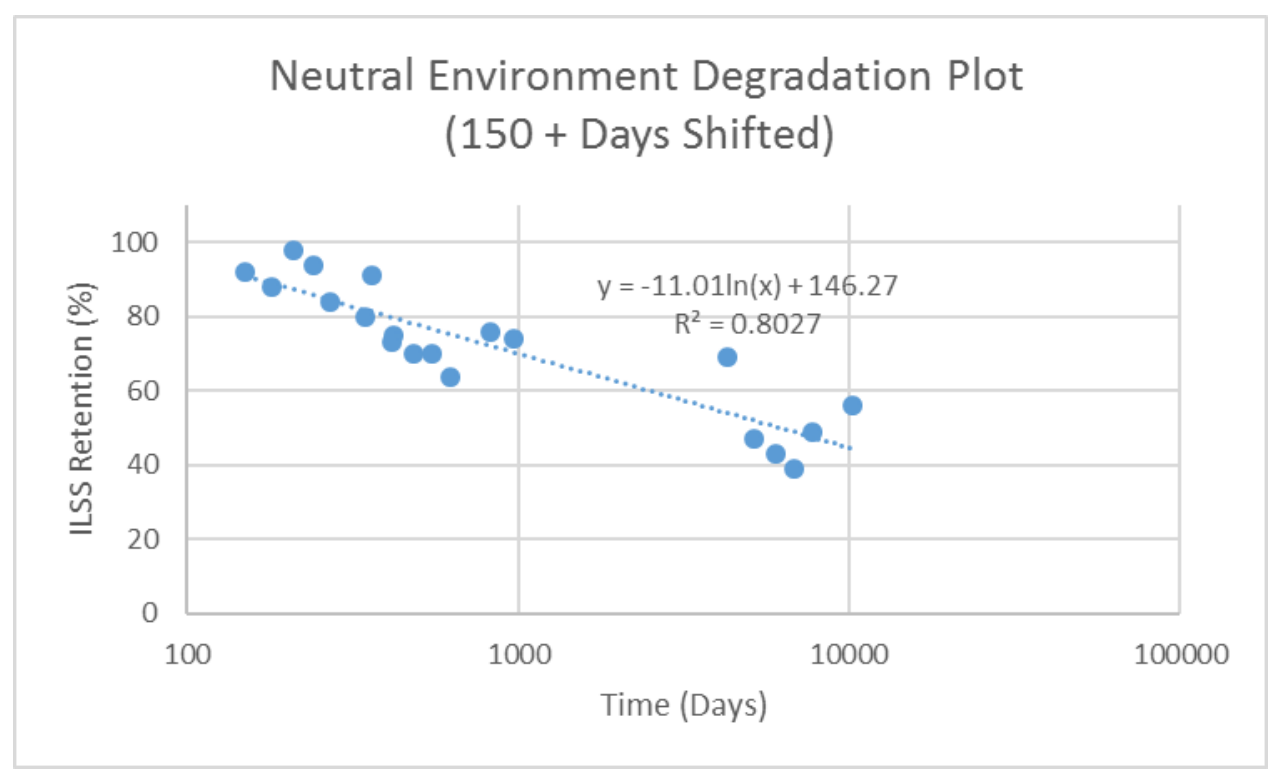




\section{F.3.2 Acidic Environment}

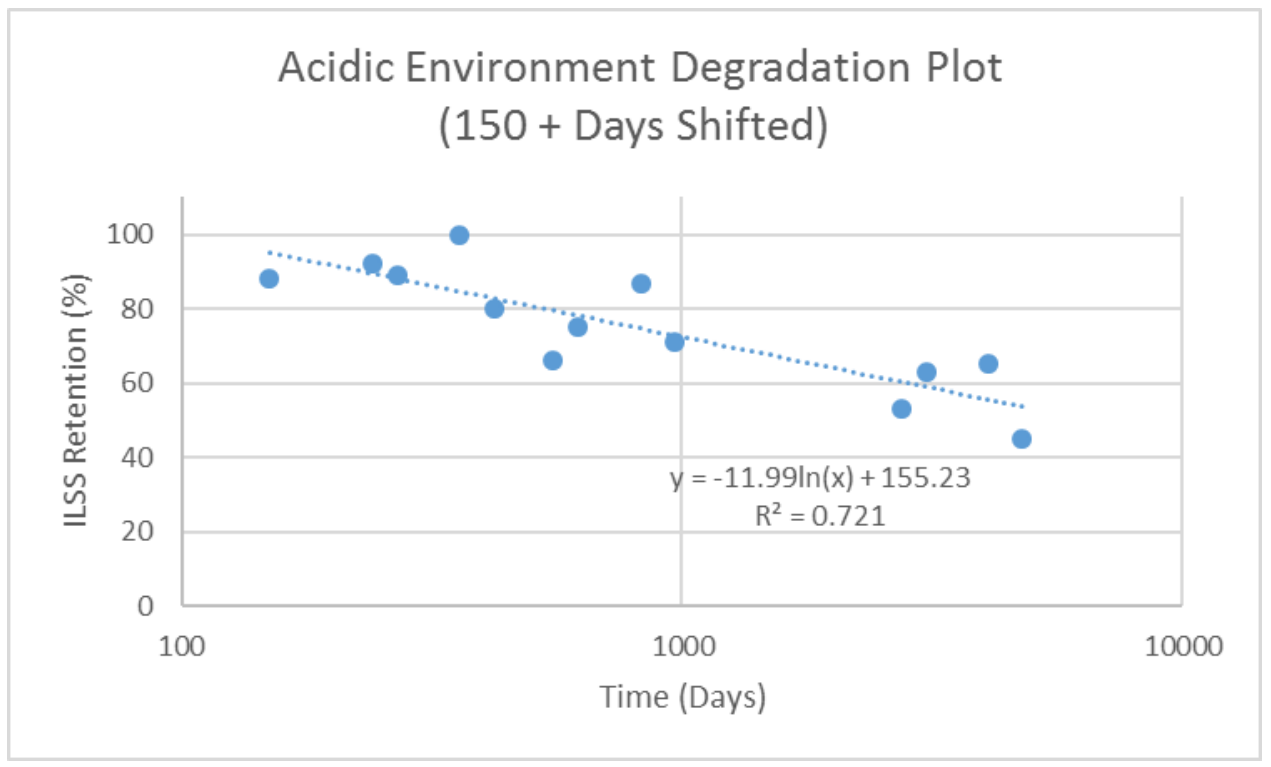

\section{F.3.3 Alkaline Environment}

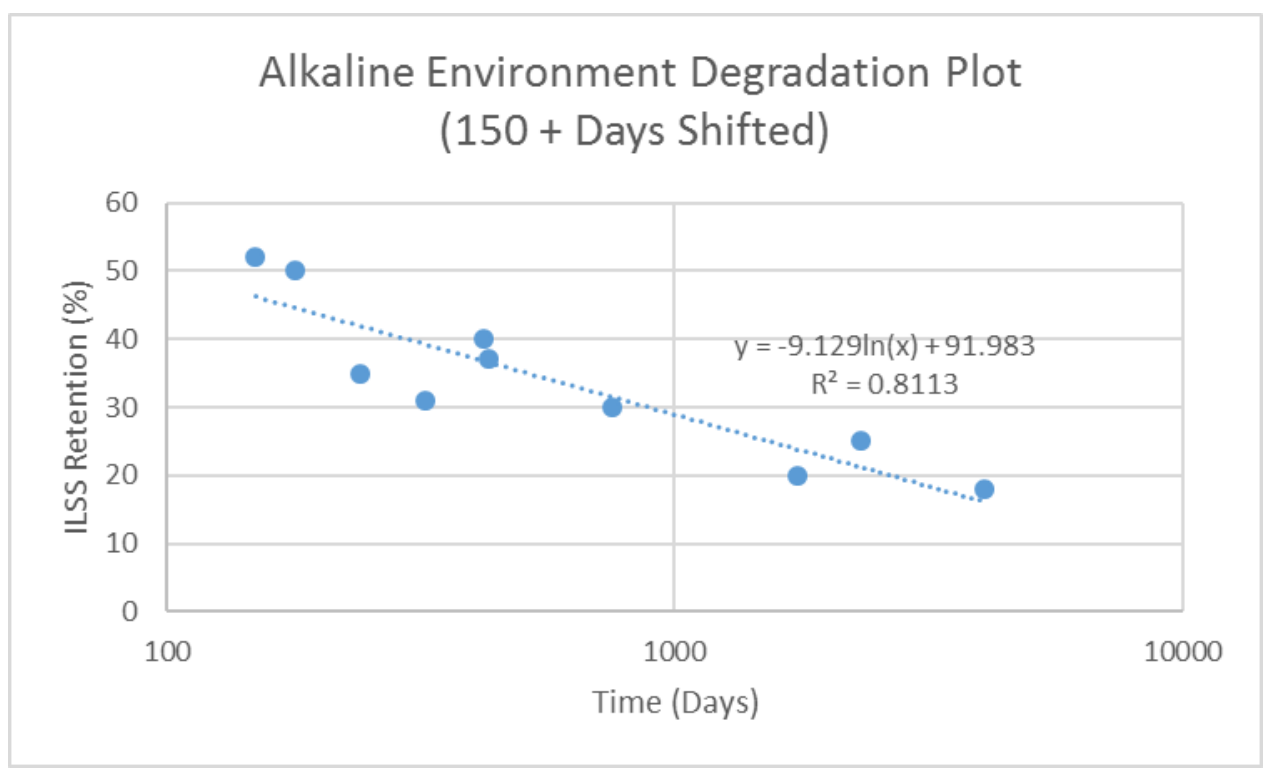

